UNIVERSIDADE DE SÃO PAULO

FACULDADE DE FILOSOFIA, CIÊNCIAS E LETRAS DE RIBEIRÃO PRETO DEPARTAMENTO DE PSICOLOGIA E EDUCAÇÃO

PROGRAMA DE PÓS-GRADUAÇÃO EM PSICOLOGIA

\title{
Normas do Rorschach em crianças de seis a oito anos
}

\section{Suélen Fernandes}

Dissertação apresentada à Faculdade de Filosofia, Ciências e Letras de Ribeirão Preto da Universidade de São Paulo, como parte dos requisitos para a obtenção do Título de Mestre em Ciências. Área: Psicologia. 

UNIVERSIDADE DE SÃO PAULO

FACULDADE DE FILOSOFIA, CIÊNCIAS E LETRAS DE RIBEIRÃO PRETO DEPARTAMENTO DE PSICOLOGIA E EDUCAÇÃO

PROGRAMA DE PÓS-GRADUAÇÃO EM PSICOLOGIA

\title{
Normas do Rorschach em crianças de seis a oito anos
}

\author{
Suélen Fernandes \\ Orientadora: Profa. Dra. Sonia Regina Pasian
}

Dissertação apresentada à Faculdade de Filosofia, Ciências e Letras de Ribeirão Preto da Universidade de São Paulo, como parte dos requisitos para a obtenção do Título de Mestre em Ciências. Área: Psicologia. 
Autorizo a reprodução e divulgação parcial deste trabalho, por qualquer meio convencional ou eletrônico, para fins de estudo e pesquisa, desde que citada a fonte.

\section{Catalogação na Publicação \\ Serviço de Biblioteca e Documentação}

Faculdade de Filosofia, Ciências e Letras da Universidade de São Paulo

Fernandes, Suélen

Normas do Rorschach em crianças de seis a oito anos. Ribeirão Preto, 2010.

$243 \mathrm{f}$.

Dissertação (Mestrado) - Faculdade de Filosofia, Ciências e Letras de Ribeirão Preto/USP. Área de concentração: Psicologia.

Orientadora: Pasian, Sonia Regina.

1. Rorschach; 2. Normas; 3. Crianças; 4. Avaliação Psicológica;

5. Técnicas projetivas; 6 . Personalidade. 


\section{FOLHA DE APROVAÇÃO}

Nome: Suélen Fernandes

Título: Normas do Rorschach em crianças de seis a oito anos

Dissertação apresentada à Faculdade de Filosofia, Ciências e Letras de Ribeirão Preto da Universidade de São Paulo, como parte dos requisitos para a obtenção do Título de Mestre em Ciências.

Área de concentração: Psicologia.

Aprovado em: ___

\section{Banca Examinadora:}

Prof.(a) Dr.(a):

Instituição: Assinatura:

Prof.(a) Dr.(a):

Instituição: Assinatura:

Prof.(a) Dr.(a):

Instituição: Assinatura: 

“... E você aprende que realmente pode suportar... Que realmente é forte, e que pode ir muito mais longe, depois de pensar que não se pode mais..." (William Shakespeare) 



\section{Dedicatória}

Dedico este trabalho aos meus pais, meus primeiros educadores, que me ensinaram os verdadeiros valores da vida e apoiaram a trajetória de meu amadurecimento pessoal $e$ profissional. Obrigada por me permitirem crescer! 



\section{Meus agradecimentos ...}

Primeiramente a Deus, pelo dom da vida e infinita força e perseverança concedida não só neste período, mas durante toda minha vida.

À minha mãe Izaura, pelo amor, pelo carinho e pela infinita compreensão e incentivo constante.

A meu pai, Luiz, pelo apoio, respaldo e por me dar a oportunidade de mais essa conquista.

À minha orientadora, Profa. Dra. Sonia Regina Pasian, por toda dedicação e empenho em enriquecer minha formação acadêmica com seus valiosos ensinamentos. Agradeço a confiança depositada em mim, o apoio, a orientação e incentivo constante. Obrigada por disponibilizar seu tempo e conhecimento contribuindo com minha formação de psicóloga, mestre e pesquisadora.

$\grave{A}$ amiga e grande companheira de trabalho, com quem compartilhei momentos tão especiais, Renata Raspantini. Agradeço sua parceria, seu apoio e constante colaboração. E, sobretudo, agradeço por permitir o fortalecimento de nossa amizade tão especial em minha vida.

À prima-amiga-irmã Patrícia Ruy, que sempre me incentivou, acolhendo minhas angústias, me dando apoio e força necessária para que eu seguisse em frente. Obrigada pelo carinho, pela ajuda incondicional e por sempre acreditar em mim.

À amiga Érika Okino, pela colaboração e incentivo constante. Agradeço sua disponibilidade, seu apoio e suas orientações tão importantes para a realização deste projeto.

À amiga Daniele Palomo, não só pela ajuda nas análises do material, mas também por me acolher em sua casa durante as muitas noites que precisei, pelas conversas e, sobretudo, pela amizade.

Aos amigos e colaboradores, Roberta Cury, Maria Luisa Maran e Rafael Barrenha, que gentilmente ajudaram nas análises do material e contribuíram para a realização deste trabalho. Obrigada também ao Rafael e à Roberta pela prazerosa companhia nos Congressos. 
Às queridas amigas Cibele Damas, Cristiane Zordan, Fernanda Murer, Talita Malaman e Tatiana Pizzirani, que acompanharam de perto minha trajetória. Obrigada por perdoarem minhas ausências, pelo carinho, pela companhia e pela torcida.

A todos os meus amigos e familiares, em especial, Priscila, Pâmela e Selma que me acompanharam e me deram valioso apoio durante essa importante jornada.

À FAPESP pelo apoio financeiro fundamental para a realização e divulgação científica deste projeto.

Ao CPP, Centro de Pesquisa em Psicodiagnóstico, da FFCLRP, e a todo o grupo de pesquisa, pelo acolhimento e suporte técnico durante a realização desta pesquisa.

A Giovanni Raspantini pela assessoria gráfica e pela paciência para agüentar nossas exigências.

À Andressa Kutschenko pela assessoria estatística e por sua disposição em ajudar e ensinar.

A Alessandro Scaduto pela colaboração nas traduções necessárias.

Às direções das escolas participantes da pesquisa por permitirem que minha coleta de dados fosse realizada dentro de seus estabelecimentos de ensino.

Aos pais das crianças participantes desta pesquisa, pela solidária colaboração, permitindo a participação de seus filhos.

Às crianças, pela colaboração e participação voluntária na pesquisa, tornando possivel sua realização. Obrigada também pela prazerosa convivência e pelos ensinamentos vivenciados ao longo da coleta de dados. 
Trabalho subvencionado pela Fundação de Amparo à Pesquisa do Estado de São Paulo FAPESP, mediante a concessão de bolsa de Mestrado (Processo 08/52241-3) 



\section{RESUMO}

FERNANDES, S. Normas do Rorschach em crianças de seis a oito anos. 243 p. Dissertação (Mestrado) - Faculdade de Filosofia, Ciências e Letras de Ribeirão Preto, Universidade de São Paulo, Ribeirão Preto, 2010.

O Psicodiagnóstico de Rorschach é uma técnica projetiva de exame psicológico, reconhecida mundialmente e utilizada em processos de avaliação da personalidade. Necessita, como qualquer instrumento de avaliação psicológica, de adequados referenciais normativos para subsidiar válida interpretação de seus indicadores. Diante da insuficiência de estudos desta natureza voltados à população infantil brasileira, este trabalho objetivou desenvolver padrões normativos do Rorschach para crianças de seis a oito anos de idade, avaliando-se também eventuais especificidades de produção nesta técnica projetiva associadas ao sexo, à idade e à origem escolar. Participaram deste estudo 180 estudantes de seis a oito anos, com sinais de desenvolvimento típico, residentes em cidade do interior paulista, distribuídos equitativamente em relação ao sexo, idade e origem escolar, autorizados para participar do estudo por meio de consentimento formal de seus pais ou responsáveis. Estes responderam inicialmente um Questionário informativo sobre histórico da criança, permitindo adequada seleção dos voluntários. As crianças foram avaliadas individualmente por meio das Matrizes Progressivas Coloridas de Raven e pelo Método do Rorschach (Escola Psicanalítica Francesa), seguindo-se seus respectivos manuais e orientações técnicas específicas. A codificação dos protocolos do Rorschach foi realizada por três avaliadores independentes, psicólogos com experiência prévia na técnica e que receberam treinamento específico para o desenvolvimento deste trabalho. Suas análises revelaram elevados índices de acordo entre examinadores, evidenciando suficiente precisão nos resultados. Os dados do Rorschach foram analisados em termos descritivos (média, desvio-padrão, mediana, valores mínimo e máximo) e inferenciais. Para as análises estatísticas inferenciais utilizou-se do modelo de regressão linear (variáveis relacionadas à produtividade e ao ritmo) e do modelo univariado e ajustado da distribuição binomial (demais variáveis da Escola Psicanalítica Francesa do Rorschach), a fim de verificar possíveis efeitos do sexo, da idade e da origem escolar nos resultados das crianças. Um panorama global dos atuais referenciais normativos apontou, em termos médios, os seguintes índices: a) produtividade e de ritmo: $\mathrm{R}=14,5$; $\mathrm{TL}=14,2$ segundos e $\mathrm{TRm}=28,8$ segundos; b) modos de apreensão: $\mathrm{G}=38,6 \%, \mathrm{D}=44,2 \%, \mathrm{Dd}=16,6 \%$ e $\mathrm{Dbl}=0,5 \%$; c) determinantes e índices formais: $\mathrm{F} \%=66,4 \%, \mathrm{~F}+\%=68,8 \%$ e $\mathrm{F}+\operatorname{ext} \%=70,0 \%$; d) estilo de vivência afetiva predominante: coartativo; e) conteúdos predominantes: A\% $=64,5 \%$ e $\mathrm{H} \%=$ $14,1 \%$; f) $\mathrm{Ban}=18,5 \%$. No que se refere à análise das possíveis influências das variáveis sexo, idade e origem escolar nos resultados do Rorschach da amostra avaliada, foram observadas diferenças estatisticamente significativas em um número reduzido de variáveis desta técnica projetiva, sugerindo possibilidade de composição de atlas único para crianças de seis a oito anos de idade, de ambos os sexos e provenientes de escolas públicas e particulares. É importante destacar que a variável idade foi aquela que pareceu exercer maior efeito no conjunto de respostas das crianças ao Rorschach, sugerindo aspectos maturacionais envolvidos no processo de interpretação desta técnica, apontando para a necessidade de se considerar, em avaliações clínicas, as atuais evidências empíricas para adequada interpretação dos resultados referentes ao Rorschach.

Palavras-Chave: Rorschach; Normas; Crianças; Avaliação Psicológica; Técnicas projetivas; Personalidade. 



\begin{abstract}
FERNANDES, S. Norms for the Rorschach in six to eight-year-old children. $243 \mathrm{p}$. Dissertation (Master Degree) - Faculty of Philosophy, Sciences and Letters of Ribeirão Preto, University of São Paulo, Ribeirão Preto, 2010.
\end{abstract}

The Psychodiagnosis of Rorschach is a psychological examination, projective technique, acknowledged worldwide in personality assessment processes. As any other psychological assessment instrument, it requires adequate normative references in order to subsidize valid interpretations of its indicators. In face of the insufficiency of studies on such references for the population of Brazilian children, the present work aimed to develop normative standards of the Rorschach for six to eight-year-old children. Also, eventual specificities on the production in this projective technique were assessed, regarding gender, age and school origin. Hundred-eighty, six to eight-year-old children took part of the study. All participants showed indicators of a typical development and lived in a city in the country region of the state of São Paulo (Brazil). The participants were equally divided in terms of gender, age and school origin, and were allowed to take part of the study through formal approval by their parents or responsible caretaker, who also responded to an initial informative questionnaire about their children for their adequate selection. All participants were assessed using the Progressive Matrices of Raven (colored version) and the Rorschach Method (French Psychoanalytical School), with their respective manuals and specific technical orientations. Coding of Rorschach protocols was performed by three independent judges, who were psychologists with prior experience in the technique and had specific training for developing the present work. These analyses revealed high agreeing indexes among the judges, evidencing a sufficient reliability level of the results. The Rorschach data was analyzed in inferential and descriptive terms (mean, standard deviation, median, minimum and maximum values). For inferential, statistical analyses, a regression linear model was used for variables related to productivity and rhythm. An univariate, adjusted model of the binomial distribution was used to analyze the remaining variables of remaining variables of the Rorschach according to the French Psychoanalytic School. Such analyses were performed in order to check for possible effects of gender, age or school origin in participants' results. A general panorama of the present normative references showed, in average terms, the following indexes: a) productivity and rhythm: $\mathrm{R}=14.5 ; \mathrm{TL}=14.2 \mathrm{~s}$ and $\mathrm{TRm}=28.8 \mathrm{~s}$; b) apprehension modes: $\mathrm{G}=38.6 \%, \mathrm{D}=44.2 \%, \mathrm{Dd}=16.6 \%$ e $\mathrm{Dbl}=0.5 \%$; ) determinants and formal indexes: $\mathrm{F} \%=66.4 \%, \mathrm{~F}+\%=68.8 \%$ e $\mathrm{F}+\mathrm{ext} \%=70.0 \%$; d) predominant affective experiencing style: coartative; e) predominant contents: $\mathrm{A} \%=64.5 \%$ and $\mathrm{H} \%=14.1 \%$; f) $\mathrm{Ban}=18.5 \%$. When regarding the analysis of possible influence of variables such as gender, age and school origin over the results on the Rorschach in the sample assessed, statistically significant differences were observed in a reduced number of variables of the projective technique, suggesting the possibility of composing a single atlas for children between six to eight years of age, of both genders and studying in both private or public schools. It must be noted, though, that age seemed to exert the highest effect on the group of responses for the Rorschach, suggesting that maturational aspects are involved in the interpretation process of this technique and pointing out to the necessity of considering, in clinical assessment processes, the present empiric evidences for the adequate interpretation of the results on the Rorschach.

Keywords: Rorschach; Norms; Children; Psychological Assessment; Projective Techniques; Personality. 



\section{LISTA DE TABELAS}

Tabela 1 - Estudos normativos do Rorschach identificados no Journal of Personality Assessment no período 1999 a 2009

Tabela 2 - Estudos normativos brasileiros do Rorschach com crianças, publicados até 1990

Tabela 3 - Estudos normativos do Rorschach apresentados nos últimos eventos científicos da área de Avaliação Psicológica e Métodos Projetivos no Brasil (2006, 2008, 2009)

Tabela 4 - Caracterização da amostra $(n=180)$ em função da idade, sexo e origem escolar ... 61

Tabela 5 - Mapeamento do percurso amostral, apresentando frequiência simples e porcentagem das crianças contadas em função da origem escolar

Tabela 6 - Panorama da distribuição dos protocolos do Rorschach entre examinadores independentes

Tabela 7 - Estatística descritiva da produtividade no Rorschach da amostra (n = 180) e comparação de médias com normas de Jacquemin (1976)

Tabela 8 - Resultados (freqüência simples e porcentagem), para cada cartão, das variáveis associadas à produtividade no Rorschach

Tabela 9 - Distribuição em freqüência simples (f) e porcentagem (\%) do total de respostas $(\mathrm{R}=2606)$ nas diferentes categorias de classificação da Escola Psicanalítica Francesa do Rorschach

Tabela 10 - Resultados e comparação de médias da atual amostra com o estudo de Jacquemin (1976)

Tabela 11 - Distribuição das crianças (em freqüência simples e porcentagem) da amostra (N=180) em função do Tipo de Vivência Afetiva e da Fórmula das Tendências Latentes

Tabela 12 - Distribuição dos resultados globais (somatória e dados médios) da amostra em algumas variáveis do Rorschach associadas ao controle afetivo 
Tabela 13 - Resultados da análise estatística das variáveis relacionadas à produtividade e ritmo no Rorschach, em função do sexo

Tabela 14 - Resultados da análise estatística das principais variáveis do Rorschach, em função do sexo

Tabela 15 - Resultados da análise estatística das variáveis relacionadas à produtividade e ritmo no Rorschach, em função da origem escolar

Tabela 16 - Resultados da análise estatística das principais variáveis do Rorschach, em função da origem escolar

Tabela 17 - Resultados da análise estatística das variáveis relacionadas à produtividade e ritmo no Rorschach, em função da idade

Tabela 18 - Resultados da análise estatística das principais variáveis do Rorschach, em função da idade

Tabela 19 - Dados descritivos e porcentagens médias das variáveis do Rorschach para o grupo de crianças de seis anos $(n=60)$

Tabela 20 - Dados descritivos e porcentagens médias das variáveis do Rorschach para o grupo de crianças de sete anos $(n=60)$

Tabela 21 - Dados descritivos e porcentagens médias das variáveis do Rorschach para o grupo de crianças de oito anos $(n=60)$

Tabela 22 - Resultados descritivos e inferenciais das variáveis do Rorschach na amostra geral $(\mathrm{N}=180)$

Tabela 23 - Lista de Banalidades obtidas com esta amostra $(\mathrm{N}=180)$ 


\section{LISTA DE APÊNDICES E ANEXOS}

APÊNDICE A - Carta de Apresentação da Pesquisa........................................................... 149

APÊNDICE B - Termo de Consentimento Livre e Esclarecido .......................................... 153

APÊNDICE C - Questionário informativo sobre história pessoal ...................................... 157

APENDICE D - Glossário referente ao processo de classificação das variáveis do Rorschach (adaptado de Rausch de Traubenberg, 1998; Azoulay et al.,

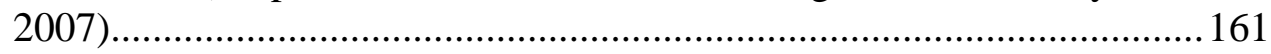

ANEXO A - Aprovação do Comitê de Ética em Pesquisa................................................... 171

ANEXO B - Documento emitido pelo Departamento Municipal de Educação de Porto

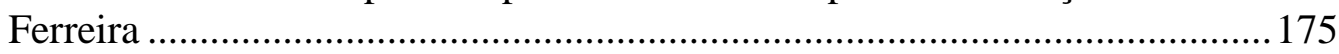





\section{SUMÁRIO}

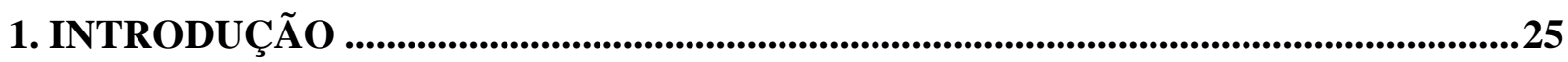

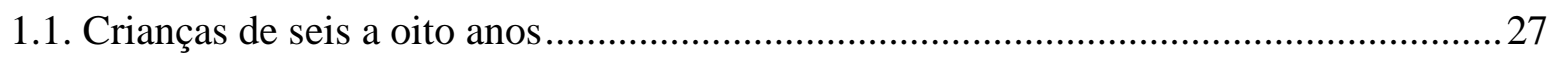

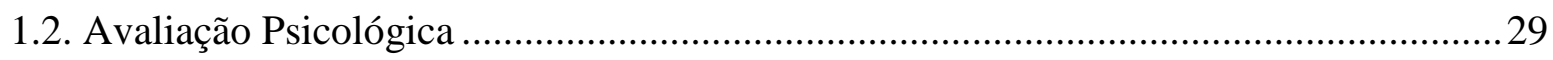

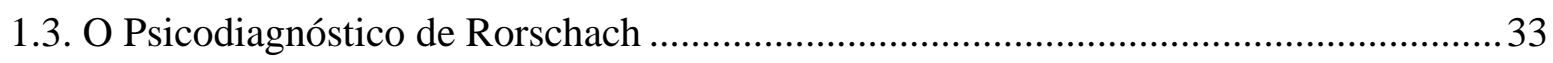

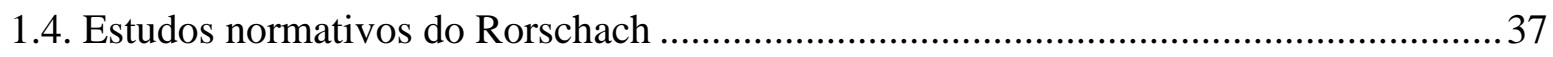

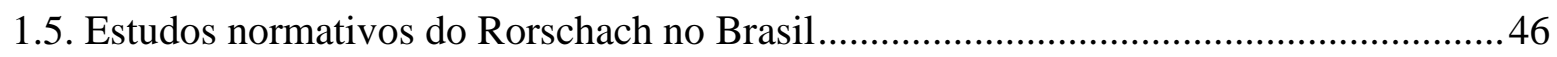

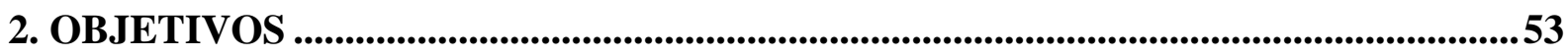

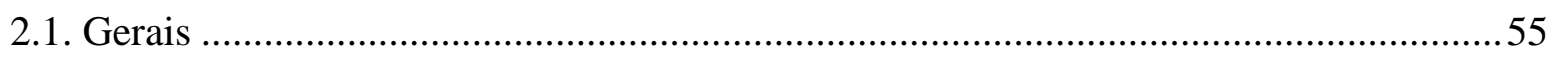

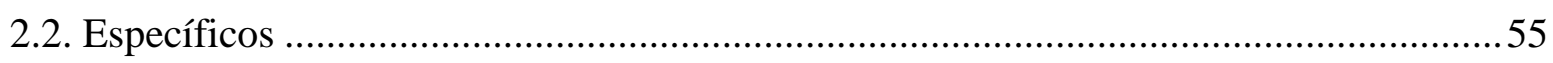

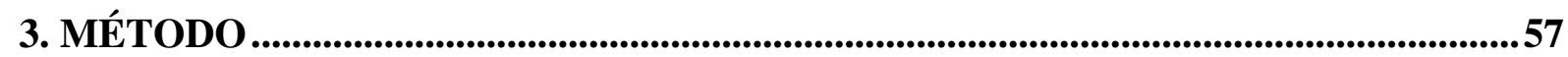

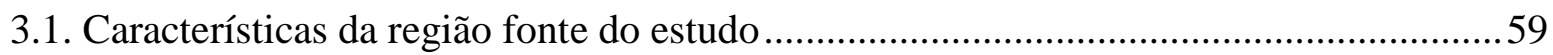

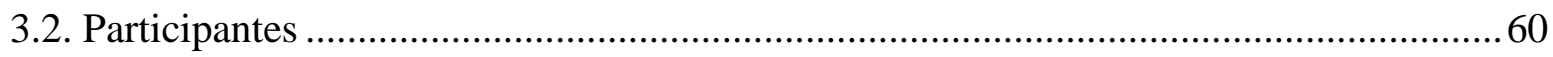

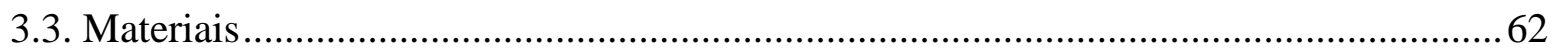

3.3.1. Carta de Apresentação da Pesquisa........................................................................62 62

3.3.2. Termo de Consentimento Livre e Esclarecido (TCLE) ..........................................62

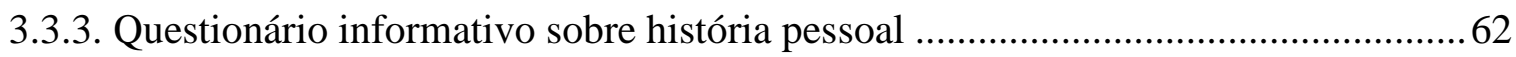

3.3.4. Teste das Matrizes Progressivas Coloridas de Raven...........................................62

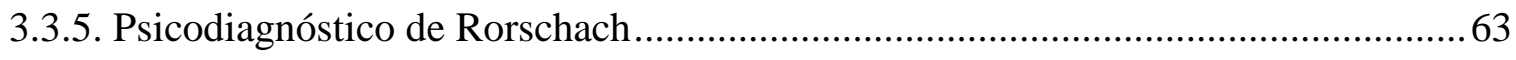

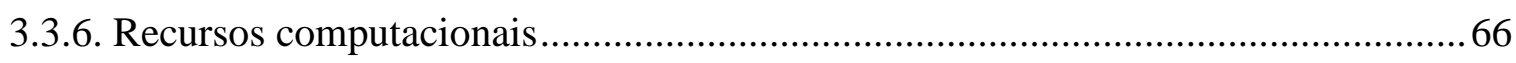

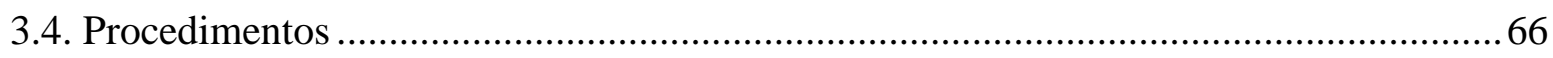

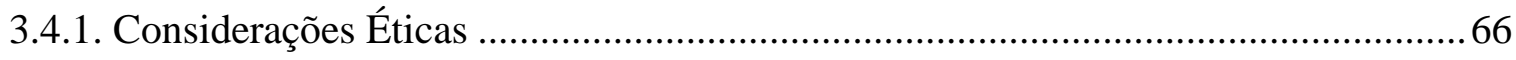

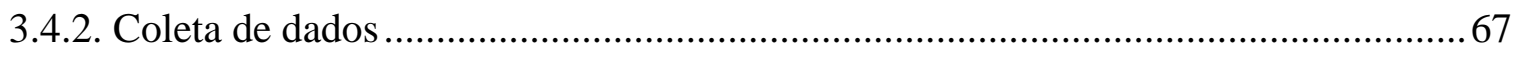

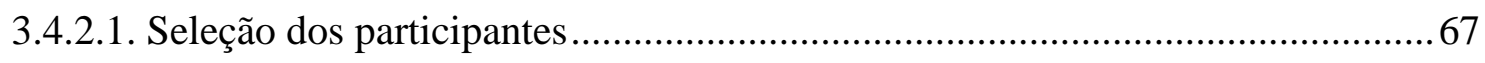

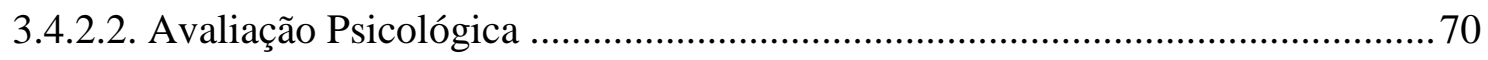

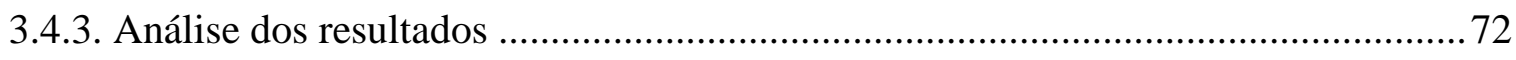

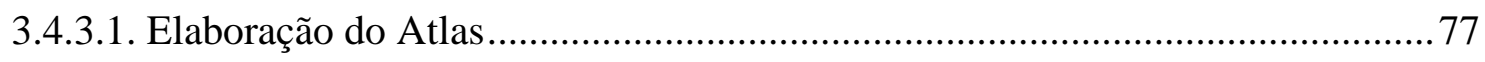

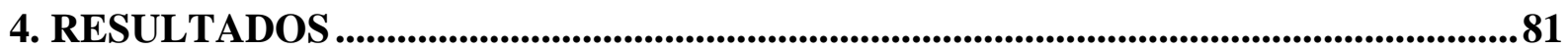

4.1. Perfil global dos resultados no Psicodiagnóstico de Rorschach ................................... 83

4.2. Análise do padrão de respostas no Rorschach em função do sexo ..............................93

4.3. Análise do padrão de respostas no Rorschach em função da origem escolar ................97

4.4. Análise do padrão de respostas no Rorschach em função da idade ............................. 102 
4.5. Síntese das comparações estatísticas e dos resultados descritivos no Rorschach do

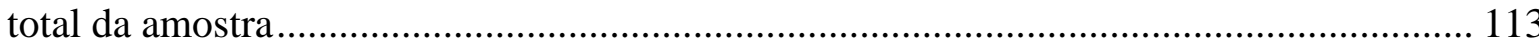

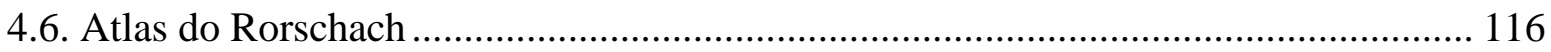

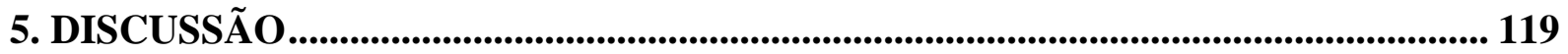

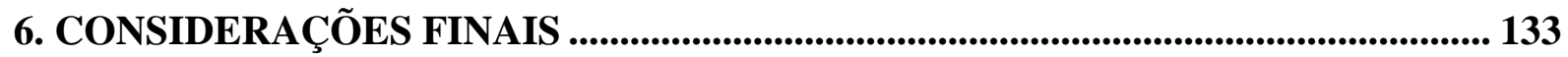

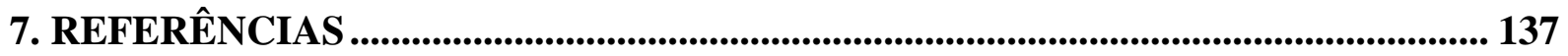

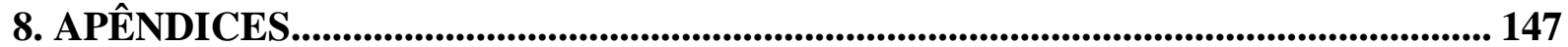

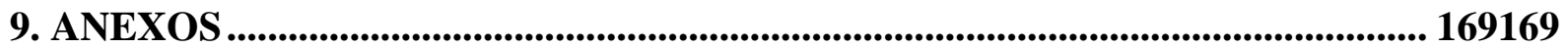


1. INTRODUÇÃO 



\subsection{Criancas de seis a oito anos}

O Psicodiagnóstico de Rorschach tem sido utilizado em crianças e adolescentes como instrumento de investigação da personalidade individual, com o objetivo de diagnóstico e de prognóstico da saúde mental. Além disso, segundo Semer (2008), por meio dele também é possível uma avaliação correspondente ao estágio de desenvolvimento humano. Os dados obtidos pelo Rorschach em protocolos infantis revelam aspectos importantes de uma personalidade em formação, o que habitualmente não é possível apreender em outros contextos. No entanto, é preciso levar em consideração que se trata de uma personalidade em desenvolvimento e de recursos internos ainda não amadurecidos, portanto, possui características de desenvolvimento específicas desta etapa, conforme reflexões ponderadas pela citada pesquisadora.

Dado que o presente trabalho focaliza o desempenho de crianças de seis a oito anos de idade nesta técnica de avaliação de personalidade, julgou-se sensato expor, em linhas gerais, argumentos teóricos sobre o desenvolvimento sócio-afetivo de crianças da faixa etária abordada. Estas noções gerais poderão funcionar como elementos úteis à posterior interpretação dos resultados na referida técnica projetiva de avaliação psicológica.

De acordo com Papalia (2006), o período compreendido aproximadamente entre os seis e os 11 anos de idade corresponde à terceira infância, período no qual a escola é tida como a experiência central. As crianças sofrem grandes alterações físicas, tornando-se mais altas, mais pesadas e mais fortes, e adquirem as habilidades motoras necessárias para participarem de jogos e de esportes organizados. Ocorrem também mudanças cognitivas e psicossociais, tais como aprimoramento da memória, da capacidade de ler e escrever e do julgamento moral. Suas diferenças individuais tornam-se mais evidentes, e suas competências influenciam o êxito na escola, assim como a própria auto-estima.

Na perspectiva de Palacios (2004), em contrapartida aos primeiros anos de vida da criança que são marcados por intensa agitação afetiva e relacional, a partir dos seis anos de idade a criança inicia um período mais tranquilo em termos afetivos, onde predomina o campo intelectual. Durante essa etapa, as crianças desenvolvem o raciocínio lógico (embora ainda concreto), disponibilizam atenção mais seletiva e memória mais estratégica, favorecendo a qualidade e a quantidade de apreensão de diversos aspectos da realidade. Verifica-se também o desenvolvimento da linguagem (compreensão e expressão), o que facilita a comunicação com o outro. 
Nesta fase do desenvolvimento, os principais contatos interpessoais acabam por se dar na escola ou em contextos sociais mais amplos do que o familiar. O contexto escolar proporciona à criança o contacto com a diversidade e a multiplicação de suas experiências, por meio da interação com outros colegas e da aprendizagem de novos conhecimentos que a preparam para se relacionar com o mundo real. A interação social torna-se, portanto, fundamental para o desenvolvimento intelectual e afetivo da criança (Palacios, 2004).

Ainda de acordo com este autor, nesse momento, a criança passa a sofrer influência de vários contextos na composição de sua personalidade. Portanto, a tarefa principal consiste em consolidar muitos dos aspectos do desenvolvimento psicossocial, entre os quais a possibilidade de fazer discriminações cada vez mais bem elaboradas na descrição de si mesmo. Dessa forma, de acordo com Palacios (2004), ao mesmo tempo em que emergem sentimentos despertados pela interação social em termos globais, a criança começa a explorar, cada vez mais, seus conteúdos internos.

Acompanhando essa perspectiva, Rabello e Passos (2007) afirmam que essa fase é marcada pelo controle da atividade física e intelectual, no sentido de equilibrá-la às regras do método de aprendizado formal. Além do amadurecimento de funções intelectuais, a criança aprende o que é valorizado no mundo adulto, e tenta se adaptar a ele. Segundo os autores, a criança agora precisa de uma forma ideal, ou seja, regulada e metódica, para canalizar sua energia psíquica. Ela encontra esta forma no estudo, que lhe dá a sensação de conquista e que a torna confiante e autônoma, permitindo que tenha iniciativa para objetivos imediatos. Começa então a participar em um programa organizado de aprendizado como uma iniciação no campo das responsabilidades e dos planejamentos.

De acordo com a Teoria Eriksoniana do desenvolvimento humano, o período compreendido entre os seis anos e o princípio da adolescência corresponde ao estágio da Diligência X Inferioridade. Seu início coincide com o que a psicanálise denomina de período de latência, marcado por certa dormência da sexualidade infantil. Neste estágio, a força rudimentar desenvolvida é a competência. A criança, na concepção de Érikson (1998), sente que tem competência ao se dedicar e concluir uma tarefa, orientada por exemplos de adultos que as instruem, e sente que adquiriu habilidade se tal tarefa foi realizada satisfatoriamente. Este prazer de realização é o que dá forças para o ego não regredir nem se sentir inferior.

Segundo Érikson (1998), a contraparte adversa da diligência (senso do domínio competente) é a inércia, que ameaça constantemente paralisar a vida produtiva do indivíduo e está decisivamente relacionada à inibição da fase anterior do desenvolvimento (fase do brincar). Se, durante o processo de realização, falhas seguidas ocorrerem, seja por falta de 
ajuda ou por excesso de exigência, origina-se o conflito da inferioridade. Esse evento pode levar a criança à competição excessiva ou induzi-la a regredir, retornando às fantasias da fase anterior e favorecendo o sentimento de inferioridade.

As descrições sobre o desenvolvimento da personalidade durante o período compreendido entre seis e oito anos de idade apontam que a criança estaria focalizada no esforço de adaptação social e realização de novas tarefas intelectuais e relacionais. A entrada na escola formal permite que o indivíduo se insira no mundo social, estimulando-o a lidar com os papéis que este envolve. Também para Erikson (1987), neste momento, a sociedade torna-se significativa para a criança porque, é através da aprendizagem de determinados papéis, que a criança vai antecipando e exercitando algumas características e habilidades, preparando-se para o futuro. Neste processo de socialização, importantes mensagens são passadas à criança, que, combinadas com sua disposição interna, tornam-se mais um elemento na construção de um plano de vida.

Cabe destacar que esta explanação a respeito do desenvolvimento sócio-afetivo infantil abordou, apenas em linhas gerais, as características específicas desta faixa etária, conforme retratam alguns teóricos e pesquisadores sobre o desenvolvimento humano. $\mathrm{O}$ intuito aqui foi apenas contextualizar a fase maturacional em que se encontram as crianças estudadas, sem o intuito de aprofundar ou esgotar as vertentes do desenvolvimento humano e suas especificidades. Isto porque aqui não se trata de um trabalho que aborda associações entre desenvolvimento humano e desempenho específico no Rorschach, mas sim, de um estudo sobre os padrões normativos para este instrumento de avaliação psicológica. Dessa forma, seguir-se-á dando maior ênfase aos temas mais diretamente ligados ao objetivo central deste estudo.

\subsection{Avaliacão Psicológica}

A avaliação psicológica pode ser entendida como um processo de coleta de dados que visa descrever e classificar comportamentos, usando, para isso, instrumentos e técnicas para responder questões específicas e obter maior conhecimento do indivíduo ou do grupo de indivíduos, fornecendo, conseqüentemente, elementos para se poder planejar intervenções e ações psicoterapêuticas, caso necessário (Cunha, 2005). O conhecimento produzido pela avaliação psicológica presume a possibilidade de enriquecimento da identificação e da compreensão sobre os problemas individuais, desde que lastreada cientificamente pelas 
exigências de investigação de fenômenos psicológicos (Cruz, 2002). Para a realização de avaliações psicológicas confiáveis, é indispensável o adequado conhecimento e o domínio técnico sobre os instrumentos de coleta de dados, assim como de suas propriedades psicométricas.

Dentre as técnicas existentes no campo da avaliação psicológica, os testes psicológicos constituem-se em procedimentos sistemáticos para a obtenção de amostras de comportamento relevantes para o funcionamento cognitivo, afetivo, social e global de um indivíduo ou de um grupo de indivíduos, incluindo a análise comparativa destas amostras com certos padrões de desempenho de outros grupos de indivíduos (Urbina, 2007). A função básica dos testes psicológicos é investigar, por meio da medida, amostras de comportamento em diferentes circunstâncias, auxiliando desta forma na identificação de características de sujeitos e de seu funcionamento psíquico, informando suas mais diversas formas de expressão de emoção/afeto, cognição/inteligência, motivação, personalidade, psicomotricidade, atenção, memória, percepção, dentre outras (CFP, 2003). Para tanto, devem ser construídos com base científica e apresentar parâmetros psicométricos adequados que atestam a confiabilidade e a representatividade do construto a ser mensurado (Anastasi \& Urbina, 2000). Passa-se, portanto, a abordar princípios destes aspectos psicométricos dos instrumentos de avaliação psicológica.

A validade é uma das propriedades psicométricas de um instrumento de avaliação psicológica. Trata-se de um índice que expressa, classicamente, o grau em que um teste realmente avalia o que se dispõe a medir. Os índices de validade oferecem uma dimensão do quanto o construto em foco está sendo alcançado, permitindo interpretações dos resultados para a vida do indivíduo de modo mais geral, a partir dos resultados obtidos. Se um instrumento não possui evidências de validade, não há segurança de que as interpretações sobre as características psicológicas dos indivíduos avaliados por este sejam legítimas (Noronha, Primi \& Alchieri, 2004).

Contudo, como nenhuma avaliação psicológica é absoluta, deve-se buscar estimar o tamanho do erro esperado nestes processos avaliativos. Desta checagem resulta o índice de precisão do instrumento de avaliação psicológica. Se um teste não possui evidências de adequada precisão, não se pode estimar quanto os resultados mudariam se fossem dadas novas oportunidades de avaliação. O instrumento deve proporcionar medidas fidedignas, de maneira que possam ser obtidos resultados aproximados quando se voltar a medir as características sob as mesmas condições do sujeito em questão (Urbina, 2007). A fidedignidade dos métodos projetivos pode ser obtida pela estabilidade das respostas e aplicações sucessivas da técnica, 
mas também pode ser alcançada pelo índice de concordância entre juízes independentes ao corrigirem e interpretarem, às cegas, os mesmos protocolos (Fensterseifer \& Werlang, 2008).

Outra característica ligada ao caráter científico de um instrumento de avaliação psicológica é a padronização, ou seja, a uniformização do material, instrução e procedimentos de aplicação, além de dados normativos (grupos de referência) para a interpretação dos resultados. A inexistência de padronização pode trazer dificuldades nas interpretações dos resultados, já que os indivíduos serão comparados com expectativas que podem ser inapropriadas, levando a decisões equivocadas por parte dos profissionais.

Tendo por base suas características psicométricas, os instrumentos de avaliação psicológica podem ser classificados, genericamente, em duas grandes classes: os mais estruturados e os menos estruturados. Dentre os primeiros estão os testes psicométricos, que, de acordo com Bandeira, Trentini, Winck e Lieberknecht (2006) são baseados em critérios objetivos (concretos e observáveis) para medir ou dimensionar determinado construto. São voltados para avaliação intelectual, percepções, aptidões e interesses. Os segundos são os métodos projetivos, que utilizam critérios dinâmicos (e não observáveis) para interpretar e/ou caracterizar um construto. São dirigidos principalmente à investigação da personalidade ou de fatores de ordem emocional, importantes para a compreensão de um sujeito ou de uma situação vivenciada ou percebida por ele. Nas palavras de Anzieu (1986, p. 18):

Os testes projetivos, analogicamente, levam o sujeito a produzir um
protocolo de respostas de tal modo que a estrutura do mesmo corresponde à
estrutura de sua personalidade, estando conservadas no primeiro as
características fundamentais da segunda.

Apesar deste padrão clássico de categorização dos instrumentos de avaliação psicológica, a literatura científica atual sobre o tema tem revisto parte destes princípios. Nesse sentido, por exemplo, Meyer e Kurtz (2006) questionam o uso da terminologia utilizada para qualificar testes de personalidade retratando que, por muito tempo, eles foram classificados de modo dicotômico como testes objetivos ou projetivos. Para esses pesquisadores é preciso cautela nesta classificação, dado que estes termos são frequientemente utilizados de modo incerto, carregando conotações distintas e que, muitas vezes, não representam suas diferenças e singularidades.

Diante disso, o que diferencia substancialmente os testes mais estruturados e as técnicas projetivas reside no fato de que estas possibilitam uma via de acesso a conteúdos inconscientes do sujeito, que revelam informações importantes sobre sua personalidade e sua forma particular de perceber o mundo. De acordo com Bandeira et al. (2006), no teste 
projetivo, o indivíduo fica livre para dizer ou fazer o que quiser, a partir do material apresentado e do tipo das atividades propostas. Não há boas e más respostas predeterminadas: boa é a primeira idéia que lhe ocorre. Como na psicanálise, vale aquilo que espontaneamente vem à consciência. Durante a realização de uma técnica projetiva, o respondente se utiliza do repertório de imagens e vivências registrado a partir de sua experiência, e põe em ação as maneiras que desenvolveu para lidar com as situações de vida, por meio de seus recursos e suas habilidades para enfrentar problemas e lidar com seus conflitos (Güntert, 2000).

A grande vantagem das técnicas projetivas é que elas estão isentas dos efeitos da desejabilidade social, isto é, o examinando não necessita admitir falhas ou problemas pessoais, como nos inventários e técnicas objetivas que se baseiam nas respostas do sujeito sobre si mesmo. Ao contrário disso, as projetivas avaliam aspectos e necessidades que os indivíduos avaliados podem não reconhecer como seus (Alves, 2006). Os estímulos das técnicas projetivas, geralmente pouco estruturados, possibilitam o aparecimento de elementos do funcionamento interno do indivíduo, impedindo que este se refugie em informações ou dados convencionais, passíveis de controle lógico. "É importante lembrar que, mais do que projetar o que é, o sujeito projeta o que recusa a ser" (Fensterseifer \& Werlang, 2008, p.18).

Outra característica dos instrumentos projetivos de avaliação psicológica, de acordo com Fensterseifer e Werlang (2008), reside na possibilidade de uma abordagem integradora psicodinâmica dos indicadores encontrados nos testes e elementos da história pessoal e do contexto de vida do sujeito avaliado. Em outras palavras, o processo de interpretação e de análise dos resultados, por parte do profissional, serão baseados não apenas nos parâmetros estatísticos do procedimento, mas também em características que possam ser comprovadas e justificadas em evidências advindas de entrevistas e de informações externas aos instrumentos utilizados. Estes dados complementares, quando entrelaçados, podem favorecer a compreensão das múltiplas informações coletadas na avaliação psicológica, fundamentando a validade clínica do processo. Esta validade proporciona uma concepção mais contextualizada dos resultados produzidos em uma avaliação psicológica, considerando o contexto e a história do indivíduo avaliado. A importância deste processo reside no pressuposto de que a atribuição de significados aos resultados de testes psicológicos é um processo bastante complexo, que só pode ter sua validade garantida se todas as fontes de informações, inclusive as de fundamento quantitativo, forem atreladas a averiguações qualitativas que estão, por sua vez, relacionadas a processos de inferência e atribuição de significados e de construções teóricas (Tavares, 2003). 
Contudo, é preciso que se admitam as limitações inerentes aos instrumentos projetivos de avaliação psicológica, na medida em que não há como abarcar a complexidade de um indivíduo em um processo técnico. Seguindo os argumentos apresentados por Tavares (2003), sempre o que se alcança são informações e hipóteses relativas aos recursos e as características deste indivíduo ou grupo de pessoas, a partir de suas manifestações nas técnicas aplicadas. Os resultados não devem ser caracterizados como um entendimento total do sujeito em questão, mas sim como a melhor compreensão que foi possível ao profissional realizar, circunscrita ao contexto do momento em que foi realizado o processo e aos alcances reais dos dados disponíveis.

Além disso, é importante ressaltar que nenhuma decisão profissional pode ser tomada a partir do desempenho do indivíduo em um único teste ou instrumento psicológico, independente de sua natureza. As técnicas projetivas podem colaborar na compreensão do mundo interno do indivíduo, favorecendo a captação de seus potenciais e de sua dinâmica funcional psíquica. Estes dados certamente são bastante importantes e úteis para o julgamento e a tomada de decisões na prática clínica de avaliação e intervenção psicológica (Fensterseifer \& Werlang, 2008). Dentro dessa pluralidade de estratégias técnicas de avaliação psicológica, o foco do atual trabalho estará no tocante à personalidade, avaliada conforme as possibilidades do Psicodiagnóstico de Rorschach (1921), material que será a seguir apresentado.

\subsection{O Psicodiagnóstico de Rorschach}

O Psicodiagnóstico de Rorschach é um instrumento projetivo de avaliação da personalidade. Foi desenvolvido pelo psiquiatra suíço Hermann Rorschach (1884-1922), com publicação inicial em 1921, a qual trouxe as bases metodológicas do método. Em 1934-1935, foi introduzido na França e traduzido para o francês em 1947, por André Ombredane, tendo sofrido adaptações realizadas pelo próprio Ombredane e por N. Canivet, em 1948 (Azoulay, Emmanuelli, Rausch de Traubenberg, Corroyer, Rozencwajg \& Savina, 2007).

Segundo Adrados (1985), o Rorschach é uma técnica de investigação da personalidade universalmente aceita, baseada na percepção e na comunicação verbal elementar. Desde sua criação, tem se mostrado eficiente e sensível para a compreensão da dinâmica do psiquismo humano, ocupando posição de destaque entre os outros instrumentos da comunidade 
científica. Constitui atualmente um dos métodos mais utilizados no mundo para a avaliação da personalidade (Azoulay et al., 2007).

O Método de Rorschach permite revelar não apenas características de personalidade conscientes e observáveis no comportamento, mas também as mais reprimidas e inconscientes, ou seja, possibilita a manifestação de conteúdos primitivos do examinando. Dessa forma, os dados colhidos mediante esta técnica podem ser considerados preditores do comportamento e esclarecedores da dinâmica de personalidade do sujeito em questão. (Adrados, 1985)

Apesar do tempo que requer sua aplicação, o Rorschach é um instrumento amplamente usado e muito valorizado por clínicos e pesquisadores de diversos países, bem-estabelecido quanto a validade e a confiabilidade dos seus informes na avaliação funcional e dinâmica da personalidade e absolutamente útil no estabelecimento de diagnósticos diferenciais, plano de tratamento e avaliação dos processos interventivos. As respostas nesta prova projetiva representam uma gama de atitudes que vão do perceptivo ao projetivo, em cada uma das respostas. Esses dois aspectos tem um peso relativamente difícil de avaliar, na medida em que constituem um modo de articulação entre os dois tipos de processamento interno dos estímulos propostos. Nesse sentido, para interpretar os resultados desta prova é necessário analisar adequadamente a interação dos dados entre si, os quais exprimem a organização dinâmica da personalidade (Rausch de Traubenberg, 1998).

Por se tratar de um instrumento de investigação da personalidade baseado na análise de respostas a estímulos não estruturados, que contém aspectos objetivos e subjetivos, o Rorschach serve de base para a observação dos fenômenos psíquicos complexos relacionados com os processos de percepção, associação e projeção, permitindo acesso ao mundo interno dos sujeitos desde uma idade precoce. Este método gera informações úteis sobre o funcionamento da personalidade porque confronta os indivíduos com uma tarefa de solução de problema à qual respondem como geralmente o fazem em situações equivalentes de suas vidas, revelando assim diversas facetas de sua individualidade. Além disso, segundo Weiner (2000), apresenta às pessoas uma situação de associação e estímulo à fantasia, permitindolhes revelar suas necessidades, atitudes, conflitos e preocupações subjacentes.

O grande valor do teste de Rorschach e de outras técnicas projetivas está no fato de que não existem respostas certas ou erradas. $\mathrm{O}$ examinando tem de procurar pistas internas e associações relativas ao seu passado, conforme the é dado e modulado por processos do ego (Alves, 2006, p. 180). 
Para além disso, o Rorschach, tal como os demais instrumentos projetivos, ultrapassa a possibilidade de informação através do auto-relato, atribuindo a esse método uma qualidade técnica que vai além de outros tipos de técnicas baseadas na percepção e nas informações conscientemente referidas. Reafirma-se, portanto, que o Psicodiagnóstico de Rorschach é, sem dúvida, um dos instrumentos de avaliação psicológica mais utilizados, tanto no contexto nacional e quanto internacional. Seu amplo reconhecimento é facilmente detectado pela história de desenvolvimento desta prova e pela quantidade e diversidade de investigações científicas por ela suscitadas. A abrangência de seu uso se dá em diversos campos da Psicologia e da Saúde Mental, sendo considerado um dentre os métodos projetivos mais sofisticados para estudar o funcionamento psíquico de um sujeito (Weiner, 1993; Pasian, 2002; Nascimento, 2002; Lelé, 2006; Villemor-Amaral, Yagizi, Nascimento, Primi \& Semer, 2006).

Indubitavelmente, o prestígio de um instrumento de avaliação psicológica é determinado a partir de suas qualidades psicométricas, presumidas em suas aplicações práticas; da frequiência com que é aplicado e do valor atribuído pelos usuários. O Rorschach foi um dos primeiros métodos de investigação da personalidade a receber análises e procedimentos técnicos a ponto de embasar sua cientificidade, recuperando a credibilidade no meio das pesquisas internacionais (Fensterseifer \& Werlang, 2008).

$\mathrm{O}$ volume de trabalhos dedicados a esse método, apresentados a cada congresso específico da área, revela sua ampla utilização, tanto em pesquisas cientificas quanto na clínica (Güntert, 2000). Especificamente a respeito da validade e da confiabilidade do Rorschach, de acordo com Villemor-Amaral e Pasqualini-Casado (2006), na década de 1990 foram feitos quatro estudos metanalíticos originais endereçados à validade do Rorschach (Bornstein, 1996, 1999; Hiller, Rosenthal, Bornstein, Berry \& Brunell-Neuleib, 1999; Meyer \& Handler, 1997 apud Villemor-Amaral \& Pasqualini-Casado, 2006). Todos eles concluíram que, em termos gerais, a validade deste método projetivo está sustentada suficientemente por bases empíricas.

Para além da essencial necessidade de validade e de precisão, é imprescindível a elaboração e atualização de adequados referenciais normativos para utilização apropriada de um instrumento de avaliação psicológica. Nesse sentido, Japur (1982) afirma que, para descrever a estrutura da personalidade de uma pessoa, é necessário indicar o grupo ao qual ela pertence e, ao mesmo tempo, destacar os traços individuais que a convertem em um indivíduo específico. 
Também preocupados com o desenvolvimento e atualização de padrões normativos para o Rorschach, autores de diversos países (Silva \& Dias, 2006, 2007; Matsumoto, Suzuki, Shirai \& Nakabayashi, 2007; Meyer, Edberg \& Shaffer, 2007) evidenciaram diferenças entre dados normativos em função da cultura e de padrões socioeconômicos específicos das diversas regiões por eles pesquisadas. Os mesmos enfatizaram a importância de que mais estudos desta natureza fossem realizados em diferentes grupos populacionais, de forma a gerar dados representativos dos indivíduos típicos de cada região.

Diante disso, conclui-se que os dados normativos desta técnica podem não ser aplicáveis a todas as populações, ou seja, tais referenciais podem não representar fidedignamente grupos com características geográficas e socioeconômicas diversas. Desse modo, é importante destacar a necessidade de se considerar a variabilidade e a evolução das normas em função de múltiplos e diferentes fatores para a constituição dos grupos de sujeitos testados, bem como as épocas e o contexto sociocultural que os acompanham. Diante disso, portanto, os dados normativos constituem-se em um elemento vital para os processos de exame psicológico.

Com a finalidade de aprimoramento da prática de avaliação psicológica num panorama internacional, a Comissão Internacional de Testes (ITC, 2003) formulou diretrizes para a utilização desses instrumentos nos diferentes países. Um dos trabalhos desenvolvidos pela ITC foi o estímulo à reflexão e à promoção de uma prática adequada para os processos de adaptação de instrumentos de avaliação psicológica. Um dos destaques apontados foi relativo à necessidade de cuidadosa adaptação dos testes às diferenças culturais, sendo sua mera tradução um procedimento insuficiente (Van de Vijver \& Hambleton, 1996; Fuster, 2008). Foram enumerados, inclusive, passos fundamentais para a construção e adaptação de um teste psicológico, abordando enfaticamente a importância dos conceitos de validade, fidedignidade e padronização.

Dentro dessa perspectiva, apontando para a necessidade de sistematização objetiva dos parâmetros utilizados pelo Psicodiagnóstico de Rorschach, Pasian (1998) argumentou que, para uma adequada avaliação do material produzido nesta técnica, existe a necessidade de um grupo de referência para análise dos protocolos. Apontou, portanto, o cuidado técnico em se procurar informações sobre como se comportam as variáveis desta prova projetiva na população. Assim sendo, o grupo de referência faz parte do processo comparativo implícito na análise do Rorschach.

No entanto, até hoje, os dados normativos do Rorschach configuram-se como um problema técnico de difícil solução, pois exigem longo tempo de trabalho em sua construção, 
devido ao sofisticado sistema de análise e interpretação dos resultados (Güntert, 2000). Com isso, não existem muitos estudos desta natureza em vários dos contextos onde o instrumento é utilizado, tendendo a gerar análises comparativas entre indivíduos de culturas muito diversas, o que, no geral, é um procedimento de risco (Pasian, 1998; Anastasi \& Urbina, 2000; Urbina, 2007).

Ao seguir esta linha de reflexão sobre o Psicodiagnóstico de Rorschach, pode-se inferir que, para compreender a adaptação do indivíduo à realidade, existirão os padrões normativos como referenciais externos para a consideração daquele indivíduo dentro de seu grupo sociocultural. Nesse sentido, Nascimento (2002) vem afirmar que tanto nas experiências da vida, como ao responder ao Rorschach, existe uma motivação derivada da pulsão (aspectos individuais) e ao mesmo tempo uma orientação e um controle para que a expressão seja legítima e condizente aos padrões de uma determinada cultura. A relação entre esses dois pólos é bastante complexa. E os especialistas nesta técnica projetiva devem estar preparados para compreender tanto a personalidade individual, quanto os elementos socioculturais que interferem nos padrões de suas respostas, pois o Rorschach, como todas as experiências humanas, revela ao mesmo tempo aspectos estritamente individuais e características que são próprias de seu grupo social e de sua cultura.

\subsection{Estudos normativos do Rorschach}

O conjunto das considerações anteriores evidenciam que existem variações nos resultados das técnicas de avaliação psicológica, mesmo quando se estudam pessoas de um mesmo país, mas de origens étnicas e culturais diversas. Além disso deve-se considerar ainda que o ser humano se modifica no tempo em razão de sua experiência, de seus relacionamentos significativos e do contexto no qual está inserido. É indiscutível, portanto, que estudos normativos para o Rorschach deverão ser desenvolvidos em diferentes contextos e condições socioculturais, sempre procurando acompanhar a realidade atual e suas especificidades (Adrados, 1985; CFP, 2003; Pasian, 2002; Lelé, 2006; Resende, Rezende \& Martins, 2006; Villemor-Amaral et al., 2006).

Nessa perspectiva, pesquisadores de diversos países e contextos têm se empenhado na tarefa de desenvolver normas para o Rorschach. Os resultados advindos destes estudos reafirmam a necessidade de que mais estudos desta natureza sejam desenvolvidos com vários 
grupos populacionais, permitido padrões de referência adequados aos indivíduos que se quer compreender.

$\mathrm{Na}$ tentativa de apresentar alguns dessas pesquisas, inicialmente será oferecido o devido destaque ao clássico estudo normativo do Rorschach desenvolvido por Ames, Learned, Metraux e Walker (1961), que enfocou especificamente a população infantil. Esses autores procuraram estabelecer padrões estatísticos rigorosos para o Rorschach investigando 650 crianças norte-americanas de dois a dez anos, considerando as variáveis sexo, idade, nível socioeconômico e nível evolutivo. Tinham como objetivo distinguir entre imaturidade, anormalidade e individualidade. Seus dados foram apresentados em análises específicas por idade, comparando-se diferenças em função do sexo. Dos complexos índices apresentados neste clássico estudo, cabe aqui enfatizar os resultados referentes à faixa etária de seis a oito anos, a ser abordada no presente trabalho. Segundo estes autores, o número médio de respostas $(\mathrm{R})$ foi de 15,8 em crianças de seis anos, 18,3 em crianças de sete anos e 15,8 em crianças de oito anos. Houve predomínio da localização "global" sobre a localização "grande detalhe", seguido de "pequeno detalhe" e médias percentuais de respostas formais (F) de $56,7 \%$ e respostas formais positivas $(\mathrm{F}+)$ de $83,3 \%$ para esta faixa etária. Estes resultados serão detalhados e discutidos oportunamente no presente trabalho.

$\mathrm{Na}$ tentativa de buscar trabalhos normativos recentes a respeito do Psicodiagnóstico de Rorschach e realizados especificamente com crianças, consultando-se a base de dados PsycInfo, pode-se identificar, o trabalho da equipe de Matsumoto et al. (2002). Este foi um estudo empírico sobre o Rorschach com crianças japonesas, tendo como propósito fazer uma comparação internacional de resultados normativos, contrapondo crianças não-pacientes do Japão, dos Estados Unidos e da França, tendo utilizado o Sistema Compreensivo. Neste trabalho os autores ressaltaram a importância de fatores culturais como componentes da expressão nesta técnica projetiva, almejando avaliar características do desenvolvimento afetivo-social, exigindo adequada interpretação de resultados comparativos entre diferentes ambientes e países.

Ainda com a perspectiva de caracterizar a literatura científica sobre o Rorschach, julgou-se importante destacar os trabalhos divulgados no Journal of Personality Assessment, por ser um periódico científico de renome na área, que se constitui em um meio de comunicação internacional que retrata a história e o desenvolvimento metodológico desta técnica projetiva. Procurou-se enfocar os estudos normativos do Rorschach que examinavam a população infantil e/ou juvenil, desenvolvidos nos últimos dez anos (1999 a 2009). A partir 
deste levantamento, foram destacados oito artigos desta natureza, os quais foram sintetizados na Tabela 1, e serão expostos detalhadamente a seguir.

Tabela 1 - Estudos normativos do Rorschach identificados no Journal of Personality Assessment no período 1999 a 2009.

\begin{tabular}{|c|c|c|c|c|c|}
\hline Autor(es) & Ano & Nacionalidade & Participantes & Idade & Sistema \\
\hline Silva \& Dias & 2007 & Portuguesa & 357 & 6 a 10 & Compreensivo \\
\hline Hamel \& Shaffer & 2007 & $\begin{array}{c}\text { Norte- } \\
\text { americana }\end{array}$ & 100 & 6 a 12 & Compreensivo \\
\hline Van Patten et al. & 2007 & $\begin{array}{c}\text { Norte- } \\
\text { americana }\end{array}$ & 37 & 15 a 17 & Compreensivo \\
\hline Valetino et al. & 2007 & $\begin{array}{l}\text { Mexico- } \\
\text { americana }\end{array}$ & 42 & 8 a 10 & Compreensivo \\
\hline Salcuni et al. & 2007 & Italiana & 223 & 5 a 11 & Compreensivo \\
\hline Lis et al. & 2007 & Italiana & 223 & 12 a 18 & Compreensivo \\
\hline Hansen & 2007 & Dinamarquesa & 75 & 9 & Compreensivo \\
\hline Matsumoto et al. & 2007 & Japonesa & 346 & 5 a 14 & Compreensivo \\
\hline
\end{tabular}

Ao avaliar 357 crianças portuguesas, Silva e Dias (2007) procuraram desenvolver um estudo normativo do Rorschach para a faixa etária de seis a dez anos, provenientes de escolas públicas (maioria) e particulares. Foram usados como critérios de exclusão a presença de distúrbios de aprendizagem, problemas comportamentais e/ou dificuldades interpessoais. Participaram da coleta de dados 18 psicólogos, devidamente treinados no Sistema Compreensivo (SC) do Rorschach. Iniciaram as avaliações com a aplicação das Matrizes Progressivas Coloridas de Raven que, segundo os autores, além de ser um instrumento válido para obter dados sobre o nível intelectual das crianças, mostrou ser uma das formas mais apropriadas para iniciar o procedimento de coleta de dados. Em seus principais resultados sobre o padrão geral de desempenho, os autores observaram número médio de respostas (R) de 22,7 em crianças de seis anos; 25,2 em crianças de sete anos; e 24,5 em crianças de oito anos. Também pode ser observada predominância da área de localização grande detalhe em detrimento da localização global, diferenciando-se dos resultados da amostra americana, com a qual este estudo foi comparado. Além disso, identificaram pequeno número de respostas 
com determinante cor em todos os grupos etários, elementos que foram cuidadosamente analisados em suas possibilidades interpretativas e debatidos com a literatura internacional da área.

Com o objetivo de formular referenciais normativos do Rorschach para o contexto norte-americano, Hamel e Shaffer (2007) investigaram 100 crianças dos Estados Unidos da América, divididas em dois grupos: um composto por crianças de seis a nove anos e outro por crianças de dez a 12 anos. Aplicaram o Rorschach (SC) às crianças e, o Conner's Parent Rating Scale-93 (CPRS-93), aos pais. Foi adotado como critério de inclusão na amostra a ausência de histórico de tratamento psicológico e/ou psiquiátrico, de violação legal, de mau comportamento estudantil e de abuso de álcool e/ou substâncias ilícitas, bem como possuir adequado rendimento escolar. A administração e a codificação dos protocolos do conjunto da amostra foram realizadas por um único avaliador. Seus resultados mostram que o grupo de crianças com idade entre seis e nove anos produziram, em termos médios, 24,5 respostas, com prevalência de respostas grande detalhe $(9,80)$, seguida de respostas pequeno detalhe $(7,82)$ e globais $(6,90)$. O segundo grupo, por sua vez, composto por crianças de dez a 12 anos, apresentou número médio de 26,5 respostas, com predomínio também de respostas grande detalhe $(8,96)$, mas com um resultado bem próximo às globais $(8,76)$ e pequeno detalhe $(8,74)$. Os dois grupos de crianças manifestaram predominantemente o estilo de vivência afetiva evitativo.

Também em contexto norte-americano, Van Patten, Shaffer, Erdberg e Canfield (2007) desenvolveram um estudo normativo com a participação de 37 jovens com idade de 15 a 17 anos, selecionados de modo a não apresentarem histórico de prisão e/ou hospitalização para tratamento psiquiátrico. A aplicação e a avaliação do Rorschach (SC) foram realizadas pela primeira autora desse trabalho. Posteriormente, 20 protocolos foram selecionados aleatoriamente e recodificados por uma psicóloga treinada no Sistema Compreensivo (SC) do Rorschach, com o intuito de se calcular a fidedignidade entre examinadores, obtendo-se índices de concordância que variaram de 71 a $98 \%$, dependendo da variável em questão. Como principais resultados observaram número médio de respostas de 24,7, com predomínio de respostas globais $(10,1)$ sobre respostas grande detalhe $(7,7)$ e pequeno detalhe $(6,8)$. Segundo os autores, seus dados diferem em vários aspectos dos referenciais desenvolvidos por Exner, em 1995, como, por exemplo, o aumento de respostas pequeno detalhe (Dd) e a diminuição de respostas populares. Argumentam que o reduzido tamanho dessa amostra deve ser levado em consideração, bem como o fato dos participantes serem provenientes de uma área geográfica específica do país. Por fim, os referidos pesquisadores enfatizam a 
necessidade de se ampliar e diversificar a amostra, a fim de que ela possa, de fato, representar os jovens em um dado contexto, evitando assim conclusões precipitadas sobre o tema em questão.

Ao pesquisar indícios de diferenças culturais entre a cultura hispânica e americana, refletidos nos resultados do Psicodiagnóstico de Rorschach, Valentino, Shaffer, Erdberg e Figueroa (2007) avaliaram uma amostra composta por 42 crianças mexicanas, com idade entre oito e dez anos, residentes nos Estados Unidos da América. Todas elas eram bilíngües (falavam espanhol e inglês), no entanto, a técnica foi administrada na língua inglesa, com o objetivo de examinar as diferenças culturais, e não lingüísticas, da amostra estudada. A aplicação do Rorschach (SC) foi realizada na residência de cada criança, sendo todo o material coletado e codificado por um único examinador. Nenhum protocolo apresentou um número menor que 14 respostas, portanto não houve caso eliminado da amostra. A fim de avaliar a fidedignidade entre examinadores, 25 protocolos foram selecionados e recodificados por uma psicóloga experiente na técnica, obtendo-se índices de concordância que variaram de 70 a 99\%, de acordo com a variável em foco. Em linhas gerais, os resultados apontaram para um número médio de respostas $(\mathrm{R})$ de 23,9, estilo de vivência afetiva predominantemente evitativo e prevalência de respostas globais $(9,6)$, seguidas de grande detalhe $(9,1)$ e pequeno detalhe $(5,2)$. Finalizando este estudo, os autores ressaltaram que, apesar do número reduzido de participantes, ele consiste no primeiro trabalho realizado com uma amostra de participantes de nacionalidade específica, porém residentes em outro país, podendo, assim, fomentar análises relativas a elementos socioculturais no desenvolvimento da personalidade.

Seguindo essa mesma linha de investigação, Salcuni, Lis, Parolin e Mazzeschi (2007), estudaram 223 crianças, não pacientes, oriundas de diferentes escolas públicas da Itália. Deste grupo, 75 crianças tinham entre cinco e sete anos e as demais 148 crianças estavam entre oito e 11 anos de idade. Excluíram de sua amostra os participantes com antecedentes psicológicos e/ou psiquiátricos. Os examinadores foram 15 psicólogas com experiência na área de avaliação psicológica, mas que ainda assim participaram de um curso sobre a administração da técnica em estudo. Cada uma delas coletou cerca de 11 a 20 protocolos do Rorschach. Foram descartados dez protocolos por apresentarem menos de 14 respostas. Posteriormente, 30 casos foram selecionados aleatoriamente e recodificados para cálculo da fidedignidade entre avaliadores. Os índices de concordância variaram entre 81 a 98\%, dependendo da variável analisada. Obtiveram como principais resultados número médio de respostas de 21,3 para o grupo de cinco a sete anos e 20,7 para o grupo de oito a 11 anos. No primeiro grupo prevaleceram as respostas grande detalhe, e no segundo, as respostas globais. 
Em suas discussões, as autoras evidenciaram a possibilidade de generalização de seus achados no contexto da Itália, já que crianças de várias regiões do país foram avaliadas no estudo. Contudo, as autoras salientaram a importância de se diferenciar parâmetros normativos do Rorschach em relação a estudos realizados com a avaliação de não pacientes. Para essas pesquisadoras, uma amostra normativa deveria contar também com certo número de participantes que já passaram por algum tipo de tratamento relacionado à saúde mental, com o intuito de representar a diversidade e a complexidade dos indivíduos que compõem os grupos populacionais.

Ainda referente ao contexto italiano, Lis, Salcuni e Parolin (2007) apresentaram evidências empíricas de pesquisa desenvolvida com uma amostra de 223 jovens, divididos em 116 pré-adolescentes (com idade entre 12 e 14 anos) e 117 adolescentes (com idade entre 15 e 18 anos). Foram excluídos da amostra participantes com história de hospitalização psiquiátrica, tratamento psicológico nos últimos dois anos e/ou alguma doença grave nos últimos seis meses. Essas informações foram colhidas em breve entrevista semi-estruturada, ao final da avaliação psicológica. Participaram da coleta de dados dez estudantes de Psicologia com, pelos menos, dois anos de prática em pesquisa com o Rorschach, sendo que também passaram por treinamento específico para este estudo. Cada estudante aplicou e codificou cerca de 10 a 25 protocolos, os quais foram posteriormente recodificados por um dos dois primeiros autores do trabalho. Em seguida, 30 protocolos foram selecionados aleatoriamente e recodificados pela terceira autora do trabalho, para verificação da fidedignidade entre os avaliadores. Os índices de concordância variaram de 81 a 97\%, dependendo da variável avaliada. Nos resultados concernentes aos índices de produtividade, as autoras apontaram que a média de respostas no grupo de pré-adolescentes foi de 22,31, com prevalência de respostas globais e, no grupo de adolescentes foi de 21,79, com prevalência de respostas grande detalhe. Ao final do trabalho, as pesquisadoras questionaram se os dados encontrados podem ser generalizados para além da amostra estudada, ponderando o fato de que todos os participantes são provenientes de uma área específica do país, concluindo que seria importante a realização de outras pesquisas desta natureza para ampliar a dimensão da amostra.

Hansen (2007), por sua vez, avaliou uma amostra de 75 crianças não pacientes, de nove anos de idade, provindas de nove diferentes regiões (urbanas e rurais) da Dinamarca. Em sua amostra incluiu apenas crianças que não apresentaram histórico de atendimento psicológico e/ou psiquiátrico. Participaram de sua coleta de dados dez psicólogos, familiarizados com o Sistema Compreensivo (SC) e que, ainda assim, participaram de um 
treinamento específico para esta técnica projetiva. As aplicações foram realizadas na própria escola das crianças participantes e nenhum protocolo com menos de 14 respostas foi integrado à amostra. Os protocolos foram codificados pelos próprios psicólogos e revistos pelo grupo de pesquisa, para posterior análise do próprio autor, a fim de assegurar a consistência das codificações. A seguir, um total de 20 protocolos foi aleatoriamente selecionado para verificação da fidedignidade entre examinadores, a qual obteve elevados índices de acordo (92\% a 99\%) nas variáveis estudadas. Seus resultados apontaram para números médios de respostas de 23,6 e índices bem próximos entre médias das respostas globais $(10,3)$ e grande detalhe $(10,1)$, seguidos de respostas pequeno detalhe $(3,2)$. Em sua discussão, o autor afirma ter selecionado uma amostra representativa da população dentro da faixa etária em foco nesse trabalho, na medida em que as crianças foram selecionadas aleatoriamente e com origem em diferentes regiões do país. No entanto, salienta que o fato da amostra ser exclusivamente proveniente de escolas públicas pode, de alguma forma, ter produzido alguma especificidade nos resultados.

Desenvolvida no contexto oriental, destaca-se a pesquisa de Matsumoto, Suzuki, Shirai e Nakabayashi, (2007), que estudaram 346 crianças japonesas, não pacientes, provenientes de escolas públicas, a partir do Sistema Compreensivo (SC) do Rorschach. Desse conjunto 144 crianças produziram menos que 14 respostas e outras 12 foram identificadas como mal ajustadas ou deficientes, a partir de informações fornecidas por seus professores. Assim, somente os protocolos de 190 crianças foram considerados no estudo, sendo divididos entre cinco grupos: cinco anos $(n=24)$, oito anos $(n=43)$, nove anos $(n=42)$, $12 \operatorname{anos}(n=42)$ e 14 anos $(n=39)$. Colaboraram com a coleta de dados nove psicólogas clínicas com experiência na técnica, tendo cada uma delas administrado cerca de 14 a 30 protocolos. Em seguida, cada caso foi avaliado independentemente por dois juízes com experiência no instrumento e, tendo sido observado desacordo entre esses examinadores, procurou-se buscar um consenso entre o grupo de pesquisa. Posteriormente, 30 protocolos foram selecionados aleatoriamente para o cálculo da fidedignidade entre avaliadores, resultando em índices de concordância que variaram de 87 a 100\%. Em seus resultados, os autores afirmaram que as crianças japonesas produziram reduzido número de respostas, com média entre 18 e 20, e predomínio de respostas globais, sendo que o grupo de crianças de cinco anos apresentou índices médios de produtividade ainda inferiores aos demais grupos avaliados, tendo predominado as respostas grande detalhe neste grupo. Para estes pesquisadores, o baixo índice de produtividade obtido pelas crianças de cinco anos pode ser atribuído ao restrito repertório verbal e de experiências vividas até esta fase da vida. 
Consideraram que os dados resultantes desta pesquisa diferenciaram-se notavelmente dos encontrados por estudos americanos e franceses. Em comparação com os estudos internacionais, os resultados levam a concluir que as crianças japonesas pareceram mais modestas em sua expressão verbal e emocional, mais passivas nos relacionamentos interpessoais, evitando estímulos exteriores. Segundo esses autores, o fato do Rorschach depender da expressão verbal pode contribuir para os resultados encontrados, aspectos que devem necessariamente ser compreendidos e interpretados dentro da cultura japonesa. Em suas considerações finais, destacam a importância do aumento da amostra de participantes, com o intuito de ampliar a base de dados normativa. Evidenciam também a necessidade de estudos transculturais para o Psicodiagnóstico de Rorschach, tendo em vista a diversidade social e humana existente nos diferentes países, o que pode explicar grande parte das divergências presentes nos vários estudos normativos com este instrumento.

Acompanhando a constatação de diferenças entre determinadas regiões e culturas, Meyer, Edberg e Shaffer (2007) realizaram um estudo no qual analisaram os dados encontrados em 21 amostras normativas compostas por adultos de 17 países, tendo como referencial o Sistema Compreensivo. A partir desta análise, observou-se que tanto a composição das amostras quanto os resultados obtidos nestes trabalhos foram bastante similares. No entanto, ao avaliar, neste mesmo trabalho, os dados de 31 amostras de crianças e adolescentes de cinco países (Dinamarca, Estados Unidos, Itália, Japão e Portugal), os autores observaram diferenças significativas entre os resultados alcançados. Nesse contexto, os pesquisadores afirmam que as normas relativas à população mundial adulta poderão, possivelmente, ser integradas. Contudo, esta possibilidade de composição de um padrão de referência internacional único para a população infantil e juvenil não deverá ocorrer tão cedo, como mostram as divergências notadas no referido estudo. Por fim, tais autores discutem sobre as possíveis causas destas diferenças, levantando hipóteses sobre as peculiaridades culturais e sociais de determinados contextos e sugerem que novos trabalhos sejam feitos nesse sentido, colaborando na compreensão dessas diferenças e no estabelecimento de padrões normativos fidedignos.

Com o intuito de estabelecer normas para a utilização do Rorschach para a população francesa, Azoulay et al. (2007) investigaram 278 sujeitos não pacientes, englobando adolescentes e jovens adultos de 13 a 25 anos, divididos de maneira relativamente equilibrada de acordo com três grupos de idade, três grupos de categorias sócio-profissionais e em função do sexo. Utilizaram como referencial técnico-teórico, a Escola Psicanalítica Francesa do Rorschach, apresentando neste trabalho a primeira vertente de resultados que abrem a 
possibilidade de comparações intra-grupos e intergrupos. Tiveram como principais resultados médios: $\mathrm{R}=25,8 ; \mathrm{G} \%=43,3 ; \mathrm{D} \%=43,6 ; \mathrm{Dd} \%=10,2 ; \mathrm{Dbl} \%=2,9 ; \mathrm{F} \%=61,3 ; \mathrm{F}+\%=65,2 ; \mathrm{H} \%$ $($ ampliado $)=20,4 ; \mathrm{A} \%($ ampliado $)=47,1$.

Em outra perspectiva investigativa, efetuou-se uma revisão dos trabalhos normativos com o Rorschach apresentados em congressos científicos internacionais da área, realizados mais recentemente. Nesse sentido, foi possível perceber que pesquisadores voltados ao estudo das características psicométricas dos métodos de avaliação psicológica continuam se esforçando na busca de resultados de diferentes grupos de referência para as técnicas projetivas e para o Rorschach. Passa-se neste momento a retratar rapidamente estes trabalhos.

A consulta aos anais do último Congresso Internacional de Rorschach e Métodos Projetivos da International Rorschach Society (IRS), realizado em Julho de 2008 na Bélgica, permitiu identificar vários autores preocupados e envolvidos com este tema. Podem ser citados os seguintes trabalhos como representantes atuais desta linha de investigação científica: Andronikof, Chudzik e Gillaizeau (2008) com adolescentes, na França; Fernandez e Pardillo (2008) com adultos, em Cuba; Nascimento, Brunoni, Sasaki, Bueno \& Parsons, (2008b) com adolescentes, no Brasil; Lelé (2008a) e Villemor-Amaral, Yazigi, Primi, Nascimento, Semer, Meyer, \& Viglione (2008), com adultos, também no Brasil.

Especificamente com a população infantil e com base no Sistema Compreensivo do Rorschach (SC) pôde-se identificar as pesquisas de: Bagdag (2008, com 480 crianças de seis a 12 anos, oriundas de escolas públicas da Tunísia); Lis, Salcuni, Parolin, Di Riso e Laghezza (2008, com 223 crianças de cinco a 11 anos provenientes de escolas públicas da Itália); Matsumoto et al. (2008, com 352 crianças de escolas públicas, com idades entre oito e 14 anos, no Japão); Yazigi, Ribeiro e Semer (2008), focalizando 211 crianças brasileiras, de sete a dez anos, provenientes de escolas públicas e particulares. Seus resultados foram comparados aos de outros pesquisadores que também analisaram a população infantil, no Brasil).

Avaliando-se o conjunto dos estudos citados até o momento, pôde-se constatar que a realização de estudos normativos configura-se como preocupação presente em diversos contextos e países. Todos têm como objetivo comum retratar adequadamente os padrões de perfil contemporâneos no Rorschach, de modo que realmente representem a variedade de grupos e de populações existentes. Ressaltam-se, sobretudo, as divergências significativas encontradas entre os resultados das amostras de crianças, embora nem todos os estudos retratem a especificidade das idades. Essas evidências empíricas fortalecem a importância e a necessidade da padronização de resultados, principalmente relacionados à população infantil. 


\subsection{Estudos normativos do Rorschach no Brasil}

Em se tratando, particularmente, do contexto brasileiro, é preciso considerar as dimensões continentais deste país, assim como toda a gama de culturas que o compõe. Essa multiplicidade de costumes, hábitos, crenças, tradições, linguagens e pensamentos faz com que cada estado tenha suas peculiaridades e, portanto, seja considerado um pólo cultural diferente (Resende \& Argimon, 2010). Além disso, é importante destacar as acentuadas mudanças significativas que o Brasil tem vivenciado, tanto em suas condições socioeconômicas quanto culturais, influenciando o modo de vida de seus indivíduos. Esta realidade, portanto, também exige da área da avaliação psicológica, reciclagens nos métodos utilizados, sobretudo cuidados em relação aos grupos populacionais usados como referenciais para a interpretação dos dados obtidos com o Psicodiagnóstico de Rorschach, com o objetivo de aprimorá-lo, e torná-lo um método cada vez mais útil, preciso e válido na investigação da personalidade (Pasian, 1998).

O Psicodiagnóstico de Rorschach é utilizado com freqüência no Brasil e está necessitando de maior reflexão em várias regiões do país, devido, justamente, à enorme diversidade de paisagens humanas, sociais e culturais que pode trazer marcas significativas aos resultados desta prova projetiva. Como pode ser observado, a cultura influencia, de alguma forma, a percepção dos indivíduos. Daí a importância de ter dados normativos em diferentes regiões do país. (Lelé, 2006, p. 97)

Acompanhando esse panorama de crescente preocupação com a importância e a necessidade de que os instrumentos psicológicos apresentem adequadas qualidades psicométricas, estimulando a garantia de sua qualidade metodológica, o Conselho Federal de Psicologia (CFP, 2003) publicou as diretrizes para análise dos instrumentos de avaliação psicológica utilizados no país, baseadas no exame minucioso de critérios como: validade, fidedignidade, padronização e normatização (Bandeira et al., 2006). A Resolução do CFP 02/2003 regulamenta o uso, a elaboração e a comercialização de testes psicológicos. Ressalta, entre outros aspectos, a necessidade do aprimoramento dos instrumentos e procedimentos técnicos de trabalho dos psicólogos e da revisão periódica das condições dos métodos e técnicas utilizados na avaliação psicológica, a fim de garantir qualidade técnica e ética à população usuária desses serviços. Além disso, essa resolução expõe a importância de se construir um sistema contínuo de avaliação dos testes psicológicos, adequado à dinâmica da comunidade científica e profissional. 
Para implementar estas diretrizes foi criado o Sistema de Avaliação de Testes Psicológicos (SATEPSI), que pretende avaliar minuciosamente a qualidade dos instrumentos psicológicos utilizados no Brasil (CFP, 2003). Assim, todo teste psicológico é submetido a uma análise de caráter objetivo, com critérios adotados segundo as normas internacionais que estabelecem o mínimo necessário para aceitação de um instrumento enquanto técnica de avaliação psicológica.

Em meio a esta realidade, em nosso país, os pesquisadores do Psicodiagnóstico de Rorschach também têm se esforçado de modo a desenvolver atualizações regionais dos parâmetros normativos dessa técnica para embasar sua correta utilização no contexto sociocultural brasileiro. Na tentativa de evidenciar esses trabalhos, Pasian (2002) realizou um levantamento dos estudos normativos brasileiros referentes ao Rorschach no período compreendido entre as décadas de 1930 e 1990. Dentro dos materiais acessíveis à consulta direta, foram detectados 19 estudos normativos com o Rorschach, sendo cinco voltados para a área infantil (até 11 anos), três para pré-adolescentes e adolescentes (até 16-17 anos), oito para a faixa adulta, um incluindo adolescentes e adultos, outro com crianças e adolescentes e um último voltado para idosos. A maioria desses estudos foi desenvolvida até a década de 70 ou pelo menos tiveram seus dados coletados nesse período. Com relação às variáveis consideradas nesses estudos, identificou-se ênfase em elementos etários e de sexo dos sujeitos, com acentuada preocupação relativa à normalidade intelectual e psíquica dos indivíduos, além de suas condições socioeconômicas.

No que se refere a estudos normativos do Rorschach dirigidos particularmente à população infantil, Pasian (2002) referiu a existência de cinco trabalhos. Estes estudos encontram-se sintetizados na Tabela 2.

Tabela 2 - Estudos normativos brasileiros do Rorschach com crianças, publicados até 1990.

\begin{tabular}{ccccc}
\hline Autor & Ano & Região & Participantes & Idade \\
\hline Barreto & 1955 & Recife & 204 & 6 a 10 \\
\hline Viana-Guerra & 1958 & Rio de Janeiro & 100 & 3 a 8 \\
\hline Windholz & 1969 & São Paulo & 400 & 7 a 10 \\
\hline Jacquemin & 1976 & Ribeirão Preto & 480 & 3 a 11 \\
\hline Adrados & 1985 & Rio de Janeiro & 200 & 7 a 14 \\
\hline
\end{tabular}


Conforme observado na Tabela 2, Barreto (1955) investigou crianças de seis a dez anos, em Recife, considerando as variáveis sexo, idade e nível socioeconômico; Viana-Guerra (1958) estudou a faixa etária de três a oito anos, no Rio de Janeiro; Windholz (1969) analisou crianças de sete a dez anos, em São Paulo; Jacquemin (1976) investigou crianças de três a dez anos em Ribeirão Preto, considerando as variáveis sexo, idade, nível socioeconômico e intelectual e normalidade psíquica; Adrados (1985) avaliou a faixa etária de sete a 14 anos, no Rio de Janeiro, levando em conta apenas as variáveis sexo e idade. Como se pode constatar, esses trabalhos já possuem uma distância temporal que, por si só, justificaria a replicação técnica, de modo a testar a estabilidade dos resultados, sobretudo diante das rápidas mudanças socioculturais contemporâneas.

Tendo em vista a natureza do tipo de estudo, quando se trata de trabalho de desenvolvimento de normas para o Psicodiagnóstico de Rorschach, na grande maioria dos casos, a publicação deste material não segue um padrão de divulgação em periódicos científicos. Sendo assim, estendeu-se a busca por trabalhos desenvolvidos com este enfoque apresentados em eventos científicos da área.

Nessa perspectiva, com o intuito de apresentar estudos normativos mais atuais com o Rorschach no Brasil, avaliou-se as produções apresentadas nos mais recentes congressos de Avaliação Psicológica e Métodos Projetivos, a saber: Encontros da Associação Brasileira de Rorschach e Métodos Projetivos - ASBRo (2006, 2008); IV Congresso Brasileiro de Avaliação Psicológica - IBAP (2009), juntamente com a XIV Conferência Internacional de Avaliação Psicológica: Formas e Contextos (2009) e o V Congresso Brasileiro de Rorschach e Outros Métodos Projetivos - ASBRo (2009).

Esse levantamento permitiu identificar uma série de trabalhos normativos do Rorschach que vem sendo desenvolvido nos últimos anos. A Tabela 3 sintetiza a apresentação destes estudos, com o intuito de facilitar sua visualização. Nesta Tabela, evidencia-se, em linhas gerais, as principais características destes trabalhos, que serão detalhadamente expostos a seguir. 
Tabela 3 - Estudos normativos do Rorschach apresentados nos últimos eventos científicos da área de Avaliação Psicológica e Métodos Projetivos no Brasil (2006, 2008, 2009).

\begin{tabular}{|c|c|c|c|c|}
\hline Autor(es) & Região & Participantes & Faixa etária & Sistema \\
\hline Lelé & Minas Gerais & 100 & 18 a 36 & Francês \\
\hline $\begin{array}{c}\text { Nascimento } \\
\text { et al. }\end{array}$ & São Paulo & 409 & $\begin{array}{l}\text { Adolescentes e } \\
\text { adultos }\end{array}$ & Compreensivo \\
\hline $\begin{array}{c}\text { Raspantini, } \\
\text { Bordão-Alves e } \\
\text { Pasian }\end{array}$ & Pirassununga - SP & 180 & 9 a 11 & Francês \\
\hline Resende et al. & Goiânia - GO & 336 & 3 a 14 & Compreensivo \\
\hline $\begin{array}{c}\text { Ribeiro, Yazigi e } \\
\text { Semer }\end{array}$ & Cuiabá - MT & 211 & 7 a 10 & Compreensivo \\
\hline $\begin{array}{l}\text { Semer, Yazigi, } \\
\text { Nascimento e } \\
\text { Carvalho }\end{array}$ & São Paulo & 211 & 31 (em média) & Compreensivo \\
\hline $\begin{array}{l}\text { Souza e Duarte } \\
\text { Junior }\end{array}$ & Belém - PA & 506 & 18 e 50 & Francês \\
\hline
\end{tabular}

Fundamentando-se na Escola Psicanalítica Francesa do Rorschach, destacam-se os trabalhos de Lelé (2006, 2008b); Raspantini e Pasian (2008) e Raspantini, Bordão Alves e Pasian (2009); e Souza e Duarte Junior (2008). Trabalhando com adultos, Lelé (2006, 2008) investigou 100 indivíduos de ambos os sexos, com idade variando entre 18 e 36 anos, de diversos níveis de escolaridade, naturais do Estado de Minas Gerais (MG). Seus resultados revelaram diferenças quando comparados com os de outros estudos brasileiros, evidenciando influências culturais em diversos fatores normativos do Rorschach, assim como a necessidade de trabalhos de investigação específicos nesta área. Souza e Duarte Junior (2008), por sua vez, realizaram um estudo com 506 adultos paraenses, com idade entre 18 e 50 anos, residentes na cidade de Belém, região norte do Brasil, objetivando analisar as respostas banais produzidas neste contexto sociocultural. Seus dados foram comparados aos de estudos realizados em outras regiões do país, e revelaram diferenças estatísticamente significativas entre eles. Essa constatação evidenciou, mais uma vez, a necessidade de se estabelecer normas regionais para a população brasileira.

Fazendo parte do mesmo centro de investigações do presente estudo, Raspantini e Pasian $(2008,2009)$ avaliaram crianças de nove a 11 anos de idade, com indicadores de 
desenvolvimento típico, distribuídos equitativamente em função do sexo, idade e origem escolar, residentes em uma cidade do interior paulista. Os instrumentos utilizados consistiram em um Questionário informativo sobre o histórico de vida das crianças (respondido pelos pais ou responsáveis), nas Matrizes Progressivas Coloridas de Raven e no Psicodiagnóstico de Rorschach (Escola Psicanalítica Francesa). A codificação dos protocolos do Rorschach foi realizada por três avaliadores independentes, psicólogos devidamente treinados para o procedimento. $\mathrm{O}$ material resultante destas análises evidenciou elevados índices de acordo entre examinadores. Apresentaram nestes eventos, os indicadores iniciais deste trabalho que, embora exigindo aprofundamentos analítico-interpretativos, apontaram sinais de maior investimento racional na interpretação da realidade em estudantes de escola pública, na faixa etária avaliada. No entanto, crianças de escolas particulares mostraram índices mais elevados de precisão formal e de integração entre elementos racionais e afetivos. Estes resultados iniciais apontaram para a necessidade de cuidados técnicos adicionais no processo de elaboração de referenciais normativos para avaliação do desempenho infantil diante do Rorschach.

Ainda com relação aos trabalhos apresentados nos eventos científicos descritos na Tabela 3, dentre os que seguem o Sistema Compreensivo do Rorschach, foram encontrados os estudos de: Nascimento et al. (2006, 2008a, 2009), Resende et al. (2006), Ribeiro et al. (2008, 2009), Semer, Yazigi, Nascimento e Carvalho (2009). Envolvendo a população adulta, Nascimento et al. (2006, 2008a, 2009) concluíram um estudo normativo de 409 adultos do estado de São Paulo. Apresentaram também os resultados parciais deste estudo normativo, com uma amostra de 120 adolescentes não-pacientes do Estado de São Paulo. Esses dados preliminares revelaram, segundo os autores, algumas semelhanças com os resultados encontrados na amostra de adultos paulistas e, também, com amostra de adolescentes italianos. No entanto, destacam a necessidade de uma análise mais sistemática destes dados. Semer, Yazigi, Nascimento e Carvalho (2009), por sua vez, apresentaram um estudo evidenciando diferenças de resultados na produção do Rorschach em função do sexo, comparando resultados de desempenho entre homens e mulheres, com idade média de 31 anos.

Especificamente com crianças, Resende et al. (2006) estão desenvolvendo um estudo cujo objetivo final é apresentar os resultados normativos do Rorschach (SC) de 336 crianças e adolescentes goianienses, com faixa etária entre três e 14 anos, provenientes de escolas públicas e creches. As autoras justificam seu trabalho apontando a carência de estudos normativos do Rorschach para crianças brasileiras e, especificamente, para sua região. Além 
do Rorschach, utilizaram uma entrevista semi-estruturada (modelo anamnese) respondida pelos pais ou responsáveis. Nesse trabalho apresentado, as citadas pesquisadoras elaboraram os dados preliminares referentes a apenas algumas variáveis do teste, com amostra parcial de 66 sujeitos, analisados até aquele momento. Estes resultados indicaram que o número de respostas tornou-se progressivamente maior com o aumento da faixa etária, com exceção das crianças com idade de dez e 11 anos. Os dados também mostraram que a porcentagem média de respostas unicamente formais (F\%) encontradas por Resende et al. (2006), que atingiu valores que variaram entre 66,7 a $80,2 \%$, apresentou-se superior ao índice encontrado em crianças e adolescentes norte-americanos.

Ribeiro, Yazigi e Semer (2008, 2009), por sua vez, desenvolveram um estudo normativo, com base no Sistema Compreensivo, de 211 de crianças de sete a dez anos, estudantes de escolas públicas e particulares da cidade de Cuiabá (MT). A conclusão deste estudo resultou na tese de Doutorado de Ribeiro (2010). Para selecionar a amostra, os pais das crianças responderam ao instrumento Child Behavior Checklist (CBCL), a fim de avaliar a competência social e identificar problemas de comportamento dos possíveis participantes. Nas crianças selecionadas pela CBCL, o teste das Matrizes Progressivas de Raven foi aplicado, com o intuito de se excluir aquelas com baixo rendimento intelectual. Na apresentação dos resultados, as crianças foram divididas em quatro grupos, tendo em vista sua idade, sendo sete $\operatorname{anos}(n=50)$; oito anos $(n=53)$; nove $\operatorname{anos}(n=53)$ e dez anos $(n=55)$. Em relação aos índices médios de produtividade, as crianças de sete anos apresentaram: $\mathrm{R}=15,9$, as de oito, $\mathrm{R}=16,6$, as de nove, $\mathrm{R}=16,2 \mathrm{e}$, por fim, as de dez anos obtiveram $\mathrm{R}=16,7$. No tocante às localizações, as crianças de sete anos apresentaram média de 5,2 respostas globais, 7,7 respostas grande detalhe (detalhe comum) e 3,0 respostas pequeno detalhe (detalhe incomum). As de oito anos manifestaram média de 5,2 respostas globais (W); 7,8 (D) e 3,6 (Dd). O grupo de nove anos obteve as médias de 3,8 (W); 8,7 (D) e 3,6 (Dd). E, por fim, as crianças de dez anos responderam, em termos médios, 4,5 (W); 8,6 (D) e 3,7 (Dd). O estudo concluiu que as crianças de escolas particulares apresentaram sinais de mais recursos cognitivos, mostraram maior facilidade em lidar com situações afetivas complexas, lidando com o afeto de modo mais intelectualizado que direto. No entanto, apresentaram mais indicadores de estresse situacional. Por sua vez, as crianças de escolas públicas apresentaram maior simplificação perceptiva, com atitude mais defensiva e de esquiva. As investigações não encontraram diferenças estatisticamente significativas com relação ao sexo das crianças, revelando que os meninos e meninas de sua amostra obtiveram resultados semelhantes nas variáveis do Rorschach. 
Em continuidade às análises preliminares dos dados normativos do Rorschach obtidos com crianças de nove a 11 anos de idade, Raspantini (2010) apresentou, detalhadamente, os achados finais de seu trabalho, concluindo sua dissertação de Mestrado recentemente. Os resultados médios de sua amostra apresentaram número de respostas igual a 16,5, sendo que o tempo de latência médio foi de 16,5 segundos e o tempo de reação médio foi de 32,8 segundos. Em relação aos modos de apreensão, obteve-se os seguintes dados médios: $\mathrm{G}=$ $39,1 \%, \mathrm{D}=34,4 \%$ e $\mathrm{Dd}=25,7 \%$. No que concerne aos índices formais, os dados obtidos foram: $\mathrm{F} \%=63,1 \%$ e $\mathrm{F}+\%=73,3 \%$. Os conteúdos mais evocados foram $\mathrm{A} \%=58,0 \%$ e $\mathrm{H} \%=$ 20,7\%. O estilo de vivência afetiva predominante foi o coartativo. E, por fim, seu índice de banalidades foi de $20,4 \%$.

Diante desta realidade, constata-se que, embora valiosos esforços tenham sido feitos nestas últimas décadas, existem poucos trabalhos nacionais voltados à obtenção de padrões normativos do Rorschach para a população infantil brasileira. Esta realidade, por si só, justifica novos investimentos nesta direção, com o intuito de alcançar atualizados padrões de referência do Rorschach para crianças de nossa região. É nesse contexto que se insere o presente trabalho, almejando-se elaborar padrões típicos de resultados nesta técnica projetiva, alcançados por crianças de seis a oito anos de idade, do interior do Estado de São Paulo, comparando-os com estudos prévios.

Os propósitos desta investigação poderão se constituir como referenciais úteis e relevantes na área de avaliação psicológica com o Psicodiagnóstico de Rorschach (Escola Psicanalítica Francesa) no Brasil, possibilitando o alcance de conhecimentos mais específicos e atualizados sobre a estrutura e funcionamento psíquico desta faixa etária infantil. Os resultados aqui obtidos poderão favorecer o trabalho clínico e científico dos profissionais que recorrem ao Psicodiagnóstico de Rorschach em seu cotidiano, permitindo processos de avaliação psicológica mais adequados e consistentes com a realidade vivenciada pelas crianças nos dias atuais. 


\section{OBJETIVOS}





\section{$\underline{\text { 2.1. Gerais }}$}

O presente trabalho teve por objetivo elaborar padrões normativos do Psicodiagnóstico de Rorschach (Escola Psicanalítica Francesa) para crianças de seis a oito anos, almejando que funcionem como referenciais analíticos atualizados deste instrumento projetivo de avaliação psicológica.

\subsection{Específicos}

2.2.1. Caracterizar o desempenho do conjunto total de crianças no Rorschach, ou seja, examinar a distribuição de freqüência das diversas categorias de classificação das respostas (localizações, determinantes e conteúdos), verificando especificidades de produção associadas ao sexo, à idade e à origem escolar.

2.2.2 Examinar os recortes interpretativos nas pranchas do Rorschach, realizados pelo conjunto global de crianças avaliadas, a fim de identificar as áreas detalhe (D) e pequeno detalhe (Dd), a partir do critério de frequiência de sua interpretação no total de respostas coletadas.

2.2.3 Examinar a qualidade formal (bem vistas, mal vistas e imprecisas) do conjunto de respostas obtidas no Rorschach com o grupo total de crianças avaliadas.

2.2.4 Verificar a freqüência específica de cada resposta do Psicodiagnóstico de Rorschach, em cada área circunscrita da prancha, para identificar as respostas banalidade (Ban).

2.2.5 Comparar os dados normativos aqui obtidos com o estudo anterior de Jacquemin (1976).

2.2.6 Elaborar o atlas do Rorschach para crianças de seis a oito anos, listando as áreas interpretadas e qualidade formal de suas respectivas respostas. 
3. MÉTODO 



\subsection{Características da região fonte do estudo}

De acordo com os dados disponíveis no endereço eletrônico da Prefeitura Municipal de Porto Ferreira (2009) e do Instituto Brasileiro de Geografia e Estatística (IBGE, 2006), a cidade de Porto Ferreira (SP), onde foi realizado este estudo, situa-se no nordeste do Estado de São Paulo, a 227 km de distância da capital do Estado, e a 95 km da cidade de Ribeirão Preto. Seu perímetro urbano corresponde a $244 \mathrm{Km}^{2}$, com uma estimativa populacional de aproximadamente 54.000 habitantes.

A cidade tem como principal fonte de renda basicamente indústrias, com destaque para o setor de cerâmica artística. A prestação de serviços é tida como fonte secundária de arrecadação de impostos do município, seguida pelo setor agrícola, cujos principais produtos cultivados são a cana-de-açúcar, laranja, batata, soja e milho. A região é configurada por população de baixa renda per capita, sendo esta de aproximadamente $\mathrm{R} \$ 700,00$. Dessa forma, pode-se perceber que esta região estudada apresenta características contextuais semelhantes a diversas cidades não só do interior do estado de São Paulo, mas também de todo o país.

Concernente aos índices demográficos, o município de Porto Ferreira (SP) apresenta Índice de Desenvolvimento Humano $(\mathrm{IDH}-\mathrm{M})^{1}$ de 0,802 , próximo aos indicadores de desenvolvimento humano do Brasil que, em 2009, obteve um IDH de 0,813. A taxa de urbanização da cidade é próxima de 97,0\%, e índice de crescimento anual da população em torno de $1,8 \%$. Cerca de $97,5 \%$ da população tem acesso ao abastecimento de água, 94,6\% tem acesso à rede de esgoto e 100,0\% à coleta de lixo.

Em relação aos aspectos educacionais, ainda segundo IBGE (2006), no último Censo Educacional realizado no município no ano de 2006, Porto Ferreira possui 15 escolas de Ensino Fundamental, com um total de 6942 alunos matriculados. Destas, 11 são escolas públicas (três estaduais, com um total de 2033 alunos matriculados, e oito municipais, com um total de 3875 alunos matriculados), e quatro escolas particulares, com uma estimativa total de 1034 alunos matriculados. As séries iniciais (de $1^{\circ}$ a $5^{\circ}$ ano) do Ensino Fundamental são oferecidas apenas pelas escolas públicas de caráter municipal e pelas particulares. Especificamente com relação aos alunos com idades entre seis a oito anos de idade (foco do presente estudo), de acordo com dados do Departamento Municipal de Educação, o município

\footnotetext{
${ }^{1}$ O IDH (Índice de Desenvolvimento Humano) é uma medida padronizada de avaliação do bem-estar da população, que leva em consideração a riqueza, a expectativa média de vida e a educação de determinada região. Inicialmente, o IDH foi divulgado pela ONU (Organização das Nações Unidas). No entanto, atualmente, além da reconhecida medida internacional, com a avaliação de países, tal índice tem assumido significativa importância nacional, na medida em que estados e municípios brasileiros geralmente são avaliados a partir deste critério.
} 
possuía 2167 crianças matriculadas no ano letivo de 2007, sendo 233 em escolas particulares e 1936 em escolas públicas (municipais) (ANEXO B).

Esta breve contextualização da cidade de Porto Ferreira (SP), fonte do presente estudo, teve por objetivo fornecer elementos mínimos para uma posterior análise compreensiva dos resultados enquanto normas do Psicodiagnóstico de Rorschach para a região de Ribeirão Preto, dadas as características de proximidade física e sociocultural entre as cidades que compõem esta área do Estado de São Paulo. Com base nestas características, poder-se-á, futuramente, refletir sobre possibilidades de aplicação dos atuais resultados do Rorschach em outros contextos similares. Destaca-se que, para avaliar a possibilidade de transposição dos dados, será necessário o julgamento analítico dos psicólogos que utilizarem este material, elaborado a partir do referencial da Escola Psicanalítica Francesa do Rorschach.

Cabe apontar, ainda, que o presente estudo integra parte dos esforços gerais do Centro de Pesquisas em Psicodiagnóstico (CPP) da Faculdade de Filosofia, Ciências e Letras de Ribeirão Preto, que vem desenvolvendo pesquisas relativas a normas para técnicas projetivas de avaliação psicológica para a região de Ribeirão Preto (SP).

\subsection{Participantes}

Dada a importância de adequada seleção e composição da amostra do presente estudo, foi inicialmente realizado um levantamento dos dados característicos da população infantil da cidade de Porto Ferreira (SP), com base no material mais atual disponível no endereço eletrônico do Instituto Brasileiro de Geografia e Estatística (IBGE, 2006) e nos dados obtidos do Departamento Municipal de Educação de Porto Ferreira (SP) (ANEXO B).

De acordo com este levantamento, estimou-se que o município possuía aproximadamente 2.167 crianças de seis a oito anos de idade matriculadas em escolas públicas e particulares de Porto Ferreira (SP), no ano letivo de 2007 (ano de elaboração do projeto de pesquisa). Nesse sentido, considerou-se como adequado e viável tecnicamente, compor uma amostra de 180 crianças, correspondendo a $8 \%$ das crianças de seis a oito anos de idade e matriculadas em instituições de ensino público e particular desta cidade, o que pode ser considerado suficiente para o tipo de estudo proposto.

De acordo com o objetivo deste estudo, portanto, foram avaliadas 180 estudantes de seis a oito anos de idade, de ambos os sexos, provenientes de escolas públicas e particulares 
de Porto Ferreira (SP). Eles foram distribuídos equitativamente a partir das variáveis sexo, idade e origem escolar, conforme demonstrado na Tabela 4.

Tabela 4 - Caracterização da amostra $(n=180)$ em função da idade, sexo e origem escolar.

\begin{tabular}{cccccc}
\hline \multicolumn{6}{c}{ Origem Escolar } \\
\hline Sexo & \multicolumn{2}{c}{ Pública } & \multicolumn{2}{c}{ Particular } & Total \\
\hline 6 anos & 15 & 15 & 15 & 15 & 60 \\
\hline 7 anos & 15 & 15 & 15 & 15 & 60 \\
\hline 8 anos & 15 & 15 & 15 & 15 & 60 \\
\hline Total & 45 & 45 & 45 & 45 & 180 \\
\hline
\end{tabular}

É valido informar ainda que no processo de seleção das crianças, foram considerados os seguintes critérios: ausência de indicadores de limitação intelectual, examinada a partir dos resultados obtidos no Teste das Matrizes Progressivas Coloridas de Raven; e ausência de tratamento psicológico, neurológico e/ou psiquiátrico no último ano, conforme informação referida por pais e/ou responsáveis em questionário informativo. Desse modo, foram integradas à amostra crianças que apresentaram, dentro das possibilidades de informação, índices de desenvolvimento típico para sua faixa etária.

Cabe ressaltar que a escolha das variáveis sexo, idade e origem escolar como elementos relevantes de análise no presente trabalho normativo pautou-se pela importância destes dados na composição de resultados no Rorschach, conforme referendado pela literatura científica da área. É importante pontuar ainda que a origem escolar foi selecionada como variável de estudo, objetivando que fosse um indicativo do padrão socioeconômico e cultural das crianças. Apesar de esta informação ter alcance limitado, tem se mostrado, na prática, uma variável útil para representar experiências culturais e sociais diversas. Postulou-se que a origem escolar poderia informar sobre o padrão socioeconômico dos estudantes, apesar dos limites inerentes a este tipo de análise de uma variável tão complexa e multidimensional.

Faz-se necessário relatar aqui que informações minuciosas sobre o processo de seleção dos participantes constam nos procedimentos deste trabalho. Neste tópico, portanto, será relatado, com detalhes, o percurso amostral aqui desenvolvido para se chegar às 180 crianças aqui avaliadas. 


\subsection{Materiais}

\subsubsection{Carta de Apresentação da Pesquisa}

A Carta de Apresentação da Pesquisa (APÊNDICE A), contendo informações sobre os objetivos do trabalho e os procedimentos implicados na coleta de dados, foi elaborada pela pesquisadora e entregue a coordenadores de escolas públicas e particulares de Porto Ferreira (SP). Este material serviu como base de aproximação da pesquisadora com as instituições de ensino, a fim de que eles pudessem colaborar no desenvolvimento do projeto, autorizando a inserção da pesquisadora no estabelecimento educacional sob sua responsabilidade.

\subsubsection{Termo de Consentimento Livre e Esclarecido (TCLE)}

O Termo de Consentimento Livre e Esclarecido (APENDICE B) apresenta, de forma sucinta, os objetivos da pesquisa, os deveres e os direitos dos participantes e o nome e telefone de contato das pesquisadoras responsáveis. Este documento foi enviado aos pais e/ou responsáveis das crianças convidadas a participar desta pesquisa, e, aqueles que concordaram com a participação do(a) filho(a) no estudo, assinaram o documento em duas vias, permanecendo uma cópia com eles e outra com a pesquisadora.

\subsubsection{Questionário informativo sobre história pessoal}

Este instrumento foi elaborado no formato de questionário, de modo a se obter informações sobre a história pessoal dos possíveis participantes (APENDICE C), contendo perguntas relativas a seu desenvolvimento pessoal e acadêmico. Este questionário foi enviado aos pais e/ou responsáveis pelas crianças que se manifestaram interessadas em participar do estudo. Com base nas informações referidas neste questionário foi realizado o processo de seleção dos participantes deste trabalho.

\subsubsection{Teste das Matrizes Progressivas Coloridas de Raven}

Para efeito de controle das características intelectuais da amostra foi utilizado o Teste das Matrizes Progressivas Coloridas de Raven (Raven, Raven \& Court, 1988), que se destina à avaliação do desenvolvimento intelectual de crianças de cinco a 11 anos de idade e, portanto, mostrou-se adequado aos propósitos de se conhecer o potencial cognitivo dos eventuais participantes deste trabalho. De modo geral, a técnica consiste em pedir que a criança aponte, dentre seis possibilidades, aquela que completa corretamente a matriz que está com uma parte inacabada. 
Como parâmetro de análise do desempenho das crianças, recorreu-se ao trabalho de Angelini, Alves, Custódio, Duarte e Duarte (1999). Esse manual do Raven contém normas adequadas para avaliação da faixa etária em estudo, material que recebeu parecer favorável para uso no Brasil pelo Sistema de Avaliação de Testes Psicológicos (SATEPSI) do Conselho Federal de Psicologia (CFP, 2009)

O material utilizado nesse trabalho, referente ao Raven, abarca manual, crivo de correção, caderno de aplicação e folhas de resposta. Cabe destacar que foram inclusas no estudo as crianças que atingiram desempenho superior ao percentil 25, ou seja, com nível de desempenho classificado como III- (ou superior) nesta técnica de investigação intelectual, sinalizando potencial pelo menos médio nessa área.

\subsubsection{Psicodiagnóstico de Rorschach}

Como material específico para a realização do estudo normativo propriamente dito, aplicou-se nas crianças participantes o Psicodiagnóstico de Rorschach (Rorschach, 1921), aprovado para uso no Brasil pelo Conselho Federal de Psicologia. Trata-se de uma técnica projetiva criada por Hermann Rorschach, na Suíça, e amplamente utilizada na investigação da personalidade. Seus princípios analítico-interpretativos foram desenvolvidos em diferentes contextos científicos e temporais, resultando em estratégias avaliativas diferenciadas (Pasian, 1998). O referencial técnico-científico utilizado no presente trabalho foi o sistema de Ombredane e Canivet do Rorschach, conhecido como Escola Psicanalítica Francesa, conforme orientações de Rausch de Traubenberg (1998) e Anzieu (1986).

Em linhas gerais, o instrumento em questão caracteriza-se por solicitar dos respondentes possíveis interpretações a dez cartões com manchas de tinta, sendo que, a partir das respostas obtidas, pode-se obter um quadro sobre as características psicológicas referentes à personalidade dos indivíduos. O material para aplicação e avaliação dessa técnica projetiva é composto, portanto, pelo conjunto de dez pranchas padronizadas, folhas para registro dos dados, folha padronizada de localização das respostas, folha para codificação das respostas e cronômetro para registrar o ritmo do trabalho associativo e interpretativo do participante. A aplicação é individual e os cartões são apresentados um a um, sendo solicitado ao examinando fazer associações sobre o que percebe diante dos estímulos apresentados.

Adotou-se, neste trabalho, os critérios de codificação das respostas nas variáveis da Escola Psicanalítica Francesa do Rorschach, conforme orientações presentes em Jacquemin (1976), Pasian (1998) e Azoulay et al (2007). Esta opção teórico-técnica tem, inclusive, como 
propósito favorecer a comparação de resultados entre estudos normativos da região de Ribeirão Preto (SP).

A Escola Psicanalítica Francesa do Rorschach prevê cinco possibilidades concernentes às localizações das respostas. São elas: G (área global), D (grande detalhe), Dd (pequeno detalhe), Dbl (detalhe branco) e Do (detalhe oligofrênico/inibitório). Cabe destacar aqui os critérios estatísticos adotados para caracterização dessas variáveis, a saber:

- D = área da prancha interpretada com freqüência igual ou maior a 4\% do total de respostas do cartão;

- Dd = área da prancha que recebeu menos de 4\% do total de respostas emitidas no cartão.

Para a classe dos determinantes, segundo Rausch de Traubenberg (1998), Anzieu (1986) e Jacquemin (1976), existem as seguintes possibilidades de categorização das respostas:

a) FORMA: resposta exclusivamente determinada pelos contornos das manchas. Pode ser subdividida, em função da qualidade formal da resposta, em:

F+: forma associada à precisão perceptual. Corresponde à resposta que, determinada pela forma, obteve frequiência igual ou superior a $2 \%$ do total de sujeitos avaliados. Caso não atinja esta freqüência, pode corresponder ainda àquela resposta que, na avaliação independente de três examinadores, alcançou classificação de "boa forma, resposta precisa".

F-: forma "mal vista": resposta determinada pela forma e associada à imprecisão formal. Corresponde à resposta que, determinada pela forma, obteve freqüência inferior a $2 \%$ do total de sujeitos avaliados. Pode corresponder ainda àquela resposta que, na avaliação independente de três examinadores, alcançou classificação de "má forma", correspondendo a uma interpretação distorcida, em termos perceptuais, da área interpretada.

b) MOVIMENTO: respostas determinadas prioritariamente pela cinestesia, podendo ser classificadas em:

K: movimento humano.

kp: movimento de parte humana

kan: movimento animal (inteiro)

kob: movimento de objeto. 
c) COR: respostas determinadas prioritariamente pela cor do cartão, podendo ser classificadas em:

FC: cor com boa qualidade formal.

CF: cor com má qualidade formal.

C: cor pura.

Caso o elemento determinante da resposta tenha sido as cores branca ou preta, o símbolo C seria substituído por $\mathrm{C}^{\prime}$, com as mesmas possibilidades de combinação existentes com o código $\mathrm{C}$.

d) SOMBREADO: respostas determinadas prioritariamente pelo manchado e pelo sombreado do cartão, podendo ser classificadas em:

FE: sombreado com boa qualidade formal.

EF: sombreado com má qualidade formal.

E: sombreado puro.

Ainda dentro da classe dos determinantes ligados ao sombreado, há a possibilidade de classificação com o código Clob (claro/escuro, na língua francesa) e suas combinações, de acordo com a qualidade formal da resposta (FClob, ClobF e Clob). Esta categorização é aplicada no caso da resposta estar determinada por uma área escura da prancha e associada a conteúdo claramente disfórico, caracterizando reação carregada de aspectos afetivos negativos.

Na sequiência da classificação das respostas viria a categorização de seus conteúdos. Segundo Rausch de Traubenberg (1998), Anzieu (1986) e Jacquemin (1976), existem as seguintes possibilidades de categorização dos conteúdos das respostas: $\mathrm{H},(\mathrm{H}), \mathrm{Hd},(\mathrm{Hd})$ que estariam relacionadas ao conteúdo humano; A, (A), Ad, (Ad) que se associariam a conteúdo animal; Anat (conteúdo anatômico); Sex (respostas de conteúdo sexual); Sg (sangue); Bot (conteúdo botânico); Geo (conteúdo geográfico); Nat (conteúdo referente à natureza); Pais (paisagem); Obj (objeto); Arq (arquitetura); Art (arte); Simb (símbolo); Abst (conteúdo abstrato); Elem (elemento) e Frag (fragmento).

Cada resposta ao Rorschach deve ser codificada em sua localização, determinante e conteúdo, cabendo ainda classificações complementares e secundárias, registradas como “tendências", utilizadas mais na prática clínica devido ao caráter interpretativo específico. Não foram, portanto, sistematizadas neste estudo as codificações referentes aos elementos de tendência, presentes nas respostas das crianças. 
Para finalizar a codificação da resposta, avalia-se se a mesma atingiu o critério para corresponder a uma resposta banal (Ban), considerada como bastante freqüente no grupo de referência. Neste estudo, adotou-se o critério de que uma resposta seria banal caso ocorresse em uma vez a cada seis protocolos (razão crítica $=1 / 6$ ). Ou seja, corresponderia à resposta com frequiência igual ou superior a $16.7 \%$ do total de indivíduos avaliados, respeitando-se o padrão técnico adotado em Jacquemin (1976).

\subsubsection{Recursos computacionais}

Foram utilizados recursos computacionais para registro e para análise de dados, tais como o Microsoft Excel 2007, o programa Statistical Package for the Social Sciences (SPSS) para Windows, versão 16.0, os programas estatísticos computacionais PROC NLMIXED e PROC LOGISTIC do software Statistical Analysis System (SAS) (versão 9.1) e Adobe Fireworks CS4.

\subsection{Procedimentos}

O estudo foi desenvolvido em diferentes etapas, descritas detalhadamente a seguir. Cabe informar que o trabalho de contato com as escolas e os participantes, incluindo a completa coleta dos dados da avaliação psicológica, foi realizado pela própria autora. Esta por sua vez, agregou a sua experiência prévia em avaliação psicológica, especifico treinamento técnico-científico (estudos de caso infantil) para este trabalho, antes de iniciar o processo de exame psicológico das crianças do estudo.

\subsubsection{Considerações Éticas}

Após a devida análise e aprovação do projeto de pesquisa pelo Comitê de Ética em Pesquisa da Faculdade de Filosofia, Ciências e Letras de Ribeirão Preto - USP (ANEXO A), conforme Resolução 196/96 do Conselho Nacional de Saúde (conselho.saude.gov/br/docs/ Resoluções/Reso196.doc) e Resolução 16/00 do Conselho Federal de Psicologia (www.pol.org.br/legislacao/doc/resolucao2000_016.doc), o processo de coleta de dados foi iniciado. Os devidos cuidados técnicos e éticos com todos os participantes foram tomados, de modo a garantir-lhes o sigilo e a liberdade de participação na pesquisa.

Aos interessados e às escolas colaboradoras, ao final do projeto, foram realizadas reuniões informativas sobre os principais resultados do trabalho, a fim de oferecer possível 
contribuição técnica aos participantes da pesquisa. Além disso, caso identificado, entre os participantes, alunos com dificuldades no desenvolvimento típico para sua idade, seria considerada a possibilidade de encaminhamento a serviços específicos de saúde nos respectivos órgãos de referência de atendimento psicológico da cidade. No entanto, nenhum desses casos ocorreu no presente estudo. Os estudantes eliminados pelo critério de desempenho cognitivo $(n=6)$, apesar desse resultado, encontravam-se bem adaptados e sem queixas escolares, não exigindo providências técnicas adicionais.

\subsubsection{Coleta de dados}

\subsubsection{Seleção dos participantes}

A partir de informações do material mais atual e disponível no endereço eletrônico do Instituto Brasileiro de Geografia e Estatística (IBGE, 2006) e nos dados obtidos do Departamento Municipal de Educação de Porto Ferreira (SP) (ANEXO B), foi realizado um levantamento das escolas (públicas e particulares) de Ensino Fundamental existentes na cidade. Dentre essas, foram identificadas aquelas que atendiam crianças entre os seis aos oito anos de idade, buscando-se conciliar as necessidades de representatividade populacional com a viabilidade do estudo.

A definição das escolas possivelmente participantes foi feita optando-se por aquelas que concentravam maior número de alunos da faixa etária pretendida, facilitando, assim, o bom andamento da coleta de dados. Esta decisão técnica, porém, não alcança a efetiva representação da diversidade socioeconômica e cultural dos estudantes desta faixa etária na cidade em questão, tratando-se apenas de uma forma de viabilização do presente trabalho. Contudo, o tamanho da amostra alcançada oferece o devido suporte para se abarcar, em grau suficiente, uma diversidade de estilos individuais, de modo a poder retratar o padrão típico de resultados no Psicodiagnóstico de Rorschach dos estudantes de seis a oito anos da cidade estudada.

Após a referida escolha, foi realizado contato com as respectivas direções e/ou coordenações (sendo ao todo, duas escolas públicas e quatro particulares), no qual foi entregue a Carta de Apresentação deste projeto, solicitando a sua colaboração. Neste contato, também foi definido um local para a realização da avaliação psicológica na própria instituição, acertando-se horários possíveis para as crianças participarem da pesquisa, sem prejuízo em suas atividades escolares. Além disso, neste momento ainda definiu-se a forma como se daria o primeiro contato da pesquisadora com as crianças em sala de aula, de modo a convidá-las ao estudo. 
Uma vez obtida a autorização por escrito da direção da escola, foi realizada uma primeira apresentação da pesquisa (em sala de aula) aos alunos das séries que agregam crianças de seis a oito anos, respeitando-se linguagem compreensível a eles. Visitou-se inicialmente o primeiro, segundo e terceiro anos do Ensino Fundamental e, posteriormente, caso houvesse necessidade, o quarto ano também era visitado. Nessa ocasião, foi entregue às crianças interessadas em participar da pesquisa o Termo de Consentimento Livre e Esclarecido (TCLE), assim como o Questionário Informativo (QI) para que os pais e/ou responsáveis das crianças pudessem avaliar e, eventualmente, autorizar sua participação neste estudo, assinando o TCLE e respondendo ao questionário. Neste momento ainda era explicado às crianças que a participação na pesquisa dependeria da autorização dos pais que iriam preencher e assinar os documentos (Questionário Informativo e TCLE), encaminhados aos pais por meio de seus próprios filhos. Após três dias letivos, a pesquisadora retornava às salas de aula para recolher os referidos documentos e dar seguimento ao processo de seleção dos participantes, com base nos critérios previamente definidos. Caso o número de crianças autorizadas fosse inferior ao número pretendido na amostra, a pesquisadora entrava em contato com uma nova escola e repetia o mesmo procedimento citado anteriormente.

Ao todo foram contatados quatro estabelecimentos de ensino particular em Porto Ferreira (SP), sendo dois de localização central e dois de localização periférica, obtendo-se a colaboração e participação dos quatro. Com relação às escolas públicas, houve tentativa de contato com duas instituições, conseguindo-se a colaboração e participação de apenas uma delas (de localização periférica-central, na cidade). Cabe informar que o primeiro contato foi feito com uma escola pública de localização central na cidade, a qual continha maior número de alunos matriculados. No entanto, a instituição carecia de infra-estrutura adequada para autorizar a realização da pesquisa, alegando falta de espaço físico viável para a aplicação das provas de forma adequada. Vale ressaltar que essa diferença entre o número de escolas públicas e particulares participantes deste estudo se deu pelo fato de que as escolas particulares contavam com número restrito de alunos matriculados em cada uma delas, bem diferentemente das escolas públicas em questão.

A Tabela 5 ilustra mais detalhadamente os contatos realizados com as instituições escolares colaboradoras da pesquisa, bem como seus respectivos alunos. Estes dados apresentam esclarecimentos, de natureza quantitativa, ilustrativos para se averiguar como se deu a adesão a este estudo em ambos os contextos, trazendo a freqüência simples e a porcentagem de crianças convidadas e autorizadas para participar da pesquisa. 
Tabela 5 - Mapeamento do percurso amostral, apresentando freqüência simples e porcentagem das crianças contatadas em função da origem escolar.

\begin{tabular}{ccccccc}
\hline \multirow{2}{*}{ Instituição } & \multirow{2}{*}{$\begin{array}{c}\text { Escolas } \\
\text { contatadas }\end{array}$} & $\begin{array}{c}\text { Escolas } \\
\text { autorizadas }\end{array}$ & \multicolumn{2}{c}{$\begin{array}{c}\text { Crianças } \\
\text { convidadas }\end{array}$} & \multicolumn{2}{c}{$\begin{array}{c}\text { Crianças } \\
\text { autorizadas }\end{array}$} \\
\cline { 4 - 7 } & 2 & 1 & 188 & $44,0 \%$ & 108 & $49,3 \%$ \\
\hline Pública & 4 & 4 & 240 & $56,0 \%$ & 111 & $50,7 \%$ \\
\hline Particular & $\mathbf{f}$ & $\mathbf{5}$ & $\mathbf{4 2 8}$ & $100,0 \%$ & $\mathbf{2 1 9}$ & $100,0 \%$ \\
\hline Total & $\mathbf{6}$ & & & & &
\end{tabular}

Conforme observado na Tabela 5, nas quatro escolas particulares foram distribuídos um total de 240 envelopes contendo os TCLE (Termo de Consentimento Livre e Esclarecido) e Questionário Informativo sobre o histórico pessoal da criança. Destes, foram devolvidos 178 envelopes, sendo que 111 tiveram seus TCLEs assinados pelos pais ou responsáveis pelas crianças. Na escola pública foram distribuídos 188 envelopes. Destes, foram devolvidos 158 , sendo que 108 destes TCLEs continham a assinatura dos pais autorizando a criança a participar da pesquisa. Em síntese: foram convidados a participar 428 crianças, porém autorizadas ficaram 219 (universo amostral inicial).

Tendo em vista o objetivo do presente estudo, foi necessário, inicialmente, examinar se os estudantes autorizados poderiam ser aceitos neste estudo, de acordo com os critérios de seleção previamente definidos, a saber:

a) Ausência de relato de transtornos de ordem psicológica ou psiquiátrica no desenvolvimento pessoal atual, ou seja, a criança não deveria se encontrar em tratamento psiquiátrico e/ou psicológico, nem estar tomando medicamento psicotrópico, no último ano. Com base neste critério, em posse dos TCLE assinados e dos Questionários preenchidos, realizou-se a seleção prévia dos participantes pelas informações contidas no questionário respondido pelos pais. Por meio desta seleção, foram excluídos 27 voluntários autorizados, sendo 11 crianças de escola particular e 16 crianças de escola pública.

b) ausência de indicadores de limitação intelectual (a partir de avaliação específica). De acordo com o desempenho das crianças nas Matrizes Progressivas Coloridas de Raven, foram inclusas neste trabalho as crianças que atingiram desempenho superior ao percentil 25 , ou seja, com nível de desempenho classificado como III- (ou superior) nesta técnica de investigação intelectual, sinalizando potencial pelo menos médio nessa área. A partir deste critério, foram excluídas seis crianças da amostra (quatro de escola particular e duas de escola pública). 
De acordo com a proposta inicial, caso o número de crianças autorizadas e selecionadas (após análise do Questionário Informativo) excedessem ao pretendido, haveria um sorteio das crianças que efetivamente participariam do estudo. Este procedimento acabou não se concretizando tendo em vista que o número de participantes selecionados (de acordo com os critérios de inclusão) praticamente coincidiu com o número exato de sujeitos pretendidos para o estudo, restando um número bastante restrito de excedentes: seis indivíduos (quatro pertencentes à escola pública e dois, à escola particular). Dessa forma, na medida em que a amostra era completada, os procedimentos de contato com as turmas de alunos das escolas eram encerrados, agradecendo-se formalmente aos colaboradores.

Em síntese, foram eliminadas 39 crianças das 219 referidas no universo amostral inicial mencionado acima. Dessas, 27 foram excluídas pelos dados relatados diante do Questionário Informativo e seis pelos resultados obtidos nas Matrizes Progressivas Coloridas de Raven. Os outros seis estudantes não foram inclusos na amostra por conta desta já ter sido completada conforme delineamento original, tendo sido possível cumprir fielmente as estratégias planejadas para a seleção de participantes deste trabalho.

\subsubsection{Avaliação Psicológica}

Após essa seleção inicial, a pesquisadora voltou às escolas nos horários combinados, conforme as disponibilidades dos participantes, sob o consentimento do responsável pelo estabelecimento de ensino para a aplicação das técnicas psicológicas. A avaliação psicológica ocorreu no primeiro contato individual com cada participante, seguindo as seguintes etapas: a pesquisadora buscava cada criança, individualmente, em sua sala de aula ou no espaço no qual estavam sendo realizadas outras atividades (educação física, pintura, xadrez) e pedia que esta a acompanhasse até o local onde seriam realizadas as tarefas da pesquisa. Estando no local designado para avaliação psicológica, a pesquisadora explicava novamente do que se tratava e procedia da seguinte forma:

- Breve rapport e reapresentação da pesquisa;

- Aplicação do Teste das Matrizes Progressivas Coloridas de Raven, segundo as normas existentes em seu respectivo manual (Angelini, Alves, Custódio, Duarte \& Duarte, 1999).

- Aplicação do Psicodiagnóstico de Rorschach, seguindo-se padrões da Escola Psicanalítica Francesa, nomeadamente Rausch de Traubenberg (1998).

Todas essas etapas foram realizadas nas próprias escolas, em sala adequada, isenta de interrupções. Cada criança foi avaliada individualmente, em uma única sessão, respeitando-se, 
dentro das possibilidades, a motivação e as necessidades de cada sujeito. As instruções eram dadas levando-se em conta a capacidade de compreensão da faixa etária das crianças desse estudo. Dessa forma, após a aplicação das Matrizes Progressivas Coloridas de Raven, o Psicodiagnóstico de Rorschach era introduzido como uma "atividade diferente" a ser realizada. Em seguida, dava-se, então, uma instrução padrão, baseando-se nas orientações de Jacquemin (1976) e Pasian (1998):

"Aqui há um conjunto de cartões, nos quais existem algumas manchas de tinta. Eu gostaria de saber com o que você acha que estas manchas poderiam se parecer. As manchas podem se parecer com várias coisas. Cada pessoa acha que se parece com algo diferente e, assim, não existem respostas certas ou erradas. Você pode dizer tudo o que acha que pode parecer. Enquanto você estiver respondendo, vou anotar suas respostas, para que eu possa me lembrar delas depois. Eu também vou anotar o tempo, mas o tempo da atividade é livre; temos o tempo de que você precisar. Então, eu vou apresentar os cartões, um de cada vez, $e$ você deve me falar tudo aquilo que pode parecer. Quando você achar que não se parece com mais nada, pode me devolver o cartão. Podemos começar?"

Essas instruções foram adaptadas conforme o nível de compreensão e de motivação do participante, incentivando-o a relatar suas percepções, sobretudo nas crianças mais novas. Observou-se que as crianças, de um modo geral, aceitavam com bastante entusiasmo a realização da tarefa, encarando-a como uma atividade divertida e diferente de tudo que já haviam feito desde então.

Terminada esta primeira etapa, dava-se início ao processo de investigação das respostas e de suas respectivas localizações. Mostrava-se novamente cada um dos cartões à criança (do I ao X), solicitando-se que localizasse sua resposta em cada cartão, inclusive contornando a área interpretada com seu próprio dedo indicador. Em seguida, buscou-se investigar os determinantes das respostas, questionando-se o porquê lhe pareceu aquele conteúdo e o que havia no cartão que fez com que parecesse determinada resposta, conforme orientações dadas por Rausch de Traubenberg (1998). Estes procedimentos seguiram-se até que as explicações da criança fossem suficientes para subsidiar a classificação de sua resposta, segundo avaliação momentânea da pesquisadora.

Ao final da aplicação do Rorschach, a pesquisadora encerrava o contato agradecendo à criança, perguntando se esta gostaria de dizer algo a respeito das atividades realizadas, procurando acolher os comentários e esclarecer eventuais dúvidas existentes. Em seguida, acompanhava as crianças até seus devidos professores, ou ainda até seus respectivos pais que estavam à espera na porta da escola (dependendo do horário em que foram realizadas as 
atividades). O processo completo de avaliação psicológica individual teve duração em torno de 50 a 80 minutos, sendo que todas elas ocorreram em uma única sessão.

\subsubsection{Análise dos resultados}

Para a avaliação dos resultados nas Matrizes Progressivas Coloridas de Raven, foram utilizados os padrões apresentados em seu respectivo manual (Angelini, Alves, Custódio, Duarte \& Duarte, 1999). Os desempenhos individuais foram avaliados em termos do número total de acertos (pontos) e em suas respectivas notas percentis.

Com o objetivo de se alcançar adequação técnica na análise, a codificação dos protocolos do Psicodiagnóstico de Rorschach, por sua vez, foi realizada por três juízes independentes, para posterior verificação de sua precisão. A classificação das respostas seguiu os padrões da Escola Psicanalítica Francesa, exposto em suas principais linhas em Anzieu (1986), em Rausch de Traubenberg (1998).

Os avaliadores foram seis psicólogos (sendo um deles a própria pesquisadora) com experiência prévia no Método de Rorschach, mas que, ainda sim, receberam treinamento específico para a realização das codificações do material coletado. Após o treinamento dos juízes, realizado pela própria pesquisadora, cada um dos seis avaliadores recebeu dez casos de Rorschach retirados da própria amostra (aproximadamente 5,5\% da amostra total aqui delineada), selecionados aleatoriamente, para codificarem de modo independente.

Por se tratar de uma amostra de crianças, a classificação inicial das respostas foi realizada com base no trabalho de Jacquemin (1976). Em seu estudo, encontramos o atlas do Rorschach (com delimitação de D e Dd, da qualidade formal e das Ban) das respostas normativas de crianças de três a dez anos de idade da cidade de Ribeirão Preto (SP), também com referencial da Escola Psicanalítica Francesa do Rorschach. Este foi um dos principais motivos pelos quais também se adotou este referencial no presente estudo, com a finalidade adicional de possibilitar comparação dos resultados destas pesquisas normativas, desenvolvidas em épocas distintas.

Concluída essa codificação inicial destes dez primeiros protocolos, foi calculado o índice de precisão entre examinadores para as quatro categorias de classificação das respostas (localização, determinante/qualidade formal, conteúdo e banalidades), seguindo-se as orientação de Weiner (1991) e Fensterseifer e Werlang (2008). Elaborou-se a porcentagem de concordância entre os avaliadores independentes em cada uma das categorias de classificação das respostas. O objetivo foi verificar se os psicólogos colaboradores estariam aptos para iniciar o processo de codificação do conjunto total de protocolos. Foi considerado acordo 
total, quando a codificação da resposta foi idêntica entre os seis juízes. O acordo parcial, por sua vez, foi atribuído quando quatro ou cinco dos avaliadores atribuíram as mesmas codificações ao segmento da resposta. Já o desacordo foi caracterizado quando apenas três juízes, ou menos, atribuíram as mesmas classificações técnicas para cada componente da resposta ao Rorschach.

É valido salientar que tanto o "acordo total" como o "acordo parcial" foram considerados como concordância entre os avaliadores independentes. Contudo, tomou-se o cuidado de ponderar as concordâncias parciais para o cálculo final da porcentagem de acordo entre os examinadores. Para tanto, seguiu se a estratégia abaixo descrita:

\begin{tabular}{|c|c|c|c|c|c|}
\hline & & $4 / 6$ & $5 / 6$ & & $6 / 6$ \\
\hline & & $\mathrm{x}$ & $\mathrm{x}$ & & $\mathrm{X}$ \\
\hline $\begin{array}{c}\text { Índice de } \\
\text { acordo entre } \\
\text { examinadores }\end{array}$ & $=$ & $\begin{array}{l}\mathrm{n}^{\circ} . \text { Segmentos de } \\
\text { respostas que } \\
\text { obtiveram quatro } \\
\text { codificações } \\
\text { semelhantes entre os } \\
\text { seis juízes }\end{array}$ & $\begin{array}{c}\mathrm{n}^{\mathrm{o}} . \text { Segmentos de } \\
\text { respostas que } \\
\text { obtiveram cinco } \\
\text { codificações } \\
\text { semelhantes entre os } \\
\text { seis juízes }\end{array}$ & + & $\begin{array}{c}\mathrm{n}^{\circ} . \text { Segmentos de } \\
\text { respostas que } \\
\text { obtiveram a } \\
\text { mesma } \\
\text { codificação entre } \\
\text { os seis juízes }\end{array}$ \\
\hline
\end{tabular}

Os valores de acordo atingidos nas quatro principais categorias de classificação das respostas da Escola Psicanalítica Francesa do Rorschach, foram os seguintes: (a) localizações $=97 \%$, (b) determinantes $=85 \%$, (c) conteúdo $=97 \%$ e (d) banalidades $=90 \%$. Esses índices de concordância entre os juízes, encontrados a partir desses cálculos, foram superiores a 80\%, conforme recomendado por Weiner (1991), portanto, resultados bastante satisfatórios. Essas evidências permitiram concluir que o treinamento técnico efetuado com os colaboradores foi eficiente, permitindo a continuidade do processo de avaliação dos demais protocolos do Rorschach.

Uma vez obtido o necessário índice de acordo entre estes seis avaliadores, cada protocolo foi avaliado, de modo independente, por três examinadores. Para tanto, os casos foram assim distribuídos entre os juízes: a própria autora do projeto, exercendo a função de primeiro juiz independente, avaliou o total de 180 protocolos. O segundo juiz foi representado por uma pesquisadora de um estudo semelhante a este, que também codificou os 180 casos. A terceira classificação de cada protocolo foi realizada por um dos quatro psicólogos restantes da equipe, de modo que cada um codificou 45 protocolos, totalizando os 180 casos. Esta distribuição dos protocolos do Rorschach entre os examinadores independentes pode ser observada na Tabela 6 . 
Tabela 6 - Panorama da distribuição dos protocolos do Rorschach entre examinadores independentes.

\begin{tabular}{cccc}
\hline Avaliação & $1^{\text {a }}$ codificação & $2^{\text {a } \text { codificação }}$ & $3^{\text {a codificação }}$ \\
\hline $\begin{array}{c}\text { Juiz } \\
\text { independente }\end{array}$ & $\begin{array}{c}\text { Autora do } \\
\text { presente } \\
\text { trabalho }\end{array}$ & $\begin{array}{c}\text { Pesquisadora } \\
\text { responsável por } \\
\text { estudo semelhante }\end{array}$ & $\begin{array}{c}\text { Psicólogos colaboradores } \\
(\mathrm{n}=\text { quatro }) \text { do grupo de } \\
\text { pesquisa em avaliação } \\
\text { psicológica }\end{array}$ \\
$\begin{array}{c}\text { Casos } \\
\text { examinados }\end{array}$ & 180 & 180 & 45 cada \\
\hline
\end{tabular}

Faz-se necessário ressaltar que, na tentativa de evitar vieses no processo de codificação dos protocolos, o material atribuído a cada um dos cinco avaliadores continha apenas o número de registro do protocolo do Rorschach e dados sobre idade, sexo e origem escolar dos participantes, encontrando-se isento de qualquer identificação pessoal (protocolos codificados às cegas). Com relação às codificações da própria aplicadora, tentou-se distanciar o período de tempo entre as aplicações e as codificações, de modo a favorecer imparcialidade na classificação dos dados, fortalecendo sua precisão.

Terminadas as codificações dos protocolos, foi calculado o índice final de precisão entre examinadores desse estudo, seguindo-se as mesmas orientações já citadas de Weiner (1991) e Fensterseifer e Werlang (2008). Para tanto, selecionou-se aleatoriamente 36 protocolos da amostra ( $20 \%$ do total de casos). Repetiu-se o mesmo procedimento descrito anteriormente para o cálculo dos índices, dividindo-se cada resposta em quatro categorias de classificação: localização, determinante/qualidade formal, conteúdo e banalidade, elaborando-se a porcentagem de concordância verificada em cada uma delas. Dado existirem neste momento três codificações para cada protocolo considerou-se duas possibilidades de concordância:

- total = codificação idêntica do segmento da resposta pelos três juízes ("concordância total") - parcial = duas codificações semelhantes ao segmento da resposta ("concordância parcial").

Ambas estas situações foram avaliadas como acordo entre os juízes, no entanto, mais uma vez tomou-se o cuidado de ponderar as concordâncias parciais para o cálculo final da porcentagem de acordo entre os codificadores, seguindo-se a estratégia abaixo descrita:

$2 / 3$

$\mathrm{X}$
$3 / 3$

$\mathrm{X}$

$+\quad \mathrm{n}^{\circ}$. Segmentos de respostas com a mesma codificação entre os três juízes 
Este procedimento justifica-se na medida em que, como dito anteriormente, a codificação final da resposta é estabelecida a partir do consenso entre dois dos três codificadores. Nesta base, a "concordância parcial” também deveria constituir o índice global de acordo entre juízes, porém, a nosso ver, ponderada, para evitar-se uma superestimação deste último.

Desta vez, os valores de acordo atingidos nas quatro principais categorias de classificação das respostas da Escola Psicanalítica Francesa do Rorschach, foram os seguintes: (a) localizações $=99 \%$, (b) determinantes $=93 \%$, (c) conteúdos $=98 \%$ e (d) banalidades $=94 \%$. Observa-se que o índice final de concordância entre os avaliadores independentes, para os diversos segmentos das respostas, tem valor superior ao de $80 \%$ recomendado por Weiner (1991), que pode ser considerado, portanto, como bastante satisfatório.

Avaliando-se esses resultados relativos à precisão, nota-se que a categoria dos determinantes foi a que obteve menor índice de acordo. Dentro deste panorama cabe lembrar que esta categoria está acoplada à qualidade formal das respostas na Escola Psicanalítica Francesa do Rorschach. Em muitas vezes ocorreu que as respostas obtidas no presente estudo não constavam da lista de classificações do material de referência utilizado pelos avaliadores para as codificações (Jacquemin, 1976). Deste modo, a qualidade formal destas respostas precisou ser avaliada por semelhança a outras respostas. Este movimento necessariamente implicou em maior diversidade avaliativa na codificação desta categoria, emergindo assim maior variabilidade entre os juízes.

Além disso, cabe destacar que na abordagem da Escola Psicanalítica Francesa do Rorschach codifica-se apenas um determinante para cada resposta, ainda que a mesma contenha elementos complementares nesta categoria, classificados como tendências que serão avaliadas qualitativamente. O que se observou, de fato, foi que parte desta variabilidade na codificação do determinante relacionou-se com a valorização diferente que os juízes fizeram sobre o fator realmente central para a determinação daquela resposta. Notou-se, por uma inspeção qualitativa do material, que, em muitos casos, o que um avaliador considerou determinante de uma resposta foi por outro avaliado como elemento secundário (tendências) ou vice-versa. Entretanto, na realidade, ambos abordavam elementos complementares da mesma resposta.

Dadas as três codificações independentes, uma folha final de codificação foi elaborada para cada caso pela própria pesquisadora, composta a partir do consenso entre os julgamentos realizados. Considerou-se concordância entre os examinadores quando ao menos dois dos 
juízes atribuíram a mesma codificação para cada parte (localização, determinante, conteúdo e banalidades) das respostas do protocolo. Caso isto não ocorresse, a pesquisadora revia a resposta em questão, considerando as diferentes avaliações prévias, discutindo com o grupo de pesquisa e a orientadora uma classificação plausível para a resposta, definida empiricamente por esta estratégia de consenso.

Concluída esta etapa, as codificações finais dos protocolos do Psicodiagnóstico de Rorschach foram inseridas em um banco de dados desenvolvido no Microsoft Office Excel 2007. Com o objetivo adicional de se compreender de modo mais integrado os possíveis efeitos de variáveis sócio-demográficas (sexo, idade e origem escolar) nos resultados do Rorschach, julgou-se sensato buscar assessoria estatística especializada, com o intuito de se conseguir análises adequadas e consistentes ao material produzido pelas crianças.

Desta forma, as principais variáveis deste banco de dados foram transpostas para planilhas específicas do programa estatístico computacional Statistical Package for the Social Sciences (SPSS) para Windows (Versão 16.0). Também foram elaboradas, pela assessoria estatística específica desta pesquisa, planilhas destes dados compatíveis aos aplicativos de análise estatística PROC NLMIXED e PROC LOGISTIC do software Statistical Analysis System (SAS) (versão 9.1). Estas planilhas permitiram a realização das análises descritivas e inferenciais dos resultados, adotando-se como nível de significância o valor de $\mathrm{p} \leq 0,05$.

Inicialmente os resultados foram elaborados em termos de estatísticas descritivas, calculando-se média, desvio-padrão, mediana, valor mínimo e máximo das principais variáveis da Escola Psicanalítica Francesa do Psicodiagnóstico de Rorschach, considerando-se o conjunto de indivíduos avaliados $(\mathrm{n}=180)$. Posteriormente foram realizadas as seguintes análises inferenciais:

a) Comparação dos resultados médios do conjunto de participantes com os parâmetros normativos de Jacquemin (1976), recorrendo-se ao Teste $t$ de Student para uma amostra. Destaca-se que a comparação de médias a partir do teste $t$ geralmente é realizada com dados que atendem aos critérios de normalidade, no entanto, essa foi a única estratégia técnica encontrada para que tais resultados fossem comparados, uma vez que os dados normativos disponíveis de Jacquemin (1976) foram apresentados unicamente em resultados médios.

b) Para se testar eventual efeito do sexo, da idade e da origem escolar nos resultados das crianças no Psicodiagnóstico de Rorschach, a assessoria estatística julgou que o modelo de regressão linear era o que melhor se aplicava às variáveis relacionadas à produtividade e ao 
ritmo $^{2}$. Com relação às demais variáveis da Escola Psicanalítica Francesa do Rorschach ${ }^{3}$, foi ponderado pela assessoria estatística que estes dados assumiam uma distribuição binomial, compatível com apresentação em forma de proporções, ou seja, freqüências em relação a um total de acontecimentos da variável. No caso do Rorschach, as variáveis associadas à localização, aos determinantes, aos conteúdos e às banalidades são examinadas em suas proporções relativas frente ao número total de respostas do protocolo $(\mathrm{R})$, confirmando este tipo de distribuição binomial de seus resultados. Foram, então, realizados dois tipos de análises inferenciais nesta etapa do trabalho:

b1) simples (univariada) para cada uma das três variáveis (sexo, idade e origem escolar), com o objetivo de investigar o efeito de apenas um destes fatores sobre os resultados relativos às variáveis do Rorschach (variáveis dependentes);

b2) múltipla ajustada (multivariada) das três variáveis, com o intuito de avaliar os possíveis efeitos das interações entre as variáveis, ou seja, se a interação do sexo, da idade e da origem escolar produziriam efeito conjunto nas variáveis do Rorschach, podendo-se detectar possíveis novos elementos de análise e de interpretação dos resultados.

\subsubsection{Elaboração do Atlas}

A fim de elaborar o atlas proposto neste trabalho, organizou-se em um banco de dados no Microsoft Office Excel 2007, o registro do total de respostas dos 180 participantes, relacionando-se cada conteúdo interpretado a sua área específica de localização. Dessa forma, foi possível sistematizar todas as áreas interpretadas, o número de vezes que cada uma delas foi emitida e sua respectiva resposta, em cada cartão do Rorschach.

Tendo em vista o elevado número de recortes feitos pelos participantes, tomou-se a decisão técnica de aglutinar alguns recortes semelhantes, a fim de se obter um conjunto de dados mais integrado. Para tanto, a resposta dada em um recorte evocado diminutas vezes e com características extremamente semelhantes (tanto na pregnância do recorte como em seu conteúdo) a outra área interpretada com maior freqüência, foi transposta para esta última. Destaca-se que todo processo de vinculação das respostas às respectivas áreas foi realizado a partir de discussões sobre sua pertinência e relevância, com a participação da autora do

\footnotetext{
${ }^{2}$ Variáveis relacionadas à produtividade e ao ritmo: R, RA, Recusa, Denegação, Tempo de latência médio (TLm) e Tempo de reação médio (TRm).

${ }^{3}$ Demais variáveis analisadas: G, D, Dd, Dbl, Do (modos de apreensão); F+, F+/-, F-, $\sum \mathrm{F}, \mathrm{K}, \mathrm{kan}, \mathrm{kp}, \mathrm{kob}, \sum \mathrm{k}$,

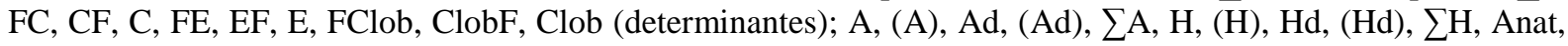
Sex, Sg, Bot, Geo, Nat, Pais, Obj, Arq, Art, Simb, Abst, Elem, Frag (conteúdos); Ban (banalidades).
} 
presente trabalho, sua orientadora e outras três pesquisadoras responsáveis por estudos semelhantes a este, focalizando outras faixas etárias.

Em seguida, passou-se para a definição das áreas que deveriam ser consideradas como D (grande detalhe), Dd (pequeno detalhe). Como já mencionado, adotou-se como D a área interpretada com freqüência maior ou igual a $4 \%$ do total de respostas ao cartão, e Dd a área que recebeu menos de $4 \%$ do total de respostas emitidas ao cartão, seguindo-se os procedimentos da proposta avaliativa elaborada por Jacquemin (1976) e Pasian (1998).

A partir da definição das áreas D e Dd, foi possível definir quais áreas interpretadas seriam classificadas como $\mathrm{G}$ amputado ${ }^{4}$. Neste trabalho, foi classificada como G amputado a interpretação dada a uma área global da mancha, mas que excluiu uma área Dd, ou a resposta dada em uma área $\mathrm{G}$ que, retiradas diminutas frações de seu contorno, manteve sua configuração de interpretação da totalidade da mancha. Este modo de apreensão (G amputado) foi computado na categoria de respostas globais. As decisões relativas a este procedimento foram feitas em conjunto com a autora e a orientadora deste estudo, tendo em vista os critérios acima descritos, retirados das orientações técnicas de Rausch de Traubenberg (1998) e em Jacquemin (1976).

Com todas as áreas devidamente caracterizadas como G, D ou Dd, passou-se, então, para a análise da qualidade formal das respostas. Nesta fase, recorreu-se, primeiramente, à análise de freqüência das interpretações, seguindo-se novamente os procedimentos da proposta avaliativa elaborada por Jacquemin (1976) e Pasian (1998). Deste modo, uma resposta foi classificada como tendo boa qualidade formal quando, em determinada área, obteve freqüência maior ou igual a $2 \%$ do total de indivíduos avaliados. Assim, a partir deste critério, a resposta com boa qualidade consistiu naquela que foi verbalizada por, pelo menos, quatro crianças, numa área circunscrita do cartão.

Posteriormente a esta análise, realizou-se, ainda, a inspeção qualitativa do material, de modo a identificar respostas que possuíam adequada constituição formal, embora sem atingir o critério estatístico de freqüência. Com este objetivo, as respostas que não atingiram a frequiência de $2 \%$ dos casos avaliados foram submetidas à apreciação de três juízes no tocante a sua qualidade formal (bem vista, mal vista ou imprecisa). Neste momento, foi também considerada uma resposta com boa qualidade formal aquela que obteve classificação positiva na avaliação independente de, pelo menos, dois examinadores. Em contrapartida, foi considerada uma resposta com má qualidade formal aquela que, na avaliação de dois juízes,

\footnotetext{
${ }^{4}$ Nomenclatura utilizada na Escola Psicanalítica Francesa do Rorschach.
} 
não correspondia formalmente à área interpretada, classificada, portanto, como resposta mal vista.

Tendo definido a qualidade formal das respostas em suas respectivas áreas, foi necessário ainda verificar a frequiência específica de cada resposta em cada área circunscrita da prancha, para que fosse possível identificar as respostas banalidade (Ban). Respeitando-se o padrão técnico adotado por Jacquemin (1976) e Pasian (1998), adotou-se o critério de que uma resposta seria banal se ocorresse uma vez a cada seis participantes, ou seja, com freqüência igual ou superior a 16,7\% do total de indivíduos avaliados. Portanto, as respostas banais consistiram naquelas que foram verbalizadas por, pelo menos, trinta crianças, numa área circunscrita específica do cartão.

Finalizando, paralelamente à realização das análises mencionadas, a pesquisadora recorreu à assessoria digital e gráfica, com o intuito de digitalizar os recortes interpretados pelos participantes do estudo, operacionalizando uma estratégia didática para representar e ilustrar o conjunto das produções alcançadas com o total de crianças avaliadas. É valido pontuar que este procedimento de digitalização e registro computacional das áreas interpretadas teve acompanhamento e supervisão direta da pesquisadora, a fim de que os recortes pudessem ser registrados da forma mais fidedigna possível, preservando as produções infantis originais. 
4. RESULTADOS 

Será primeiramente apresentada uma caracterização dos resultados da amostra total de participantes $(\mathrm{N}=180)$, de modo a retratar seu perfil global nas principais variáveis da Escola Psicanalítica Francesa do Psicodiagnóstico de Rorschach. Em um segundo momento, serão apresentadas a descrição e a análise comparativa dos resultados no Rorschach das crianças, em função do sexo, idade e origem escolar, investigando possíveis efeitos destas variáveis sobre a produção da referida amostra.

Ao longo da descrição dos resultados, serão realizadas comparações com os dados do estudo normativo de Jacquemin (1976), por se tratar de referência para a avaliação infantil pelo sistema interpretativo do Rorschach aqui utilizado. Nesse referido estudo foram apresentadas normas do Rorschach obtidas com 480 crianças, de ambos os sexos, com idade entre três e dez anos e 11 meses de idade, estudantes de escolas públicas e particulares da cidade de Ribeirão Preto, interior do Estado de São Paulo. O pesquisador dividiu a amostra em dois grupos, a saber: Grupo I = crianças de três a seis anos; Grupo II = crianças de sete a dez anos e 11 meses de idade. Considerando que a amostra do presente trabalho é composta por crianças de seis a oito anos de idade, os resultados médios aqui encontrados serão comparados, de modo global neste momento, àqueles encontrados no grupo total do estudo de Jacquemin (1976).

É importante destacar, ainda, que, embora a mediana possa se configurar como uma estratégia da estatística descritiva mais adequada para retratar resultados onde exista grande variabilidade de desempenhos - como é o caso no Rorschach e nas técnicas projetivas em geral - os dados aqui serão retratados em função da média, uma vez que foi esse o tratamento aplicado na sistematização dos resultados elaborados por Jacquemin (1976). Tal forma de apresentação possibilitou análises estatísticas comparativas dos atuais dados com o citado estudo, referencial normativo para crianças disponível na Escola Psicanalítica Francesa do Rorschach no Brasil, até o momento.

\subsection{Perfil global dos resultados no Psicodiagnóstico de Rorschach}

Inicialmente, serão apresentados os índices relativos à produtividade da amostra de 180 crianças, conforme apresentado na Tabela 7. 
Tabela 7 - Estatística descritiva da produtividade no Rorschach da amostra $(\mathrm{n}=180)$ e comparação de médias com normas de Jacquemin (1976)

\begin{tabular}{|c|c|c|c|c|c|c|c|c|}
\hline \multirow{2}{*}{$\begin{array}{l}\text { Variável } \\
\text { Rorschach }\end{array}$} & \multicolumn{5}{|c|}{ Estatística Descritiva } & \multirow{2}{*}{$\begin{array}{c}\text { Média } \\
\text { normativa }\end{array}$} & \multicolumn{2}{|c|}{$\begin{array}{c}\text { Comparação } \\
\text { estatística }\end{array}$} \\
\hline & Média & DP & Mínimo & Mediana & Máximo & & $t$ & $p$ \\
\hline $\mathbf{R}$ & 14,5 & 4,2 & 9,0 & 13,0 & 34,0 & $17,7^{5}$ & 10,377 & $\overline{0,000}$ \\
\hline $\mathbf{R A}$ & 0,2 & 0,5 & - & - & 3,0 & - & - & - \\
\hline Rec & 0,1 & 0,3 & - & - & 1,0 & - & - & - \\
\hline Den & 0,0 & 0,2 & - & - & 1,0 & - & - & - \\
\hline TLm & 14,2 & 10,6 & 1,6 & 11,1 & 97,0 & 10 a 27 & - & - \\
\hline TRm & 28,8 & 11,7 & 2,9 & 15,6 & 80,2 & 45,9 & $\begin{array}{c}- \\
19,480\end{array}$ & $\mathbf{0 , 0 0 0}$ \\
\hline
\end{tabular}

$\mathrm{R}=$ número total de respostas, $\mathrm{RA}=$ número de respostas adicionais, $\mathrm{Rec}=$ número de recusas, Den. = número de respostas negadas durante investigação, $\mathrm{TLm}=$ tempo de latência médio e $\mathrm{TRm}=$ tempo de reação médio.

Os dados relativos aos indicadores de produtividade sinalizaram, a partir dos referenciais técnicos da Escola Psicanalítica Francesa do Rorschach (Rausch de Traubenberg, 1998), boa capacidade associativo-interpretativa e agilidade nos processos de reação e de elaboração de respostas aos cartões (a partir do R e TRm). As respostas adicionais (RAs), recusas e denegações foram praticamente ausentes, denotando reduzida repressão no trabalho das crianças avaliadas neste estudo. Estes resultados confirmam expectativas de bons potenciais das crianças avaliadas, uma vez que foram selecionadas a partir de critérios compatíveis com o desenvolvimento típico para sua faixa etária.

A comparação destes resultados médios com os indicadores de produtividade do estudo normativo de Jacquemin (1976) identificou número de respostas significativamente menor nas crianças do presente trabalho. Em se tratando do TLm, o estudo anterior apenas assinala que os dados médios oscilaram entre 10 e 27 segundos, dado convergente ao aqui encontrado que foi de aproximadamente 14 segundos. No que se refere ao TRm, pode-se constatar maior rapidez associativa nas crianças atualmente analisadas (28,8 segundos) uma vez que os dados apresentados por Jacquemin (1976) mostraram um TRm de 45,3 segundos. Em outras palavras: comparativamente às crianças avaliadas há mais de três décadas, a amostra do presente estudo produziu menos respostas, porém trabalhou em tempo significativamente menor.

Completando as análises dos indicadores de produtividade no Rorschach, organizou-se o número de R, RA, recusas e denegações, para cada prancha, do conjunto da amostra, de

\footnotetext{
${ }^{5}$ Grupo de Jacquemin (1976).
} 
forma a revelar as diferenças de reação frente a cada estímulo específico do teste. Estes resultados compõem a Tabela 8 .

Tabela 8 - Resultados (frequiência simples e porcentagem), para cada cartão, das variáveis associadas à produtividade no Rorschach.

\begin{tabular}{|c|c|c|c|c|c|c|c|c|}
\hline \multirow{2}{*}{ CARTÃO } & \multicolumn{2}{|c|}{$\mathbf{R}$} & \multicolumn{2}{|c|}{ RA } & \multicolumn{2}{|r|}{ Rec } & \multicolumn{2}{|c|}{ Den } \\
\hline & $\mathbf{f}$ & $\%$ & $\mathbf{f}$ & $\%$ & f & $\%$ & $\mathbf{f}$ & $\%$ \\
\hline I & 255 & 9,8 & - & - & - & - & 3 & 37,5 \\
\hline II & 223 & 8,6 & 2 & 6,3 & 3 & 16,7 & - & - \\
\hline III & 277 & 10,6 & 1 & 3,1 & - & - & - & - \\
\hline IV & 214 & 8,6 & 3 & 9,4 & 3 & 16,7 & - & - \\
\hline $\mathbf{V}$ & 212 & 8,1 & 2 & 6,3 & 1 & 5,5 & - & - \\
\hline VI & 201 & 7,7 & 5 & 15,6 & 8 & 44,4 & 5 & 62,5 \\
\hline VII & 243 & 9,3 & 1 & 3,1 & 1 & 5,5 & - & - \\
\hline VIII & 285 & 10,9 & 5 & 15,6 & - & - & - & - \\
\hline IX & 238 & 9,1 & 4 & 12,5 & 2 & 11,1 & - & - \\
\hline $\mathbf{X}$ & 458 & 17,6 & 9 & 28,1 & - & - & - & - \\
\hline TOTAL & 2606 & 100,0 & 32 & 100,0 & 18 & 100,0 & 8 & 100,0 \\
\hline
\end{tabular}

$\mathrm{R}=$ respostas; $\mathrm{RA}=$ respostas adicionais; $\mathrm{Rec}=$ recusas aos cartões; Den $=$ Denegações.

Conforme descrito na Tabela 8, no total dos protocolos dos participantes deste estudo, foram obtidas 2606 respostas, 32 respostas adicionais, 18 recusas e oito denegações. O cartão X foi o que obteve o maior número de respostas $(17,6 \%)$, seguido do cartão VIII $(10,9 \%)$ e do cartão III (10,6\%). Posteriormente, aparecem os cartões I, VII e IX. Por fim, seguem os cartões II e IV, V e o cartão VI (com o menor número de interpretações). Convém observar que existe grande diferença entre o número de respostas da prancha mais estimuladora de interpretações $(\mathrm{X})$ e das pranchas com menos respostas (V e VI), sinalizando considerável variação no potencial de estimulação peculiar de cada um dos cartões do Rorschach para as crianças avaliadas.

Pode-se ainda observar a quantidade de respostas adicionais, recusas e denegações, que, em termos psíquicos, representam sinais de impacto emocional diante dos estímulos. Destaca-se que o cartão $X$ também foi o que apresentou maior número de respostas adicionais, seguindo-se os cartões VIII e VI. Os cartões III e VII, por sua vez, foram percebidos como os que despertaram menor número de respostas adicionais. Essas evidências levam a inferir uma possível influência das peculiaridades estruturais dos cartões na capacidade produtiva do indivíduo no mesmo. Em relação à ocorrência das recusas entre os 
cartões, os resultados apontaram o cartão VI $(44,4 \%)$ como sendo predominante para esta reação. Nota-se que este também foi o cartão que apresentou maior número de denegações $(62,5 \%)$, fazendo pensar que este determinado cartão pode ter estimulado maior grau de mobilização emocional na amostra avaliada, tendo em vista que as crianças estudadas encontram-se no período de latência, momento em que há diminuição da pulsão e negação da sexualidade.

Dando continuidade à descrição do padrão geral de produção das crianças, a Tabela 9 exibe a composição do perfil dos resultados das principais variáveis de codificação das respostas da amostra deste estudo. É importante lembrar que as codificações destas respostas foram baseadas no atlas elaborado por Jacquemin (1976).

Tabela 9 - Distribuição em frequiência simples (f) e porcentagem (\%) do total de respostas (R = 2606) nas diferentes categorias de classificação da Escola Psicanalítica Francesa do Rorschach.

\begin{tabular}{|c|c|c|c|c|}
\hline & Variáveis & $\mathbf{f}$ & $\%$ & \\
\hline \multirow{5}{*}{ Localização } & $\mathrm{G}$ & 1007 & 38,6 & \\
\hline & $\mathrm{D}$ & 1152 & 44,2 & \\
\hline & $\mathrm{Dd}$ & 433 & 16,6 & \\
\hline & Dbl & 14 & 0,5 & \\
\hline & Do & 0 & 0,0 & \\
\hline \multirow{19}{*}{ Determinantes } & $\mathrm{F}+$ & 1188 & 45,6 & \multirow{5}{*}{$66,4 \%$} \\
\hline & $\mathrm{F}+-$ & 3 & 0,1 & \\
\hline & F- & 539 & 20,7 & \\
\hline & $\sum \mathrm{F}$ & 1730 & 66,4 & \\
\hline & $\mathrm{F}+\mathrm{ext}$ & 1822 & 70,0 & \\
\hline & $\mathrm{K}$ & 81 & 3,1 & \multirow{5}{*}{$10,8 \%$} \\
\hline & kan & 185 & 7,1 & \\
\hline & kob & 9 & 0,3 & \\
\hline & $\mathrm{kp}$ & 8 & 0,3 & \\
\hline & $\sum \mathrm{k}$ & 202 & 7,7 & \\
\hline & $\mathrm{FC}$ & 295 & 11,3 & \multirow{3}{*}{$17,2 \%$} \\
\hline & $\mathrm{CF}$ & 120 & 4,6 & \\
\hline & $\mathrm{C}$ & 32 & 1,2 & \\
\hline & FE & 99 & 3,8 & \multirow{3}{*}{$5,6 \%$} \\
\hline & EF & 44 & 1,7 & \\
\hline & $\bar{E}$ & 2 & 0,1 & \\
\hline & Fclob & 1 & 0,0 & \multirow[t]{3}{*}{-} \\
\hline & ClobF & 0 & 0,0 & \\
\hline & Clob & 0 & 0,0 & \\
\hline
\end{tabular}


conclusão

\begin{tabular}{|c|c|c|c|c|}
\hline & Variáveis & $\mathbf{f}$ & $\%$ & \\
\hline \multirow{25}{*}{ Conteúdos } & A & 1279 & 49,1 & $64,4 \%$ \\
\hline & (A) & 120 & 4,6 & \\
\hline & Ad & 252 & 9,7 & \\
\hline & $(\mathrm{Ad})$ & 28 & 1,1 & \\
\hline & $\sum \mathrm{A}$ & 1679 & 64,4 & \\
\hline & $\mathrm{H}$ & 131 & 5,0 & \multirow{5}{*}{$14,1 \%$} \\
\hline & (H) & 109 & 4,2 & \\
\hline & Hd & 82 & 3,1 & \\
\hline & $(\mathrm{Hd})$ & 44 & 1,7 & \\
\hline & $\sum \mathrm{H}$ & 366 & 14,1 & \\
\hline & Anat & 77 & 2,9 & \\
\hline & $\mathrm{Sg}$ & 14 & 0,5 & \\
\hline & Sex & 0 & 0,0 & \\
\hline & Obj & 206 & 7,9 & \\
\hline & Art & 18 & 0,7 & \\
\hline & Arq & 25 & 0,9 & \\
\hline & Simb & 22 & 0,8 & \\
\hline & Abs & 2 & 0,1 & \\
\hline & Bot & 91 & 3,5 & \\
\hline & Geo & 31 & 1,2 & \\
\hline & Nat & 6 & 0,2 & \\
\hline & Pais & 11 & 0,4 & \\
\hline & Elem & 18 & 0,7 & \\
\hline & Frag & 40 & 1,5 & \\
\hline & Ban & 481 & 18,5 & \\
\hline
\end{tabular}

Examinando-se as localizações, pode-se notar predomínio das respostas Detalhe $(D=$ $44,2 \%)$, seguida das apreensões globais dos estímulos $(\mathrm{G}=38,6 \%)$ e de pequeno detalhe $(\mathrm{Dd}=$ 16,6 \%). A localização Dbl foi pouco utilizada pelos participantes $(\mathrm{Dbl}=0,5 \%)$ e a localização Do - de difícil definição operacional - não foi constatada. Tais índices denotam tendência de pensamento mais concreto e voltado aos detalhes mais relevantes da realidade na amostra avaliada.

Em relação aos determinantes, pode-se observar que a grande maioria das respostas foi determinada unicamente pela forma $(66,4 \%)$, restringindo a manifestação de elementos afetivos e imaginativos, ou seja, dos determinantes ligados a movimento, cor e sombreado. Entre estes, destacam-se as respostas associadas à cor $(17,1 \%$, cromática ou acromática), seguidas pelas respostas associadas ao movimento (humano, animal ou de objeto) (10,8\%), e, por fim, as respostas determinadas pelo sombreado (5,6\%). Esses dados sugerem que as 
crianças avaliadas no presente estudo, em sua maioria, detiveram-se aos elementos formais dos estímulos, denotando acentuado investimento racional na interpretação da realidade nesta fase do desenvolvimento, formulando respostas com nível de elaboração menos rebuscado.

A análise da distribuição das respostas unicamente determinadas pela forma, sob a perspectiva de sua qualidade formal (F+, F- e F+/-) em relação ao número total de respostas, apontou o predomínio de $\mathrm{F}+(45,6 \%)$, seguido por $\mathrm{F}-(20,7 \%)$ e uma inexpressiva porcentagem de $\mathrm{F}+/$-. Esses índices sugerem adequado nível de precisão perceptiva no grupo destes escolares. Referente aos determinantes especificamente relacionados ao movimento, pode-se observar maior destaque para as pequenas cinestesias em relação às grandes cinestesias $(\mathrm{kan}+\mathrm{kob}+\mathrm{kp}=7,7 \%>\mathrm{K}=3,1 \%)$, fazendo pensar em menor elaboração imaginativa e criadora neste momento do desenvolvimento infantil.

Em se tratando dos determinantes associados à cor, nota-se predomínio de FC $(11,3 \%)$ sobre CF $(4,6 \%)$ e C $(1,2 \%)$, sinalizando adequada integração do elemento racional a este determinante relacionado ao afeto. Composição semelhante também pode ser observada nos determinantes ligados ao sombreado, na medida em que FE $(3,8 \%)$ também se mostra mais elevado que $\mathrm{EF}(1,7 \%)$ e $\mathrm{E}(0,08 \%)$.

Examinando-se os conteúdos atribuídos às respostas, os do tipo animal $(64,4 \%)$ e humano $(14,1 \%)$ totalizaram a grande maioria das respostas da amostra avaliada, somando $78,4 \%$ do conjunto total da produção no Rorschach. Subseqüente a eles prevaleceu a classe dos objetos (7,9\%) - incluindo as subcategorias de alimento, máscara e vestimenta -, as respostas de conteúdo botânico (3,5\%), anatômico $(2,9 \%)$, de fragmento $(1,5 \%)$ e geográfico $(1,2 \%)$. Os demais conteúdos ocorreram em frequiência próxima ou inferior a 1,0\% do total de respostas, sendo, portanto, pouco expressivos. Os dados encontrados por Jacquemin (1976) também assinalaram a ocorrência prioritária dos conteúdos animal e humano nas interpretações de suas crianças, seguida pelas respostas classificadas na categoria de objeto.

Para finalizar, pode-se observar ocorrência de $18,5 \%$ de respostas consideradas banais no total da amostra avaliada, revelando adequado nível de participação no pensamento coletivo. No entanto, estas crianças emitiram respostas populares em menor frequiência que as de Jacquemin (1976), cujo valor foi de 19,6\%.

Cabe reafirmar que esta visão geral dos resultados favorece uma apreensão panorâmica do comportamento das crianças de seis a oito anos diante do Rorschach, porém se faz necessário o aprofundamento destas análises. Objetivando analisar estatisticamente eventuais diferenças entre os achados desta investigação científica com os apresentados por Jacquemin (1976), foram realizadas análises comparativas das médias, chegando-se à Tabela 
10. Ela lista os resultados de algumas variáveis das crianças avaliadas e suas respectivas comparações com os do estudo anterior, utilizando-se como parâmetro os resultados brutos expressos em termos médios.

Tabela 10 - Resultados e comparação de médias da atual amostra com o estudo de Jacquemin (1976)

\begin{tabular}{|c|c|c|c|c|}
\hline Variável & $\begin{array}{c}\text { Presente estudo } \\
\text { f }\end{array}$ & $\begin{array}{c}\text { Jacquemin } \\
\text { (1976) } \\
\mathbf{f}\end{array}$ & $t$ & $p$ \\
\hline $\mathbf{R}$ & 14,5 & 17,7 & $-10,377$ & $\mathbf{0 , 0 0 0}$ \\
\hline $\mathbf{G}$ & 5,6 & 7,3 & $-9,415$ & 0,000 \\
\hline D & 6,4 & 8,5 & $-8,656$ & 0,000 \\
\hline Dd & 2,4 & 2,3 & 0,383 & 0,702 \\
\hline Dbl & 0,1 & 0,3 & $-9,103$ & 0,000 \\
\hline $\mathbf{F}$ & 9,6 & 13,4 & $-14,126$ & 0,001 \\
\hline $\mathbf{A}$ & 9,3 & 10,2 & $-3,496$ & 0,000 \\
\hline $\mathbf{H}$ & 2,0 & 2,6 & $-3,832$ & $\mathbf{0 , 0 0 0}$ \\
\hline Ban & 2,7 & 3,9 & $-12,731$ & 0,000 \\
\hline
\end{tabular}

Os resultados da Tabela 10 apontaram diferenças estatisticamente significativas entre os resultados do presente trabalho e do estudo de Jacquemin (1976) na grande maioria das variáveis apresentadas. No entanto, a comparação das demais variáveis do Rorschach não pode ser efetuada, devido a estes dados não terem sido sistematicamente apresentados no trabalho anterior e à inacessibilidade ao seu banco de dados original. Dentro dessa realidade, a seguir pondera-se sobre uma série de hipóteses especulativas a respeito das atuais evidências encontradas, comparativamente ao estudo anteriormente referido.

No que diz respeito ao numero médio de respostas produzidas pelas crianças, encontrou-se, no presente estudo, número significativamente inferior aos achados de Jacquemin, conforme já apresentado anteriormente. Constata-se, neste momento, a importância de um referencial normativo atualizado, pois, ao se considerar os referenciais propostos por Jacquemin (1976), o número de respostas encontrado no presente trabalho seria classificado como sinal de baixa produtividade. No entanto, tal fato não deve ser assim considerado, uma vez que corresponde ao padrão perceptivo de 180 crianças com desenvolvimento típico. Nesse contexto, os desvios dos dados atuais em relação ao esperado devem ser interpretados como indicadores da relatividade das normas avaliativas do Rorschach, assim como de qualquer técnica de avaliação psicológica. Diferenças 
socioculturais existentes entre os grupos de referência, bem como a evolução temporal do comportamento humano acabam por impor a necessidade de revisões sistemáticas dos parâmetros adotados como normativos nos processos de avaliação psicológica.

Em se tratando especificamente das localizações das respostas, os dados da presente investigação evidenciaram maior frequiência de interpretações em áreas detalhe (D), seguida pela área global $(\mathrm{G})$, com menor número de apreensões dos pequenos detalhes (Dd) dos cartões e mínima atenção aos detalhes brancos (Dbl). Esses elementos caracterizariam um estilo perceptivo marcado pela apreensão de aspectos relevantes do ambiente. Destaca-se que a variável Dd foi a única que não apresentou diferença estatisticamente significativa perante os dados de Jacquemin (1976).

Atendo-se ao número médio de respostas unicamente formais (F), também foi possível observar diferença estatisticamente significativa entre os dados dos dois estudos aqui abordados. O presente trabalho identificou significativo menor número de respostas determinadas unicamente pela forma, quando comparado ao estudo de Jacquemin (1976), fazendo-se pensar na hipótese de maior expressão de elementos afetivos e imaginativos nas crianças aqui avaliadas, comparativamente àquelas examinadas na década de 70 .

Em relação aos conteúdos, notou-se que as respostas de conteúdo animal (A) e humano $(\mathrm{H})$ também apresentaram diferença estatisticamente significativa entre os dois estudos, sinalizando menor ocorrência destes conteúdos no presente trabalho. Dentro dos limites das possibilidades de compreensão dessas evidências empíricas é possível, a princípio, supor que o sentido de menor número de respostas de conteúdo animal das crianças atualmente avaliadas corresponderia a maior diversificação de seus interesses, sinalizando eventual efeito de mudanças no contexto sociocultural.

Após expor as diferenças encontradas entre os dados da atual pesquisa e os referenciais de Jacquemin (1976), tratando-se especificamente de algumas variáveis relacionadas a localizações, determinantes e conteúdos, torna-se importante enfocar neste momento as proporções entre as variáveis do Psicodiagnóstico do Rorschach associadas à vivencia emocional das crianças atualmente avaliadas. A Tabela 11 apresenta esse tipo de dados, a partir do Tipo de Ressonância Íntimo (T.R.I) e da Fórmula das Tendências Latentes (T.L.). 
Tabela 11 - Distribuição das crianças (em frequiência simples e porcentagem) da amostra $(\mathrm{N}=180)$ em função do Tipo de Vivência Afetiva e da Fórmula das Tendências Latentes

\begin{tabular}{|c|c|c|c|c|c|c|c|}
\hline \multirow{2}{*}{\multicolumn{2}{|c|}{$\begin{array}{c}\text { Tipo de Vivência } \\
\text { Afetiva }\end{array}$}} & \multicolumn{3}{|c|}{ TRI } & \multicolumn{3}{|c|}{ TL } \\
\hline & & $\mathbf{f}$ & & $\%$ & f & & $\%$ \\
\hline \multirow[t]{2}{*}{$\overline{\text { Extratensivo }}$} & Puro & 47 & \multirow{2}{*}{64} & \multirow{2}{*}{35,6} & - & \multirow{2}{*}{6} & \multirow{2}{*}{3,3} \\
\hline & Dilatado & 17 & & & 6 & & \\
\hline \multirow[t]{2}{*}{ Introversivo } & Puro & 2 & \multirow{2}{*}{9} & \multirow{2}{*}{5} & 17 & \multirow{2}{*}{53} & \multirow{2}{*}{29,4} \\
\hline & Dilatado & 7 & & & 36 & & \\
\hline Ambigual & & 3 & 9 & 1,7 & 1 & 1 & 0,6 \\
\hline Coartativo & & 92 & \multirow{2}{*}{104} & \multirow{2}{*}{57,8} & 88 & \multirow{2}{*}{120} & \multirow{2}{*}{66,7} \\
\hline Coartado & & 12 & & & 32 & & \\
\hline Total & & 180 & 180 & 100,0 & 180 & 180 & 100,0 \\
\hline
\end{tabular}

De acordo com os resultados da Tabela 11, observou-se que os participantes do atual estudo são, predominantemente, do tipo coartativo-coartado. Isso é sugestivo de que grande parte das crianças dessa amostra reagiu ao Rorschach de modo inibitório, denotando certa restrição da manifestação afetiva. Esses indicadores podem ser interpretados como evidência de que as crianças tendem a vivenciar seus afetos, neste momento de seu desenvolvimento, de forma pouco elaborada, restrita e limitada, associada a estratégias internas de acentuado controle dos impulsos. Essas características são teoricamente esperadas para a faixa etária em estudo. Nesta fase do desenvolvimento há, teoricamente, maior necessidade de investimento no funcionamento lógico, como estratégia defensiva para organização e estímulo ao desenvolvimento global da criança. Estas características confirmam a identificação da vivência dessas crianças como compatível ao período de latência, onde há maior controle afetivo e busca por objetos culturais (escola), favorecendo a socialização.

Prosseguindo com a análise do TRI, constata-se que o tipo extratensivo apareceu em segundo lugar de freqüência (35,6\% das crianças), manifestando-se em sua maioria no subtipo puro, sinalizando socialização e orientação afetiva para o mundo exterior. Apresentando-se na minoria dos casos, o tipo introversivo apareceu em 5,0\% dos casos, sendo o subtipo dilatado o mais presente. $\mathrm{O}$ tipo ambigual atingiu pequena ocorrência no TRI da amostra avaliada $(1,7 \%$ das crianças). Jacquemin (1976) encontrou resultados bastante próximos em sua amostra, a qual apresentou como predominante o mesmo TRI (coartativo-coartado), com porcentagem de 45,3\%. No entanto, apesar da semelhança entre os dados de ambos os estudos, a proporção aqui encontrada é maior do que a de Jacquemin (1976).

Fortalecendo a hipótese de vivências afetivas inibitórias por parte das crianças de seis a oito anos de idade, a maioria da amostra aqui avaliada foi classificada também no tipo coartativo-coartado $(66,7 \%)$ na segunda fórmula, correspondente às Tendências Latentes 
(TL). Jacquemin (1976), por sua vez, observou dado similar ao atual, com freqüência deste tipo de TL em 57,3\% de sua amostra. Em seguida, emergiram as tendências introversivas $(29,4 \%)$ e, com índices bem reduzidos, as tendências extratensivas $(3,3 \%)$ e ambiguais $(0,6 \%)$. Notou-se um aumento do potencial introversivo, sugerindo que as vivências afetivas atuais e os recursos potenciais se complementam.

Continuando ainda a descrever as características afetivas das crianças a partir do Psicodiagnóstico de Rorschach, seguiu-se com a análise de algumas variáveis teoricamente relacionadas, na Escola Psicanalítica Francesa, ao controle dos impulsos. Esses resultados estão na Tabela 12, que exprime a somatória e os dados brutos médios da frequiência das variáveis dentro de um panorama total de 2606 respostas obtidas na amostra de 180 crianças.

Tabela 12 - Distribuição dos resultados globais (somatória e dados médios) da amostra em algumas variáveis do Rorschach associadas ao controle afetivo.

\begin{tabular}{ccc}
\hline Variáveis do Rorschach & $\begin{array}{c}\text { Freqüuência total } \\
\text { (somatória) }\end{array}$ & Proporção Média \\
\hline G:K & $1007: 81$ & $5,6: 0,5$ \\
\hline K: $\sum \mathbf{k}$ & $81: 202$ & $0,5: 1,1$ \\
\hline FC:CF+C & $295: 152$ & $1,6: 0,9$ \\
\hline FE:EF+E & $99: 46$ & $0,6: 0,3$ \\
\hline
\end{tabular}

Analisando-se os dados dessa Tabela 12 foi possível inferir, pela relação entre a localização $G$ e o determinante movimento $K$, sinal de ampla captação dos estímulos do ambiente, talvez em detrimento de sua interpretação mais reflexiva e elaborada. Dessa forma, indicaria uma interpretação mais superficial da realidade nas crianças atualmente avaliadas. Essa tendência acompanha, mais uma vez, as expectativas teóricas relativas à faixa etária em questão, marcando sinais de imaturidade afetiva.

A proporção $\mathrm{K}$ : k, por sua vez, reafirma este tipo de evidência, uma vez que produziu indicadores de bom potencial de dinamismo interno, mas parcialmente utilizado, sugerindo sinais de imaturidade emocional nos escolares esta fase de vida. Com relação às proporções $\mathrm{FC}: \mathrm{CF}+\mathrm{C}$ e de FE: $E F+E$, as crianças aqui examinadas apresentaram sinais de suficiente e eficiente controle racional das emoções, sendo possível também coordenar a ansiedade por meio de recursos do funcionamento lógico, confirmando mais uma vez, os indicadores de controle afetivo descritos anteriormente. Estes resultados configuraram uma imagem pouco consistente com o teoricamente esperado a respeito da coordenação entre afeto e razão, na medida em que as crianças de seis a oito anos tenderiam a ter parcial ou reduzido controle lógico do afeto. As atuais 
evidências empíricas, no entanto, evidenciaram que mesmo no início da escolarização formal (seis a oito anos), as crianças tendem a conseguir coordenar racionalmente suas emoções.

Até o momento foram retratadas as evidências descritivas referentes ao padrão geral de resultados no Rorschach da amostra analisada neste estudo. Concomitantemente, foi possível estabelecer as possíveis comparações com as normas disponíveis no estudo normativo anterior (Jacquemin, 1976). Prosseguir-se-á, a partir de agora, com uma abordagem de análise estatística inferencial, examinando-se possível influência das variáveis: sexo, idade e origem escolar nos resultados obtidos no presente estudo.

\subsection{Análise do padrão de respostas no Rorschach em funcão do sexo}

Com o intuito de efetivar a análise comparativa dos resultados no Rorschach de meninos e meninas, foi utilizado, como mencionado anteriormente, o modelo de regressão linear para as variáveis relacionadas a produtividade e ritmo, e o modelo de distribuição binomial, para as demais variáveis. As Tabelas 13 e 14 apresentam, deste modo, os dados relativos a esta comparação estatística em função do sexo (90 meninas e 90 meninos), nas principais variáveis de classificação das respostas da Escola Psicanalítica Francesa. As variáveis com diferenças estatisticamente significativas encontram-se em negrito.

Tabela 13 - Resultados da análise estatística das variáveis relacionadas a produtividade e ritmo no Rorschach, em função do sexo.

\begin{tabular}{|c|c|c|c|c|c|}
\hline Variável & Sexo & Média & DP & $p$-valor & $p$-valor ajustado \\
\hline \multirow{2}{*}{$\mathbf{R}$} & $F$ & 14,6 & 4,4 & \multirow{2}{*}{0,748} & \multirow{2}{*}{0,730} \\
\hline & $\mathrm{M}$ & 14,4 & 3,9 & & \\
\hline \multirow{2}{*}{ RA } & $\mathrm{F}$ & 0,2 & 0,5 & \multirow{2}{*}{0,760} & \multirow{2}{*}{0,760} \\
\hline & M & 0,2 & 0,5 & & \\
\hline \multirow{2}{*}{ Rec } & $\mathrm{F}$ & 0,1 & 0,3 & \multirow{2}{*}{0,138} & \multirow{2}{*}{0,139} \\
\hline & M & 0,1 & 0,3 & & \\
\hline \multirow{2}{*}{ Den } & $\mathrm{F}$ & 0,0 & 0,2 & \multirow{2}{*}{0,150} & \multirow{2}{*}{0,150} \\
\hline & M & 0,1 & 0,3 & & \\
\hline \multirow{2}{*}{ TLm } & $\mathrm{F}$ & 16,0 & 10,2 & \multirow{2}{*}{0,022} & \multirow{2}{*}{$\mathbf{0 , 0 2 0}$} \\
\hline & M & 12,4 & 10,8 & & \\
\hline \multirow{2}{*}{ TRm } & $\mathrm{F}$ & 30,5 & 13,3 & \multirow{2}{*}{0,045} & \multirow{2}{*}{$\mathbf{0 , 0 3 2}$} \\
\hline & M & 27,1 & 9,5 & & \\
\hline
\end{tabular}

$\mathrm{R}=$ respostas; $\mathrm{RA}=$ respostas adicionais; $\mathrm{Rec}=$ recusas aos cartões; Den $=$ Denegações; $\quad \mathrm{TLm}=$ Tempo de Latência médio; TRm = Tempo de Reação médio. 
Pode-se observar diferenças estatisticamente significativas em somente duas variáveis correspondentes ao ritmo de trabalho: as crianças do sexo feminino evidenciaram tempo de latência médio [TLm] e tempo de reação médio [TRm] superior ao do sexo masculino, sugerindo maior necessidade de tempo para apresentar reação inicial aos cartões. No entanto, há que se lembrar que essa diferença não deve, necessariamente, ser interpretada como dificuldade de elaboração dos estímulos por parte das meninas, mas apenas como divergências nos ritmos associativos entre os sexos, tendo em vista que não houve diferenças nos índices de produtividade entre os dois subgrupos em comparação. De acordo com os dados atuais, as meninas evidenciaram desempenho compatível com gasto maior de tempo em seus processos associativos para formular interpretações a respeito dos estímulos percebidos, sugerindo talvez maior cautela ou mesmo nível diferenciado de elaboração destas respostas, conforme poderá ser observado na Tabela 14.

Tabela 14 - Resultados da análise estatística das principais variáveis do Rorschach, em função do sexo.

\begin{tabular}{|c|c|c|c|c|c|}
\hline Variável & Sexo & Proporção $^{6}$ & $\%$ & p-valor & p-valor ajustado \\
\hline \multirow[t]{2}{*}{$\mathbf{G}$} & $\mathrm{F}$ & $474 / 1312$ & 36,1 & \multirow{2}{*}{0,008} & \multirow{2}{*}{$\mathbf{0 , 0 0 8}$} \\
\hline & M & $533 / 1294$ & 41,2 & & \\
\hline \multirow[t]{2}{*}{$\mathbf{D}$} & $\mathrm{F}$ & $614 / 1312$ & 46,8 & \multirow{2}{*}{0,007} & \multirow{2}{*}{0,007} \\
\hline & M & $538 / 1294$ & 41,6 & & \\
\hline \multirow[t]{2}{*}{ Dd } & $\mathrm{F}$ & $217 / 1312$ & 16,5 & \multirow{2}{*}{0,917} & \multirow{2}{*}{0,868} \\
\hline & M & $216 / 1294$ & 16,7 & & \\
\hline \multirow[t]{2}{*}{ Dbl } & $\mathrm{F}$ & $7 / 1312$ & 0,5 & \multirow{2}{*}{0,979} & \multirow{2}{*}{0,968} \\
\hline & $\mathrm{M}$ & $7 / 1294$ & 0,5 & & \\
\hline \multirow[t]{2}{*}{ Do } & $\mathrm{F}$ & - & - & \multirow{2}{*}{-} & \multirow[b]{2}{*}{ - } \\
\hline & M & - & - & & \\
\hline \multirow[t]{2}{*}{$\mathbf{F}+$} & $\mathrm{F}$ & $621 / 1312$ & 47,3 & \multirow{2}{*}{0,072} & \multirow{2}{*}{0,067} \\
\hline & M & $567 / 1294$ & 43,8 & & \\
\hline \multirow[t]{2}{*}{$\mathbf{F}+/-$} & $\mathrm{F}$ & $2 / 1312$ & 2,4 & \multirow[t]{2}{*}{0,579} & \multirow[t]{2}{*}{0,604} \\
\hline & M & $1 / 1294$ & 3,5 & & \\
\hline \multirow[t]{2}{*}{ F- } & $\mathrm{F}$ & $246 / 1312$ & 2,4 & \multirow{2}{*}{0,014} & \multirow{2}{*}{$\mathbf{0 , 0 1 4}$} \\
\hline & M & 293/1294 & 3,5 & & \\
\hline \multirow[t]{2}{*}{$\sum \mathbf{F}$} & $\mathrm{F}$ & $869 / 1312$ & 66,23 & \multirow{2}{*}{0,870} & \multirow{2}{*}{0,888} \\
\hline & M & $861 / 1294$ & 66,54 & & \\
\hline \multirow[t]{2}{*}{$\mathbf{K}$} & $\mathrm{F}$ & $48 / 1312$ & 3,7 & \multirow{2}{*}{0,105} & \multirow{2}{*}{0,120} \\
\hline & M & $33 / 1294$ & 2,6 & & \\
\hline \multirow[t]{2}{*}{ kan } & $\mathrm{F}$ & $87 / 1312$ & 6,6 & \multirow{2}{*}{0,349} & \multirow[t]{2}{*}{0,364} \\
\hline & M & $98 / 1294$ & 7,6 & & \\
\hline
\end{tabular}

${ }^{6}$ Este dado diz respeito à proporção de respostas dadas em determinada variável sobre o número total de respostas produzidas no Rorschach, em cada subgrupo. 
continuação

\begin{tabular}{|c|c|c|c|c|c|}
\hline Variável & Sexo & Proporção $^{6}$ & $\%$ & p-valor & p-valor ajustado \\
\hline \multirow[t]{2}{*}{ kob } & $\mathrm{F}$ & $2 / 1312$ & 0,2 & \multirow{2}{*}{0,114} & \multirow[t]{2}{*}{0,113} \\
\hline & M & $7 / 1294$ & 0,5 & & \\
\hline \multirow[t]{2}{*}{ kp } & $\mathrm{F}$ & $4 / 1312$ & 0,3 & \multirow{2}{*}{0,984} & \multirow{2}{*}{0,990} \\
\hline & $\mathrm{M}$ & $4 / 1294$ & 0,3 & & \\
\hline \multirow[t]{2}{*}{$\sum \mathbf{k}$} & $\mathrm{F}$ & $93 / 1312$ & 7,09 & \multirow{2}{*}{0,203} & \multirow{2}{*}{0,215} \\
\hline & M & $109 / 1294$ & 8,42 & & \\
\hline \multirow{2}{*}{ FC } & $\mathrm{F}$ & $149 / 1312$ & 11,4 & \multirow{2}{*}{0,953} & \multirow{2}{*}{0,934} \\
\hline & M & $146 / 1294$ & 11,3 & & \\
\hline \multirow{2}{*}{$\mathbf{C F}$} & $\mathrm{F}$ & $54 / 1312$ & 2,4 & \multirow{2}{*}{0,231} & \multirow{2}{*}{0,217} \\
\hline & $\mathrm{M}$ & $66 / 1294$ & 3,5 & & \\
\hline \multirow{2}{*}{$\mathbf{C}$} & $\mathrm{F}$ & $21 / 1312$ & 1,6 & \multirow{2}{*}{0,087} & \multirow{2}{*}{0,087} \\
\hline & M & $11 / 1294$ & 0,9 & & \\
\hline \multirow{2}{*}{ FE } & $\mathrm{F}$ & $55 / 1312$ & 4,2 & \multirow{2}{*}{0,291} & \multirow{2}{*}{0,289} \\
\hline & M & $44 / 1294$ & 3,4 & & \\
\hline \multirow{2}{*}{ EF } & $\mathrm{F}$ & $22 / 1312$ & 1,7 & \multirow{2}{*}{0,963} & \multirow{2}{*}{0,927} \\
\hline & $\mathrm{M}$ & $22 / 1294$ & 1,7 & & \\
\hline $\mathbf{E}$ & $\mathrm{F}$ & $0 / 1312$ & 0,0 & & \\
\hline & $\mathrm{M}$ & $2 / 1294$ & 0,2 & 0,942 & 0,930 \\
\hline FClob & $\mathrm{F}$ & $1 / 1312$ & 0,1 & 0960 & 0936 \\
\hline & M & $0 / 1294$ & 0,0 & 0,900 & U,950 \\
\hline ClobF & $\mathrm{F}$ & - & - & 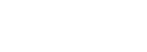 & 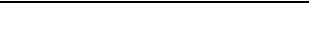 \\
\hline & $\mathrm{M}$ & - & - & $\begin{array}{l}- \\
-\end{array}$ & - \\
\hline Clob & $\mathrm{F}$ & - & - & & \\
\hline & $\mathrm{M}$ & - & - & - & - \\
\hline $\mathbf{A}$ & $\mathrm{F}$ & $659 / 1312$ & 50,2 & 0237 & 0208 \\
\hline & $\mathrm{M}$ & $620 / 1294$ & 47,9 & 0,231 & U, 208 \\
\hline (A) & $\mathrm{F}$ & $47 / 1312$ & 3,6 & 0013 & 0016 \\
\hline & $\mathrm{M}$ & $73 / 1294$ & 5,6 & 0,015 & 0,010 \\
\hline Ad & $\mathrm{F}$ & $118 / 1312$ & 9,0 & 0240 & \\
\hline & M & $134 / 1294$ & 10,4 & 0,240 & 0,211 \\
\hline (Ad) & $\mathrm{F}$ & $12 / 1312$ & 0,9 & 0.427 & 0.435 \\
\hline & $\mathrm{M}$ & $16 / 1294$ & 1,2 & & \\
\hline$\sum \mathbf{A}$ & $\mathrm{F}$ & $836 / 1312$ & 63,72 & 0447 & 0494 \\
\hline & $\mathrm{M}$ & $843 / 1294$ & 65,15 & $0,44 /$ & 0,494 \\
\hline $\mathbf{H}$ & $\mathrm{F}$ & $78 / 1312$ & 5,9 & 0032 & 0.036 \\
\hline & $\mathrm{M}$ & $53 / 1294$ & 4,1 & 0,032 & 0,030 \\
\hline (H) & $\mathrm{F}$ & $58 / 1312$ & 4,4 & 0.541 & 0.589 \\
\hline & $\mathrm{M}$ & $51 / 1294$ & 3,9 & & \\
\hline Hd & $\mathrm{F}$ & $35 / 1312$ & 2,7 & 0160 & 0153 \\
\hline & M & $47 / 1294$ & 3,6 & 0,100 & 0,153 \\
\hline (Hd) & $\mathrm{F}$ & $19 / 1312$ & 1,4 & 0340 & 0348 \\
\hline & M & 25/1294 & 1,9 & 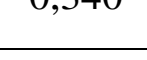 & O \\
\hline$\sum \mathbf{H}$ & $\mathrm{F}$ & $190 / 1312$ & 14,48 & 0518 & 0,573 \\
\hline & $\mathrm{M}$ & $176 / 1294$ & 13,60 & 0,310 & \\
\hline
\end{tabular}


conclusão

\begin{tabular}{|c|c|c|c|c|c|}
\hline Variável & Sexo & Proporção $^{6}$ & $\%$ & p-valor & p-valor ajustado \\
\hline \multirow[t]{2}{*}{ Anat } & $\mathrm{F}$ & $32 / 1312$ & 2,4 & \multirow{2}{*}{0,119} & \multirow[t]{2}{*}{0,123} \\
\hline & M & $45 / 1294$ & 3,5 & & \\
\hline \multirow[t]{2}{*}{ Sg } & $\mathrm{F}$ & $7 / 1312$ & 0,5 & \multirow{2}{*}{0,979} & \multirow{2}{*}{0,976} \\
\hline & M & $7 / 1294$ & 0,5 & & \\
\hline \multirow{2}{*}{ Sex } & $\mathrm{F}$ & - & - & - & - \\
\hline & M & - & - & - & - \\
\hline \multirow{2}{*}{ Obj } & $\mathrm{F}$ & $96 / 1312$ & 7,3 & \multirow{2}{*}{0,263} & \multirow{2}{*}{0,260} \\
\hline & $\mathrm{M}$ & $110 / 1294$ & 8,5 & & \\
\hline \multirow{2}{*}{ Art } & $\mathrm{F}$ & $12 / 1312$ & 0,9 & \multirow{2}{*}{0,173} & \multirow{2}{*}{0,186} \\
\hline & M & $6 / 1294$ & 0,5 & & \\
\hline \multirow{2}{*}{ Arq } & $\mathrm{F}$ & $14 / 1312$ & 1,1 & \multirow{2}{*}{0,571} & \multirow{2}{*}{0,537} \\
\hline & M & $11 / 1294$ & 0,9 & & \\
\hline \multirow[t]{2}{*}{ Simb } & $\mathrm{F}$ & $14 / 1312$ & 1,1 & \multirow{2}{*}{0,216} & \multirow{2}{*}{0,202} \\
\hline & M & $8 / 1294$ & 0,6 & & \\
\hline \multirow[t]{2}{*}{ Abst } & $\mathrm{F}$ & $2 / 1312$ & 0,2 & \multirow{2}{*}{0,943} & \multirow{2}{*}{0,936} \\
\hline & M & $0 / 1294$ & 0,0 & & \\
\hline \multirow[t]{2}{*}{ Bot } & $\mathrm{F}$ & $49 / 1312$ & 3,7 & \multirow{2}{*}{0,497} & \multirow{2}{*}{0,520} \\
\hline & M & $42 / 1294$ & 3,2 & & \\
\hline \multirow[t]{2}{*}{ Geo } & $\mathrm{F}$ & $15 / 1312$ & 1,1 & \multirow{2}{*}{0,826} & \multirow{2}{*}{0,842} \\
\hline & $\mathrm{M}$ & $16 / 1294$ & 1,2 & & \\
\hline \multirow[t]{2}{*}{ Nat } & $\mathrm{F}$ & $5 / 1312$ & 0,4 & \multirow{2}{*}{0,145} & \multirow{2}{*}{0,155} \\
\hline & M & $1 / 1294$ & 0,1 & & \\
\hline Pais & $\mathrm{F}$ & $6 / 1312$ & 0,5 & 0780 & \\
\hline & M & $5 / 1294$ & 0,4 & $0, / 80$ & 0,808 \\
\hline Elem & $\mathrm{F}$ & $13 / 1312$ & 1,0 & 0.073 & 0.076 \\
\hline & M & $5 / 1294$ & 0,4 & 0,013 & \\
\hline Frag & $\mathrm{F}$ & $21 / 1312$ & 1,6 & 0784 & 0791 \\
\hline & $\mathrm{M}$ & $19 / 1294$ & 1,5 & $0, / 84$ & 0,191 \\
\hline Ban & $\mathrm{F}$ & $259 / 1312$ & 19,7 & 0.089 & 0.085 \\
\hline & M & $222 / 1294$ & 17,2 & & \\
\hline
\end{tabular}

Comparando as demais variáveis, foram constatadas diferenças estatisticamente significativas em apenas outras cinco variáveis, sendo elas: G, D, F-, (A) e H. Em vista disso, pode-se considerar que o desempenho das crianças do sexo masculino e feminino foi bastante semelhante, distinguindo-se apenas em algumas particularidades produtivas, as quais serão comentadas a seguir.

Em relação ao modo de apreensão, os meninos apresentaram maior frequiência de respostas globais, sugerindo concentração nos aspectos gerais na interpretação da realidade. Isto se contrapõe aos resultados das meninas, cuja freqüência maior foi de respostas grande detalhe, denotando maior atenção aos aspectos pregnantes, práticos e de maior relevância do ambiente. 
Concernente ao grupo dos determinantes, os meninos apresentaram maior freqüência de F- em comparação às meninas, sinalizando menor precisão perceptiva e menor atenção aos elementos de convenção social. No tocante aos conteúdos das respostas ao Rorschach, os meninos apresentaram maiores índices de conteúdo animal [(A)] em suas respostas, enquanto que as meninas, por sua vez, manifestaram o conteúdo humano $[\mathrm{H}]$ com maior frequiência. Tais dados reforçam a possibilidade de maior nível de elaboração nas respostas femininas. No entanto, quando essas variáveis foram tratadas em sua categoria geral de classificação [categoria animal - A, (A), Ad, (Ad) e categoria humana $\mathrm{H},(\mathrm{H}), \mathrm{Hd},(\mathrm{Hd})]$, estas diferenças de desempenho entre os grupos desapareceram. Nesse contexto, pode-se inferir que estas diferenças não se mostraram consistentes no conjunto de dados analisados, podendo ser desprezadas em seu sentido interpretativo. Estes achados, portanto, não apresentam evidências empíricas suficientes para justificar a elaboração de referenciais normativos do Rorschach específicos para meninos e para meninas.

\subsection{Análise do padrão de respostas no Rorschach em funcão da origem escolar}

Partindo-se do pressuposto das divergências dinâmicas e estruturais existentes nas escolas públicas e particulares do Brasil, julgou-se necessário avaliar possíveis efeitos da procedência escolar sobre as variáveis do Rorschach, uma vez que as crianças aqui investigadas se encontram em uma fase de desenvolvimento onde o ambiente exerce reconhecida influência sobre estas. Dessa forma, partindo-se do mesmo procedimento técnico adotado anteriormente, foram realizadas comparações estatísticas dos resultados das crianças provenientes de escolas públicas $(n=90)$ e particulares $(n=90)$ nas mesmas 54 variáveis do Rorschach, formulando-se, assim, as Tabelas 15 e 16. 
Tabela 15 - Resultados da análise estatística das variáveis relacionadas a produtividade e ritmo no Rorschach, em função da origem escolar.

\begin{tabular}{|c|c|c|c|c|c|}
\hline Variável & $\begin{array}{l}\text { Origem } \\
\text { escolar }\end{array}$ & Média & DP & $p$-valor & $p$-valor ajustado \\
\hline \multirow{2}{*}{$\mathbf{R}$} & Part & 16,0 & 4,8 & \multirow{2}{*}{$<0,001$} & \multirow{2}{*}{$<0,001$} \\
\hline & Publ & 13,0 & 2,8 & & \\
\hline \multirow{2}{*}{ RA } & Part & 0,2 & 0,6 & \multirow{2}{*}{0,221} & \multirow{2}{*}{0,223} \\
\hline & Publ & 0,1 & 0,4 & & \\
\hline \multirow{2}{*}{ Rec } & Part & 0,1 & 0,3 & \multirow{2}{*}{0,622} & \multirow{2}{*}{0,621} \\
\hline & Publ & 0,1 & 0,3 & & \\
\hline \multirow{2}{*}{ Den } & Part & 0,0 & 0,2 & \multirow{2}{*}{0,472} & \multirow{2}{*}{0,470} \\
\hline & Publ & 0,1 & 0,2 & & \\
\hline \multirow{2}{*}{ TLm } & Part & 12,7 & 11,7 & \multirow{2}{*}{0,062} & \multirow{2}{*}{0,057} \\
\hline & Publ & 15,7 & 9,2 & & \\
\hline \multirow{2}{*}{ TRm } & Part & 25,2 & 10,7 & \multirow{2}{*}{$<0,001$} & \multirow{2}{*}{$<0,001$} \\
\hline & Publ & 32,4 & 11,5 & & \\
\hline
\end{tabular}

$\mathrm{R}=$ respostas; $\mathrm{RA}=$ respostas adicionais; $\mathrm{Rec}=$ recusas aos cartões; Den = Denegações; $\quad$ TLm $=$ Tempo de Latência médio; TRm = Tempo de Reação médio.

Os dados apresentados na Tabela 15 revelam duas diferenças estatisticamente significativas em relação a produtividade e ritmo de reação ao Rorschach. Como pode ser observado, as crianças provenientes de escolas particulares apresentaram maior número de respostas (R) nesta técnica projetiva, ao passo que as crianças provindas de escolas públicas utilizaram tempos mais amplos (TRm) em suas produções. Essa maior produtividade por parte dos estudantes de escolas particulares pode indicar sinais de maior facilidade de associação e mais recursos cognitivos, fazendo pensar que estas crianças estejam recebendo estímulos socioculturais e ambientais favorecedores dos processos associativo-interpretativos, como aqueles solicitados no Rorschach. Já as crianças de escolas públicas, por sua vez, sinalizaram menor envolvimento e maior nível de simplificação perceptiva, sugerindo que os indivíduos de classes sociais menos favorecidas tendem a perceber a realidade de modo mais limitado, com menor utilização de seus recursos pessoais. A Tabela 16, por sua vez, traz as análises das demais variáveis da Escola Psicanalítica Francesa do Rorschach. 
Tabela 16 - Resultados da análise estatística das principais variáveis do Rorschach, em função da origem escolar.

\begin{tabular}{|c|c|c|c|c|c|}
\hline Variável & Origem Escolar & Proporção & $\%$ & p-valor & p-valor ajustado \\
\hline \multirow[t]{2}{*}{$\mathbf{G}$} & Part & $504 / 1437$ & 35,1 & \multirow{2}{*}{0,838} & \multirow{2}{*}{$<0,001$} \\
\hline & Publ & $503 / 1169$ & 43,0 & & \\
\hline \multirow[t]{2}{*}{$\mathbf{D}$} & Part & $631 / 1437$ & 43,9 & \multirow{2}{*}{0,737} & \multirow{2}{*}{0,716} \\
\hline & Publ & $521 / 1169$ & 44,6 & & \\
\hline \multirow[t]{2}{*}{ Dd } & Part & $294 / 1437$ & 20,5 & \multirow{2}{*}{$<0,001$} & \multirow{2}{*}{$<0,001$} \\
\hline & Publ & $139 / 1169$ & 11,9 & & \\
\hline \multirow[t]{2}{*}{ Dbl } & Part & $8 / 1437$ & 0,6 & \multirow{2}{*}{0,880} & \multirow{2}{*}{0,819} \\
\hline & Publ & $6 / 1169$ & 0,5 & & \\
\hline \multirow[t]{2}{*}{ Do } & Part & - & - & \multirow[b]{2}{*}{-} & \multirow{2}{*}{-} \\
\hline & Publ & - & - & & \\
\hline \multirow[t]{2}{*}{$\mathbf{F}+$} & Part & $669 / 1437$ & 46,6 & \multirow{2}{*}{0,272} & \multirow{2}{*}{0,261} \\
\hline & Publ & $519 / 1169$ & 44,4 & & \\
\hline \multirow[t]{2}{*}{$\mathbf{F}+/-$} & Part & $2 / 1437$ & 0,1 & \multirow{2}{*}{0,691} & \multirow{2}{*}{0,689} \\
\hline & Publ & $1 / 1169$ & 0,1 & & \\
\hline \multirow[t]{2}{*}{ F- } & Part & $300 / 1437$ & 20,9 & \multirow{2}{*}{0,787} & \multirow{2}{*}{0,818} \\
\hline & Publ & 239/1169 & 20,4 & & \\
\hline \multirow[t]{2}{*}{$\sum \mathbf{F}$} & Part & $971 / 1437$ & 67,57 & \multirow{2}{*}{0,155} & 150 \\
\hline & Publ & $759 / 1169$ & 64,93 & & 0,159 \\
\hline $\mathbf{K}$ & Part & $49 / 1437$ & 3,4 & 0326 & 0376 \\
\hline & Publ & $32 / 1169$ & 2,7 & $0,3<0$ & $0,3 / 0$ \\
\hline kan & Part & $98 / 1437$ & 6,8 & 0,538 & \\
\hline & Publ & $87 / 1169$ & 7,4 & & 0,508 \\
\hline kob & Part & $5 / 1437$ & 0,3 & & \\
\hline & Publ & $4 / 1169$ & 0,3 & 0,980 & 0,981 \\
\hline kp & Part & $5 / 1437$ & 0,3 & & \\
\hline & Publ & $3 / 1169$ & 0,3 & $0,0 / 0$ & U,080 \\
\hline$\sum \mathbf{k}$ & Part & $108 / 1437$ & 7,52 & 0618 & 0641 \\
\hline & Publ & $94 / 1169$ & 8,04 & 0,010 & 0,041 \\
\hline FC & Part & $154 / 1437$ & 10,7 & 0281 & 0305 \\
\hline & Publ & $141 / 1169$ & 12,1 & 0,201 & $0,50 J$ \\
\hline $\mathrm{CF}$ & Part & $68 / 1437$ & 4,7 & 0731 & 0607 \\
\hline & Publ & $52 / 1169$ & 4,4 & $0, / 31$ & 0,092 \\
\hline $\mathbf{C}$ & Part & $9 / 1437$ & 0,6 & 0.003 & 0003 \\
\hline & Publ & $23 / 1169$ & 2,0 & 0,003 & 0,003 \\
\hline FE & Part & $52 / 1437$ & 3,6 & 0594 & 0548 \\
\hline & Publ & $47 / 1169$ & 4,0 & 0,594 & 0,340 \\
\hline EF & Part & $25 / 1437$ & 1,7 & 0822 & 0824 \\
\hline & Publ & $19 / 1169$ & 1,6 & $0,8<2$ & $0,8<4$ \\
\hline $\mathbf{E}$ & Part & $1 / 1437$ & 0,1 & 0,884 & 0,876 \\
\hline & Publ & $1 / 1169$ & 0,1 & & \\
\hline
\end{tabular}




\begin{tabular}{|c|c|c|c|c|c|}
\hline Variável & Origem Escolar & Proporção & $\%$ & p-valor & p-valor ajustado \\
\hline \multirow[t]{2}{*}{ FClob } & Part & $0 / 1437$ & 0,0 & \multirow{2}{*}{0,957} & \multirow{2}{*}{0,934} \\
\hline & Publ & $1 / 1169$ & 0,1 & & \\
\hline \multirow[t]{2}{*}{ ClobF } & Part & - & - & & \multirow{2}{*}{ - } \\
\hline & Publ & - & - & & \\
\hline \multirow[t]{2}{*}{ Clob } & Part & - & - & & \multirow{2}{*}{-} \\
\hline & Publ & - & - & - & \\
\hline \multirow[t]{2}{*}{$\mathbf{A}$} & Part & $713 / 1437$ & 49,6 & \multirow{2}{*}{0,542} & \multirow{2}{*}{0,458} \\
\hline & Publ & $566 / 1169$ & 48,4 & & \\
\hline \multirow[t]{2}{*}{ (A) } & Part & $64 / 1437$ & 4,5 & \multirow{2}{*}{0,683} & \multirow{2}{*}{0,731} \\
\hline & Publ & $56 / 1169$ & 4,8 & & \\
\hline \multirow[t]{2}{*}{ Ad } & Part & $130 / 1437$ & 9,0 & \multirow{2}{*}{0,233} & \multirow{2}{*}{0,214} \\
\hline & Publ & $122 / 1169$ & 10,4 & & \\
\hline \multirow[t]{2}{*}{ (Ad) } & Part & $15 / 1437$ & 1,0 & \multirow{2}{*}{0,867} & \multirow{2}{*}{0,901} \\
\hline & Publ & $13 / 1169$ & 1,1 & & \\
\hline \multirow[t]{2}{*}{$\sum \mathbf{A}$} & Part & $922 / 1437$ & 64,16 & \multirow{2}{*}{0,753} & \multirow{2}{*}{0,863} \\
\hline & Publ & $757 / 1169$ & 64,76 & & \\
\hline \multirow[t]{2}{*}{$\mathbf{H}$} & Part & $64 / 1437$ & 4,5 & \multirow{2}{*}{0,139} & \multirow{2}{*}{0,108} \\
\hline & Publ & $67 / 1169$ & 5,7 & & \\
\hline (H) & Part & $69 / 1437$ & 4,8 & & \\
\hline & Publ & $40 / 1169$ & 3,4 & 0,082 & $0,0 / 4$ \\
\hline Hd & Part & $55 / 1437$ & 3,8 & 0,029 & 0031 \\
\hline & Publ & $27 / 1169$ & 2,3 & & 0,031 \\
\hline (Hd) & Part & $25 / 1437$ & 1,7 & 0822 & 0707 \\
\hline & Publ & $19 / 1169$ & 1,6 & $0,8<2$ & 0,191 \\
\hline$\sum \mathbf{H}$ & Part & $213 / 1437$ & 14,82 & & \\
\hline & Publ & $153 / 1169$ & 13,09 & 0,205 & $0,2 \angle 4$ \\
\hline Anat & Part & $39 / 1437$ & 2,7 & 0427 & 0415 \\
\hline & Publ & $38 / 1169$ & 3,3 & $0,4 \angle 2$ & 0,415 \\
\hline Sg & Part & $4 / 1437$ & 0,3 & 0057 & 0054 \\
\hline & Publ & $10 / 1169$ & 0,9 & U,U I & 0,054 \\
\hline Sex & Part & $0 / 1431$ & - & 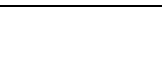 & 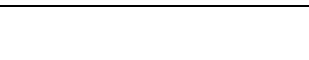 \\
\hline & Publ & $0 / 1531$ & - & - & - \\
\hline Obj & Part & $124 / 1437$ & 8,6 & (120 & 0120 \\
\hline & Publ & $82 / 1169$ & 7,0 & 0,129 & 0,138 \\
\hline Art & Part & $8 / 1437$ & 0,6 & 0364 & 0310 \\
\hline & Publ & $10 / 1169$ & 0,9 & 0,504 & 0,310 \\
\hline Arq & Part & $16 / 1437$ & 1,1 & 0374 & 0368 \\
\hline & Publ & $9 / 1169$ & 0,8 & $0,3 / 4$ & 0,500 \\
\hline Simb & Part & $13 / 1437$ & 0,9 & & \\
\hline & Publ & $9 / 1169$ & 0,8 & $0, / 09$ & $0, / 39$ \\
\hline Abst & Part & $2 / 1437$ & 0,1 & 0.946 & 0,937 \\
\hline & Publ & $0 / 1169$ & 0,0 & & \\
\hline
\end{tabular}


conclusão

\begin{tabular}{|c|c|c|c|c|c|}
\hline Variável & Origem Escolar & Proporção & $\%$ & p-valor & p-valor ajustado \\
\hline \multirow[t]{2}{*}{ Bot } & Part & $40 / 1437$ & 2,8 & \multirow{2}{*}{0,030} & \multirow{2}{*}{0,024} \\
\hline & Publ & $51 / 1169$ & 4,4 & & \\
\hline \multirow[t]{2}{*}{ Geo } & Part & $20 / 1437$ & 1,4 & \multirow{2}{*}{0,294} & \multirow{2}{*}{0,288} \\
\hline & Publ & $11 / 1169$ & 0,9 & & \\
\hline \multirow[t]{2}{*}{ Nat } & Part & $2 / 1437$ & 0,1 & \multirow{2}{*}{0,298} & \multirow{2}{*}{0,284} \\
\hline & Publ & $4 / 1169$ & 0,3 & & \\
\hline \multirow[t]{2}{*}{ Pais } & Part & $7 / 1437$ & 0,5 & \multirow{2}{*}{0,572} & \multirow{2}{*}{0,604} \\
\hline & Publ & $4 / 1169$ & 0,3 & & \\
\hline \multirow[t]{2}{*}{ Elem } & Part & $7 / 1437$ & 0,5 & \multirow{2}{*}{0,172} & \multirow{2}{*}{0,150} \\
\hline & Publ & $11 / 1169$ & 0,9 & & \\
\hline \multirow[t]{2}{*}{ Frag } & Part & $20 / 1437$ & 1,4 & \multirow{2}{*}{0,511} & \multirow{2}{*}{0,503} \\
\hline & Publ & $20 / 1169$ & 1,7 & & \\
\hline \multirow[t]{2}{*}{ Ban } & Part & $255 / 1437$ & 17,7 & \multirow{2}{*}{0,299} & \multirow{2}{*}{0,327} \\
\hline & Publ & $226 / 1169$ & 19,3 & & \\
\hline
\end{tabular}

Os dados apresentados na Tabela 16 revelam diferenças estatisticamente significativas em outras cinco das 54 variáveis analisadas, distribuídas entre as categorias: localização [G e Dd], determinante [C] e conteúdo [Hd e Bot]. Estudantes de escolas públicas apresentaram maiores índices de respostas globais [G], sugerindo maior atenção aos aspectos gerais na interpretação da realidade. Já as crianças de escolas particulares deram respostas de pequeno detalhe $[\mathrm{Dd}]$ em maior freqüência, sugerindo maior atenção às minúcias do ambiente. $\mathrm{Na}$ categoria dos determinantes, a única diferença encontrada foi com relação às respostas de determinante cromático, mais reportadas pelo grupo advindo de escolas públicas. Este dado sinalizou maior influência da afetividade, desprovida de controle racional, na determinação das respostas destas crianças e, por conseguinte, na interpretação da realidade como um todo.

No tocante a conteúdos das respostas, o indicador de resposta parcialmente humana [Hd] foi mais freqüente em estudantes de escolas particulares. No entanto, quando essa variável foi tratada em sua categoria geral de classificação [categoria humana - H, $(\mathrm{H}), \mathrm{Hd},(\mathrm{Hd})$ ], estas diferenças de resultados entre os grupos desapareceram. Nesse contexto, pode-se inferir que tais diferenças não se mostraram consistentes no conjunto de dados analisados, podendo ser desprezadas em seu sentido interpretativo por se tratarem de aspectos possivelmente aleatórios. A última diferença encontrada foi relativa ao conteúdo botânico [Bot], sendo este mais reportado pelas crianças procedentes de escolas públicas. Embora mereça atenção, este dado, examinado em separado, não possui relevante significado interpretativo.

Diante destas evidências, pode-se reconhecer que o contexto ambiental (no caso, a origem escolar) pode ter alguma interferência no desenvolvimento infantil e, talvez, o que os atuais dados apontem seja uma sinalização de possível efeito dessas diferenças no desempenho nesta técnica 
projetiva de avaliação de personalidade. No entanto, em vista da análise geral dos resultados obtidos, pode-se pressupor que o número e a natureza das diferenças observadas entre as variáveis do Rorschach podem ser consideradas casuais ou pouco expressivas dentro do conjunto global de resultados da amostra. Portanto, não se justifica a divisão de normas avaliativas em função da origem escolar, possibilitando assim, a integração dos dados de crianças provindas de escolas públicas e particulares na descrição e nas análises a serem efetivadas.

\subsection{Análise do padrão de respostas no Rorschach em funcão da idade}

Em último plano examinou-se a possibilidade de efeito da idade específica das crianças sobre as variáveis do Psicodiagnóstico de Rorschach, recorrendo-se a estratégias técnicas similares ao anteriormente relatado. Para tanto, foram realizadas comparações estatísticas dos resultados em função da idade das crianças, compondo-se três subgrupos, a saber: seis anos (n= $60)$, sete anos $(n=60)$ e oito anos $(n=60)$. As Tabelas 17 e 18 compõem esses resultados.

Tabela 17 - Resultados da análise estatística das variáveis relacionadas a produtividade e ritmo no Rorschach, em função da idade.

\begin{tabular}{|c|c|c|c|c|c|}
\hline Variável & Idade & Média & DP & $p$-valor & $p$-valor ajustado \\
\hline \multirow{3}{*}{$\mathbf{R}$} & 6 & 14,0 & 3,8 & \multirow{3}{*}{0,066} & \multirow{3}{*}{0,050} \\
\hline & 7 & 14,1 & 3,6 & & \\
\hline & 8 & 15,4 & 5,0 & & \\
\hline \multirow{3}{*}{$\mathbf{R A}$} & 6 & 0,2 & 0,5 & \multirow{3}{*}{0,708} & \multirow{3}{*}{0,709} \\
\hline & 7 & 0,1 & 0,4 & & \\
\hline & 8 & 0,2 & 0,5 & & \\
\hline \multirow{3}{*}{$\operatorname{Rec}$} & 6 & 0,1 & 0,3 & \multirow{3}{*}{0,763} & \multirow{3}{*}{0,762} \\
\hline & 7 & 0,1 & 0,3 & & \\
\hline & 8 & 0,1 & 0,3 & & \\
\hline \multirow{3}{*}{ Den } & 6 & 0,1 & 0,3 & \multirow{3}{*}{0,186} & \multirow{3}{*}{0,186} \\
\hline & 7 & 0,1 & 0,2 & & \\
\hline & 8 & 0,0 & 0,1 & & \\
\hline \multirow{3}{*}{ TLm } & 6 & 15,5 & 9,9 & \multirow{3}{*}{0,068} & \multirow{3}{*}{0,063} \\
\hline & 7 & 15,2 & 13,8 & & \\
\hline & 8 & 11,9 & 6,7 & & \\
\hline \multirow{3}{*}{ TRm } & 6 & 30,5 & 12,7 & \multirow{3}{*}{0,012} & \multirow{3}{*}{0,008} \\
\hline & 7 & 30,6 & 12,6 & & \\
\hline & 8 & 25,2 & 8,6 & & \\
\hline
\end{tabular}

$\mathrm{R}=$ respostas; $\mathrm{RA}=$ respostas adicionais; Rec $=$ recusas aos cartões; Den $=$ Denegações; $\quad$ TLm $=$ Tempo de Latência médio; TRm = Tempo de Reação médio. 
Em relação às variáveis associadas à produtividade e ao ritmo, pode-se notar que houve diferenças estatisticamente significativas nas variáveis R e TRm entre os subgrupos de idade. Constatou-se que na medida em que a idade aumentou, o número de respostas aumentou e o tempo de resposta médio (TRm) diminuiu, sugerindo que as crianças de oito anos de idade produziram mais respostas em menos tempo. Essa evidência é sugestiva de que os processos associativo-interpretativos do Rorschach mostraram-se mais ágeis e rápidos em crianças mais velhas dessa amostra. Estas diferenças encontradas podem, portanto, ser de natureza maturacional e desenvolvimental.

Prosseguindo com a avaliação das possíveis influências da idade específica na produção do Rorschach, serão apresentados os dados relativos às demais variáveis do Rorschach aqui analisadas.

Tabela 18 - Resultados da análise estatística das principais variáveis do Rorschach, em função da idade.

\begin{tabular}{|c|c|c|c|c|c|}
\hline Variável & Idade & Proporção & $\%$ & $p$-valor & $p$-valor ajustado \\
\hline \multirow{3}{*}{$\mathbf{G}$} & 6 & $351 / 837$ & 41,9 & \multirow{3}{*}{0,016} & \multirow{3}{*}{$\mathbf{0 , 0 2 3}$} \\
\hline & 7 & $351 / 848$ & 41,4 & & \\
\hline & 8 & $351 / 921$ & 38,1 & & \\
\hline \multirow{3}{*}{ D } & 6 & $361 / 837$ & 43,1 & \multirow{3}{*}{0,745} & \multirow{3}{*}{0,722} \\
\hline & 7 & $378 / 848$ & 44,6 & & \\
\hline & 8 & $413 / 921$ & 44,8 & & \\
\hline \multirow{3}{*}{ Dd } & 6 & $120 / 837$ & 14,3 & \multirow{3}{*}{0,005} & \multirow{3}{*}{$\mathbf{0 , 0 1 0}$} \\
\hline & 7 & $131 / 848$ & 15,4 & & \\
\hline & 8 & $182 / 921$ & 19,8 & & \\
\hline \multirow{3}{*}{ Dbl } & 6 & $5 / 837$ & 0,6 & \multirow{3}{*}{0,115} & \multirow{3}{*}{0,114} \\
\hline & 7 & $8 / 848$ & 0,9 & & \\
\hline & 8 & $1 / 921$ & 0,1 & & \\
\hline \multirow{3}{*}{ Do } & 6 & - & - & \multirow{3}{*}{-} & \multirow{3}{*}{-} \\
\hline & 7 & - & - & & \\
\hline & 8 & - & - & & \\
\hline \multirow{3}{*}{$\mathbf{F}+$} & 6 & $379 / 837$ & 45,3 & \multirow{3}{*}{0,551} & \multirow{3}{*}{0,500} \\
\hline & 7 & $399 / 848$ & 47,1 & & \\
\hline & 8 & $410 / 921$ & 44,5 & & \\
\hline \multirow{3}{*}{$\mathbf{F}+/-$} & 6 & $2 / 837$ & 0,2 & \multirow{3}{*}{0,810} & \multirow{3}{*}{0,802} \\
\hline & 7 & $0 / 848$ & 0,0 & & \\
\hline & 8 & $1 / 921$ & 0,1 & & \\
\hline \multirow{3}{*}{ F- } & 6 & $161 / 837$ & 19,2 & \multirow{3}{*}{0,319} & \multirow{3}{*}{0,315} \\
\hline & 7 & $174 / 848$ & 20,5 & & \\
\hline & 8 & $204 / 921$ & 22,1 & & \\
\hline
\end{tabular}




\begin{tabular}{|c|c|c|c|c|c|}
\hline Variável & Idade & Proporção & $\%$ & $p$-valor & $p$-valor ajustado \\
\hline \multirow{3}{*}{$\sum \mathbf{F}$} & 6 & $542 / 837$ & 64,76 & \multirow{3}{*}{0,451} & \multirow[t]{3}{*}{0,460} \\
\hline & 7 & $573 / 848$ & 67,57 & & \\
\hline & 8 & $615 / 921$ & 66,78 & & \\
\hline \multirow{3}{*}{$\mathbf{K}$} & 6 & $23 / 837$ & 2,7 & \multirow{3}{*}{0,023} & \multirow{3}{*}{0,028} \\
\hline & 7 & $18 / 848$ & 2,1 & & \\
\hline & 8 & $40 / 921$ & 4,3 & & \\
\hline \multirow{3}{*}{ kan } & 6 & $62 / 837$ & 7,4 & \multirow{3}{*}{0,490} & \multirow{3}{*}{0,514} \\
\hline & 7 & $65 / 848$ & 7,7 & & \\
\hline & 8 & $58 / 921$ & 6,3 & & \\
\hline \multirow{3}{*}{ kob } & 6 & $1 / 837$ & 0,1 & \multirow{3}{*}{0,372} & \multirow{3}{*}{0,365} \\
\hline & 7 & $3 / 848$ & 0,4 & & \\
\hline & 8 & $5 / 921$ & 0,5 & & \\
\hline \multirow{3}{*}{ kp } & 6 & $1 / 837$ & 0,1 & \multirow{3}{*}{0,465} & \multirow{3}{*}{0,465} \\
\hline & 7 & $4 / 848$ & 0,5 & & \\
\hline & 8 & $3 / 921$ & 0,3 & & \\
\hline \multirow{3}{*}{$\sum \mathbf{k}$} & 6 & $64 / 837$ & 7,65 & \multirow{3}{*}{0,203} & \multirow{3}{*}{0,215} \\
\hline & 7 & $72 / 848$ & 8,49 & & \\
\hline & 8 & $66 / 1169$ & 5,65 & & \\
\hline \multirow{3}{*}{ FC } & 6 & $102 / 837$ & 12,2 & \multirow{3}{*}{0,336} & \multirow{3}{*}{0,354} \\
\hline & 7 & $100 / 848$ & 11,8 & & \\
\hline & 8 & 93/921 & 10,1 & & \\
\hline \multirow{3}{*}{$\mathbf{C F}$} & 6 & $51 / 837$ & 6,1 & \multirow{3}{*}{0,047} & \multirow{3}{*}{0,044} \\
\hline & 7 & $33 / 848$ & 3,9 & & \\
\hline & 8 & $36 / 921$ & 3,9 & & \\
\hline \multirow{3}{*}{ C } & 6 & $12 / 837$ & 1,4 & 0782 & 0814 \\
\hline & 7 & $9 / 848$ & 1,1 & 0,102 & 0,014 \\
\hline & 8 & $11 / 921$ & 1,2 & & \\
\hline & 6 & $23 / 837$ & 2,7 & 0112 & 0108 \\
\hline FE & 7 & $33 / 848$ & 3,9 & 0,112 & 0,100 \\
\hline & 8 & $43 / 921$ & 4,7 & & \\
\hline & 6 & $18 / 837$ & 2,2 & 0307 & 0206 \\
\hline EF & 7 & $10 / 848$ & 1,2 & $0,30 /$ & 0,300 \\
\hline & 8 & $16 / 921$ & 1,7 & & \\
\hline & 6 & $1 / 837$ & 0,1 & 0.096 & 0.096 \\
\hline $\mathbf{E}$ & 7 & $0 / 848$ & 0,0 & טרני, & טרנק, \\
\hline & 8 & $1 / 921$ & 0,1 & & \\
\hline & 6 & $1 / 837$ & 0,1 & 0996 & 0996 \\
\hline FClob & 7 & - & - & 0,990 & 0,990 \\
\hline & 8 & - & - & & \\
\hline & 6 & - & - & & \\
\hline ClobF & 7 & - & - & - & - \\
\hline & 8 & - & - & & \\
\hline
\end{tabular}


continuação

\begin{tabular}{|c|c|c|c|c|c|}
\hline Variável & Idade & Proporção & $\%$ & $p$-valor & $p$-valor ajustado \\
\hline \multirow{3}{*}{ Clob } & 6 & - & - & \multirow{3}{*}{-} & \multirow{3}{*}{-} \\
\hline & 7 & - & - & & \\
\hline & 8 & - & - & & \\
\hline \multirow{3}{*}{$\mathbf{A}$} & 6 & $431 / 837$ & 51,5 & \multirow{3}{*}{0,001} & \multirow{3}{*}{0,001} \\
\hline & 7 & $442 / 848$ & 52,1 & & \\
\hline & 8 & $406 / 921$ & 44,1 & & \\
\hline \multirow{3}{*}{ (A) } & 6 & $35 / 837$ & 4,2 & \multirow{3}{*}{0,054} & \multirow{3}{*}{0,067} \\
\hline & 7 & $51 / 848$ & 6,0 & & \\
\hline & 8 & $34 / 921$ & 3,7 & & \\
\hline \multirow{3}{*}{ Ad } & 6 & $83 / 837$ & 9,9 & \multirow{3}{*}{0,149} & \multirow{3}{*}{0,130} \\
\hline & 7 & $69 / 848$ & 8,1 & & \\
\hline & 8 & $100 / 921$ & 10,9 & & \\
\hline \multirow{3}{*}{ (Ad) } & 6 & $11 / 837$ & 1,3 & \multirow{3}{*}{0,505} & \multirow{3}{*}{0,511} \\
\hline & 7 & $10 / 848$ & 1,2 & & \\
\hline & 8 & $7 / 921$ & 0,8 & & \\
\hline \multirow{3}{*}{$\sum \mathbf{A}$} & 6 & $560 / 837$ & 66,91 & \multirow{3}{*}{$<0,001$} & \multirow{3}{*}{$<0,001$} \\
\hline & 7 & $572 / 848$ & 67,45 & & \\
\hline & 8 & $547 / 921$ & 59,39 & & \\
\hline \multirow{3}{*}{$\mathbf{H}$} & 6 & $35 / 837$ & 4,2 & \multirow{3}{*}{0,008} & \multirow{3}{*}{0,008} \\
\hline & 7 & $33 / 848$ & 3,9 & & \\
\hline & 8 & $63 / 921$ & 6,8 & & \\
\hline \multirow{3}{*}{ (H) } & 6 & $51 / 837$ & 6,1 & \multirow{3}{*}{0,004} & \multirow{3}{*}{$\mathbf{0 , 0 0 3}$} \\
\hline & 7 & $25 / 848$ & 2,9 & & \\
\hline & 8 & $33 / 921$ & 3,6 & & \\
\hline \multirow{3}{*}{ Hd } & 6 & $24 / 837$ & 2,9 & 0630 & 0677 \\
\hline & 7 & $25 / 848$ & 2,9 & 0,039 & $0,0 / 2$ \\
\hline & 8 & $33 / 921$ & 3,6 & & \\
\hline & 6 & $15 / 837$ & 1,8 & & \\
\hline (Hd) & 7 & $16 / 848$ & 1,9 & 0,713 & 0,721 \\
\hline & 8 & $13 / 921$ & 1,4 & & \\
\hline & 6 & $125 / 837$ & 14,93 & & \\
\hline$\sum \mathbf{H}$ & 7 & $99 / 848$ & 11,67 & 0,052 & 0,058 \\
\hline & 8 & $142 / 1169$ & 12,15 & & \\
\hline & 6 & $21 / 837$ & 2,5 & 0653 & 0657 \\
\hline Anat & 7 & $27 / 848$ & 3,2 & 0,053 & ( \\
\hline & 8 & $29 / 921$ & 3,1 & & \\
\hline & 6 & $4 / 837$ & 0,5 & 0841 & 0807 \\
\hline Sg & 7 & $4 / 848$ & 0,5 & 0,841 & 0,802 \\
\hline & 8 & $6 / 921$ & 0,7 & & \\
\hline & 6 & - & - & & \\
\hline Sex & 7 & - & - & - & - \\
\hline & 8 & - & - & & \\
\hline
\end{tabular}




\begin{tabular}{|c|c|c|c|c|c|}
\hline Variável & Idade & Proporção & $\%$ & $p$-valor & $p$-valor ajustado \\
\hline \multirow{3}{*}{ Obj } & 6 & $59 / 837$ & 7,0 & \multirow{3}{*}{0,447} & \multirow[t]{3}{*}{0,472} \\
\hline & 7 & $67 / 848$ & 7,9 & & \\
\hline & 8 & $80 / 921$ & 8,7 & & \\
\hline \multirow{3}{*}{ Art } & 6 & $3 / 837$ & 0,4 & \multirow{3}{*}{0,034} & \multirow{3}{*}{$\mathbf{0 , 0 3 3}$} \\
\hline & 7 & $3 / 848$ & 0,4 & & \\
\hline & 8 & $12 / 921$ & 1,3 & & \\
\hline \multirow{3}{*}{ Arq } & 6 & $5 / 837$ & 0,6 & \multirow{3}{*}{0,228} & \multirow{3}{*}{0,217} \\
\hline & 7 & $12 / 848$ & 1,4 & & \\
\hline & 8 & $8 / 921$ & 0,9 & & \\
\hline \multirow{3}{*}{ Simb } & 6 & $2 / 837$ & 0,2 & \multirow{3}{*}{0,107} & \multirow{3}{*}{0,104} \\
\hline & 7 & $10 / 848$ & 1,2 & & \\
\hline & 8 & $10 / 921$ & 1,1 & & \\
\hline \multirow{3}{*}{ Abst } & 6 & $2 / 837$ & 0,2 & \multirow{3}{*}{0,996} & \multirow{3}{*}{0,997} \\
\hline & 7 & $0 / 848$ & 0,0 & & \\
\hline & 8 & $0 / 921$ & 0,0 & & \\
\hline \multirow{3}{*}{ Bot } & 6 & $24 / 837$ & 2,9 & \multirow{3}{*}{0,057} & \multirow{3}{*}{0,047} \\
\hline & 7 & $24 / 848$ & 2,8 & & \\
\hline & 8 & $43 / 921$ & 4,7 & & \\
\hline \multirow{3}{*}{ Geo } & 6 & $9 / 837$ & 1,1 & \multirow{3}{*}{0,763} & \multirow{3}{*}{0,756} \\
\hline & 7 & $12 / 848$ & 1,4 & & \\
\hline & 8 & $10 / 921$ & 1,1 & & \\
\hline \multirow{3}{*}{ Nat } & 6 & $3 / 837$ & 0,4 & \multirow{3}{*}{0,991} & \multirow{3}{*}{0,994} \\
\hline & 7 & $0 / 848$ & 0,0 & & \\
\hline & 8 & $3 / 921$ & 0,3 & & \\
\hline \multirow{3}{*}{ Pais } & 6 & $3 / 837$ & 0,4 & \multirow{3}{*}{0,404} & \multirow{3}{*}{0,417} \\
\hline & 7 & $2 / 848$ & 0,2 & & \\
\hline & 8 & $6 / 921$ & 0,7 & & \\
\hline \multirow{3}{*}{ Elem } & 6 & $4 / 837$ & 0,5 & & \\
\hline & 7 & $4 / 848$ & 0,5 & 0,216 & 0,209 \\
\hline & 8 & $10 / 921$ & 1,1 & & \\
\hline & 6 & $13 / 837$ & 1,6 & 0.034 & \\
\hline Frag & 7 & $12 / 848$ & 1,4 & 0,934 & 0,931 \\
\hline & 8 & $15 / 921$ & 1,6 & & \\
\hline & 6 & $168 / 837$ & 20,1 & 0164 & 0170 \\
\hline Ban & 7 & $160 / 848$ & 18,9 & 0,104 & $0,1 / 0$ \\
\hline & 8 & $153 / 921$ & 16,6 & & \\
\hline
\end{tabular}

Os dados desta análise apontaram que outras dez das 54 variáveis do Rorschach apresentaram diferenças estatisticamente significativas em função do ano de vida da criança. São elas: G, Dd, K, CF, A, $\sum$ A H, (H), Art e Bot.

Conforme se observa na Tabela 18, as crianças de seis anos apresentaram maior frequiência de respostas globais $[\mathrm{G}]$ em detrimento das demais faixas etárias, principalmente 
se comparadas às crianças de oito anos. Estas, por sua vez, apresentaram maior ocorrência de respostas pequeno detalhe [Dd], sobretudo em relação às crianças de seis anos.

No que diz respeito aos determinantes, as diferenças manifestaram-se apenas nas variáveis $\mathrm{K}$ e CF. As crianças de oito anos apresentaram média mais elevada na variável $\mathrm{K}$, fazendo pensar que as crianças mais velhas sinalizaram indicativos de processos analíticointerpretativos mais elaborados e com maior dinamismo que as mais novas. Estes dados foram ainda sugestivos de maior agilidade no processamento imaginativo e associativo nas crianças de maior idade desta amostra. Isso, em princípio, confirma o percurso do desenvolvimento humano geral em termos psíquicos. No tocante ao conteúdo $\mathrm{CF}$, observou-se que este foi mais freqüentemente reportado pelas crianças de seis anos, sugerindo maior influência da afetividade com reduzido controle racional na determinação das respostas das crianças mais novas da amostra aqui avaliada e, por conseguinte, na sua interpretação da realidade como um todo.

As demais diferenças estatisticamente significativas ocorreram na categoria dos conteúdos, envolvendo as variáveis de conteúdo animal $[\mathrm{A}, \Sigma \mathrm{A}]$, de conteúdo humano $[\mathrm{H}$, (H)] e conteúdos artístico [Art] e botânico [Bot]. O conteúdo $H$ foi mais referido pelas crianças mais velhas, sugerindo que estas tenham mais forte identificação e interesse pelo contato humano em relação às mais novas. $\mathrm{Na}$ realidade, a elevada freqüência da variável $\mathrm{H}$ nas crianças mais velhas é forçosamente atrelada ao maior número de respostas $\mathrm{K}$ desse subgrupo, dado que neste está implícito (por definição técnica) o conteúdo humano. Já o conteúdo $(\mathrm{H})$, contrariamente ao anterior, apresentou-se mais freqüente nas crianças de seis anos. Este, por sua vez, está relacionado a conteúdos fantasiosos e marcados por características pára - humanas sendo, de fato, mais comumente esperados em crianças de mais tenra idade. As respostas de conteúdo animal também foram mais freqüentes nas crianças mais novas. Essa maior identificação com a categoria animal pode sinalizar maior imaturidade e estereotipia do pensamento por parte das crianças mais novas, o que também seria esperado, de acordo com o desenvolvimento maturacional.

Os conteúdos Art e Bot, por sua vez, foram mais aludidos pelas crianças de oito anos. No entanto, cabe lembrar que estas variáveis tiveram freqüência bastante reduzida no conjunto total dos resultados, tornando esta evidência empírica pouco expressiva.

Considerando as análises comparativas apresentadas, nota-se que a variável idade foi aquela que pareceu exercer maior efeito no conjunto de respostas das crianças avaliadas pelo Método de Rorschach. No entanto, inexistem evidências suficientes que justifiquem a necessidade de elaboração de referenciais normativos específicos paras as crianças de seis, 
sete e oito anos, respectivamente. Apesar desta decisão técnica, faz-se necessário que as avaliações clínicas por meio do Rorschach considerem e ponderem suficientemente sobre essas diferenças empirias atuais. Deste modo, poder-se-á contribuir para a adequada interpretação dos resultados referentes ao Rorschach. Com o intuito de facilitar a identificação destas diferenças entre essas variáveis, julgou-se pertinente, neste momento, apresentar os dados descritivos específicos das idades aqui avaliadas e que estão dispostos nas Tabelas 19, 20 e 21.

Tabela 19 - Dados descritivos e porcentagens médias das variáveis do Rorschach para o grupo de crianças de seis anos $(n=60)$

\begin{tabular}{|c|c|c|c|c|c|c|}
\hline Variáveis & Mediana & Média & $\begin{array}{l}\text { Desvio- } \\
\text { padrão }\end{array}$ & Média (\%) & Mínimo & Máximo \\
\hline $\mathbf{R}$ & 13,0 & 14,0 & 3,8 & - & 9,0 & 26,0 \\
\hline RA & 0,0 & 0,2 & 0,5 & - & 0,0 & 3,0 \\
\hline Rec & 0,0 & 0,1 & 0,3 & - & 0,0 & 1,0 \\
\hline Den & 0,0 & 0,1 & 0,3 & - & 0,0 & 1,0 \\
\hline TLm $^{7}$ & 12,8 & 15,4 & 9,9 & - & 3,7 & 49,0 \\
\hline TRm & 27,7 & 30,5 & 12,7 & - & 15,1 & 80,2 \\
\hline G & 5,0 & 5,9 & 1,8 & 42,0 & 3,0 & 10,0 \\
\hline D & 6,0 & 6,0 & 3,5 & 43,1 & 0,0 & 17,0 \\
\hline Dd & 2,0 & 2,0 & 1,5 & 14,3 & 0,0 & 6,0 \\
\hline Dbl & 0,0 & 0,1 & 0,3 & 0,6 & 0,0 & 1,0 \\
\hline Do & 0,0 & 0,0 & 0,0 & 0,0 & 0,0 & 0,0 \\
\hline$F+$ & 6,0 & 6,3 & 2,9 & 45,3 & 2,0 & 13,0 \\
\hline $\mathbf{F}+-$ & 0,0 & 0,0 & 0,2 & 0,1 & 0,0 & 1,0 \\
\hline F- & 2,0 & 2,7 & 1,5 & 19,2 & 0,0 & 7,0 \\
\hline$\sum \mathbf{F}$ & 8,0 & 9,0 & 3,5 & 64,8 & 4,0 & 17,0 \\
\hline $\mathbf{K}$ & 0,0 & 0,4 & 0,9 & 2,7 & 0,0 & 6,0 \\
\hline kan & 1,0 & 1,0 & 1,0 & 7,4 & 0,0 & 4,0 \\
\hline kob & 0,0 & 0,0 & 0,1 & 0,1 & 0,0 & 1,0 \\
\hline kp & 0,0 & 0,0 & 0,1 & 0,1 & 0,0 & 1,0 \\
\hline$\sum \mathbf{k}$ & 1,0 & 1,1 & 1,0 & 7,6 & 0,0 & 4,0 \\
\hline FC & 1,0 & 1,7 & 1,5 & 12,2 & 0,0 & 6,0 \\
\hline $\mathbf{C F}$ & 1,0 & 0,9 & 1,0 & 6,1 & 0,0 & 4,0 \\
\hline C & 0,0 & 0,2 & 0,5 & 1,4 & 0,0 & 2,0 \\
\hline FE & 0,0 & 0,4 & 0,6 & 2,7 & 0,0 & 2,0 \\
\hline $\mathbf{E F}$ & 0,0 & 0,3 & 0,5 & 2,2 & 0,0 & 2,0 \\
\hline $\mathbf{E}$ & 0,0 & 0,0 & 0,1 & 0,1 & 0,0 & 1,0 \\
\hline Fclob & 0,0 & 0,0 & 0,1 & 0,1 & 0,0 & 1,0 \\
\hline ClobF & 0,0 & 0,0 & 0,0 & 0,0 & 0,0 & 0,0 \\
\hline
\end{tabular}

${ }^{7} \mathrm{O}$ tempo de latência médio (TLm) e o tempo de reação médio (TRm) estão expressos em segundos. 
conclusão

\begin{tabular}{ccccccc}
\hline Variáveis & Mediana & Média & $\begin{array}{c}\text { Desvio- } \\
\text { padrão }\end{array}$ & Média $(\%)$ & Mínimo & Máximo \\
\hline Clob & 0,0 & 0,0 & 0,0 & 0,0 & 0,0 & 0,0 \\
\hline A & 7,0 & 7,2 & 3,2 & 51,5 & 2,0 & 16,0 \\
\hline (A) & 0,0 & 0,6 & 0,8 & 4,2 & 0,0 & 3,0 \\
\hline Ad & 1,0 & 1,4 & 1,5 & 9,9 & 0,0 & 6,0 \\
\hline (Ad) & 0,0 & 0,2 & 0,4 & 1,3 & 0,0 & 2,0 \\
\hline$\sum$ A & 9,0 & 9,3 & 3,5 & 66,9 & 2,0 & 21,0 \\
\hline H & 0,0 & 0,6 & 1,1 & 4,2 & 0,0 & 6,0 \\
\hline (H) & 0,0 & 0,9 & 1,1 & 6,1 & 0,0 & 4,0 \\
\hline Hd & 0,0 & 0,4 & 0,7 & 2,9 & 0,0 & 3,0 \\
(Hd) & 0,0 & 0,3 & 0,6 & 1,8 & 0,0 & 3,0 \\
\hline$\sum \mathbf{H}$ & 2,0 & 2,1 & 2,0 & 14,9 & 0,0 & 9,0 \\
\hline Anat & 0,0 & 0,4 & 0,7 & 2,5 & 0,0 & 3,0 \\
\hline Sg & 0,0 & 0,1 & 0,4 & 0,5 & 0,0 & 2,0 \\
\hline Sex & 0,0 & 0,0 & 0,0 & 0,0 & 0,0 & 0,0 \\
\hline Obj & 1,0 & 1,0 & 1,2 & 7,0 & 0,0 & 6,0 \\
\hline Art & 0,0 & 0,1 & 0,2 & 0,4 & 0,0 & 1,0 \\
\hline Arq & 0,0 & 0,1 & 0,3 & 0,6 & 0,0 & 2,0 \\
\hline Simb & 0,0 & 0,0 & 0,2 & 0,2 & 0,0 & 1,0 \\
\hline Abs & 0,0 & 0,0 & 0,2 & 0,2 & 0,0 & 1,0 \\
\hline Bot & 0,0 & 0,4 & 1,0 & 2,9 & 0,0 & 5,0 \\
\hline Geo & 0,0 & 0,2 & 0,4 & 1,1 & 0,0 & 1,0 \\
\hline Nat & 0,0 & 0,1 & 0,2 & 0,4 & 0,0 & 1,0 \\
\hline Pais & 0,0 & 0,1 & 0,2 & 0,4 & 0,0 & 1,0 \\
\hline Elem & 0,0 & 0,1 & 0,3 & 0,5 & 0,0 & 1,0 \\
\hline Frag & 0,0 & 0,2 & 0,5 & 1,6 & 0,0 & 2,0 \\
\hline Ban & 3,0 & 2,8 & 1,3 & 20,1 & 0,0 & 6,0 \\
\hline & & & & & & \\
\hline & 0,0 & & \\
\hline & 0,0 & & \\
\hline
\end{tabular}


Tabela 20 - Dados descritivos e porcentagens médias das variáveis do Rorschach para o grupo de crianças de sete anos $(n=60)$.

\begin{tabular}{ccccccc}
\hline Variáveis & Mediana & Média & $\begin{array}{c}\text { Desvio- } \\
\text { padrão }\end{array}$ & Média $(\boldsymbol{\%})$ & Mínimo & Máximo \\
\hline R & 13,0 & 14,1 & 3,6 & - & 10,0 & 29,0 \\
\hline RA & 0,0 & 0,1 & 0,4 & - & 0,0 & 2,0 \\
\hline Rec & 0,0 & 0,1 & 0,3 & - & 0,0 & 1,0 \\
\hline Den & 0,0 & 0,1 & 0,2 & - & 0,0 & 1,0 \\
\hline TLm & 11,3 & 15,2 & 13,8 & - & 1,6 & 97,0 \\
\hline TRm & 27,2 & 30,6 & 12,6 & - & 16,0 & 75,3 \\
\hline G & 5,0 & 5,5 & 2,8 & 39,0 & 1,0 & 19,0 \\
\hline D & 6,0 & 6,3 & 3,2 & 44,6 & 1,0 & 21,0 \\
\hline Dd & 2,0 & 2,2 & 2,0 & 15,4 & 0,0 & 12,0 \\
\hline Dbl & 0,0 & 0,1 & 0,3 & 0,9 & 0,0 & 1,0 \\
\hline Do & 0,0 & 0,0 & 0,0 & 0,0 & 0,0 & 0,0 \\
\hline F+ & 7,0 & 6,7 & 2,6 & 47,1 & 1,0 & 16,0 \\
\hline F+- & 0,0 & 0,0 & 0,0 & 0,0 & 0,0 & 0,0 \\
\hline F- & 2,5 & 2,9 & 2,0 & 20,5 & 0,0 & 11,0 \\
\hline$\sum \mathbf{F}$ & 9,0 & 9,3 & 3,1 & 67,6 & 5,0 & 22,0 \\
\hline K & 0,0 & 0,3 & 0,5 & 2,1 & 0,0 & 2,0 \\
\hline kan & 1,0 & 1,1 & 1,0 & 7,7 & 0,0 & 4,0 \\
\hline kob & 0,0 & 0,1 & 0,2 & 0,4 & 0,0 & 1,0 \\
\hline kp & 0,0 & 0,1 & 0,3 & 0,5 & 0,0 & 2,0 \\
\hline$\sum \mathbf{k}$ & 1,0 & 1,2 & 1,2 & 8,5 & 0,0 & 5,0 \\
\hline FC & 1,0 & 1,7 & 1,3 & 11,8 & 0,0 & 6,0 \\
\hline CF & 0,0 & 0,6 & 1,1 & 3,9 & 0,0 & 7,0 \\
\hline C & 0,0 & 0,2 & 0,5 & 1,1 & 0,0 & 3,0 \\
\hline FE & 0,5 & 0,6 & 0,6 & 3,9 & 0,0 & 2,0 \\
\hline EF & 0,0 & 0,2 & 0,4 & 1,2 & 0,0 & 1,0 \\
\hline E & 0,0 & 0,0 & 0,0 & 0,0 & 0,0 & 0,0 \\
\hline Fclob & 0,0 & 0,0 & 0,0 & 0,0 & 0,0 & 0,0 \\
\hline ClobF & 0,0 & 0,0 & 0,0 & 0,0 & 0,0 & 0,0 \\
\hline Clob & 0,0 & 0,0 & 0,0 & 0,0 & 0,0 & 0,0 \\
\hline A & 7,0 & 7,4 & 2,9 & 52,1 & 2,0 & 22,0 \\
\hline (A) & 0,0 & 0,9 & 1,1 & 6,0 & 0,0 & 5,0 \\
\hline Ad & 1,0 & 1,2 & 1,4 & 8,1 & 0,0 & 5,0 \\
\hline Ad) & 0,0 & 0,2 & 0,4 & 1,2 & 0,0 & 2,0 \\
\hline$\sum$ A & 9,0 & 9,5 & 2,9 & 67,5 & 3,0 & 23,0 \\
\hline H & 0,0 & 0,6 & 0,9 & 3,9 & 0,0 & 3,0 \\
\hline H) & 0,0 & 0,4 & 0,8 & 2,9 & 0,0 & 4,0 \\
\hline $\mathbf{H d )}$ & 0,0 & 0,4 & 0,8 & 2,9 & 0,0 & 4,0 \\
\hline & 0,0 & 0,3 & 0,7 & 1,9 & 0,0 & 4,0 \\
\hline & & & & & & $c 0 n t i n u a$ \\
\hline
\end{tabular}

\footnotetext{
${ }^{8} \mathrm{O}$ tempo de latência médio (TLm) e o tempo de reação médio (TRm) estão expressos em segundos.
} 
conclusão

\begin{tabular}{ccccccc}
\hline Variáveis & Mediana & Média & $\begin{array}{c}\text { Desvio- } \\
\text { padrão }\end{array}$ & Média (\%) & Mínimo & Máximo \\
\hline$\sum$ H & 1,0 & 1,7 & 1,4 & 11,7 & 0,0 & 6,0 \\
\hline Anat & 0,0 & 0,5 & 0,9 & 3,2 & 0,0 & 6,0 \\
\hline Sg & 0,0 & 0,1 & 0,4 & 0,5 & 0,0 & 2,0 \\
\hline Sex & 0,0 & 0,0 & 0,0 & 0,0 & 0,0 & 0,0 \\
\hline Obj & 1,0 & 1,1 & 1,2 & 7,9 & 0,0 & 6,0 \\
\hline Art & 0,0 & 0,1 & 0,2 & 0,4 & 0,0 & 1,0 \\
\hline Arq & 0,0 & 0,2 & 0,5 & 1,4 & 0,0 & 3,0 \\
\hline Simb & 0,0 & 0,2 & 0,4 & 1,2 & 0,0 & 1,0 \\
\hline Abs & 0,0 & 0,0 & 0,0 & 0,0 & 0,0 & 0,0 \\
\hline Bot & 0,0 & 0,4 & 0,8 & 2,8 & 0,0 & 4,0 \\
\hline Geo & 0,0 & 0,2 & 0,5 & 1,4 & 0,0 & 2,0 \\
\hline Nat & 0,0 & 0,0 & 0,0 & 0,0 & 0,0 & 0,0 \\
\hline Pais & 0,0 & 0,0 & 0,2 & 0,2 & 0,0 & 1,0 \\
\hline Elem & 0,0 & 0,1 & 0,3 & 0,5 & 0,0 & 1,0 \\
\hline Frag & 0,0 & 0,2 & 0,4 & 1,4 & 0,0 & 2,0 \\
\hline Ban & 2,5 & 2,7 & 1,2 & 18,9 & 0,0 & 6,0 \\
\hline
\end{tabular}


Tabela 21 - Dados descritivos e porcentagens médias das variáveis do Rorschach para o grupo de crianças de oito anos $(n=60)$.

\begin{tabular}{ccccccc}
\hline Variáveis & Mediana & Média & $\begin{array}{c}\text { Desvio- } \\
\text { padrão }\end{array}$ & Média $(\boldsymbol{\%})$ & Mínimo & Máximo \\
\hline R & 14,0 & 15,4 & 5,0 & - & 10,0 & 34,0 \\
\hline RA & 0,0 & 0,2 & 0,5 & - & 0,0 & 2,0 \\
\hline Rec & 0,0 & 0,1 & 0,3 & - & 0,0 & 1,0 \\
\hline Den & 0,0 & 0,0 & 0,1 & - & 0,0 & 1,0 \\
\hline TLm & 10,3 & 11,9 & 6,7 & - & 4,0 & 35,7 \\
\hline TRm & 23,6 & 25,2 & 8,6 & - & 2,9 & 50,1 \\
\hline G & 5,0 & 5,4 & 2,6 & 35,3 & 1,0 & 15,0 \\
\hline D & 6,0 & 6,9 & 3,2 & 44,8 & 2,0 & 14,0 \\
\hline Dd & 2,0 & 3,0 & 3,8 & 19,8 & 0,0 & 20,0 \\
\hline Dbl & 0,0 & 0,0 & 0,1 & 0,1 & 0,0 & 1,0 \\
\hline Do & 0,0 & 0,0 & 0,0 & 0,0 & 0,0 & 0,0 \\
\hline F+ & 6,5 & 6,8 & 3,0 & 44,5 & 1,0 & 15,0 \\
\hline F+- & 0,0 & 0,0 & 0,1 & 0,1 & 0,0 & 1,0 \\
\hline F- & 3,0 & 3,4 & 2,4 & 22,1 & 0,0 & 11,0 \\
\hline$\sum \mathbf{F}$ & 10,0 & 10,3 & 4,1 & 66,8 & 2,0 & 26,0 \\
\hline K & 0,0 & 0,7 & 0,9 & 4,3 & 0,0 & 4,0 \\
\hline kan & 1,0 & 1,0 & 1,0 & 6,3 & 0,0 & 3,0 \\
\hline kob & 0,0 & 0,1 & 0,3 & 0,5 & 0,0 & 1,0 \\
\hline kp & 0,0 & 0,1 & 0,2 & 0,3 & 0,0 & 1,0 \\
\hline$\sum \mathbf{k}$ & 1,0 & 1,1 & 1,1 & 7,2 & 0,0 & 5,0 \\
\hline FC & 1,0 & 1,6 & 1,2 & 10,1 & 0,0 & 4,0 \\
\hline CF & 0,0 & 0,6 & 0,9 & 3,9 & 0,0 & 4,0 \\
\hline C & 0,0 & 0,2 & 0,5 & 1,2 & 0,0 & 2,0 \\
\hline FE & 0,5 & 0,7 & 1,0 & 4,7 & 0,0 & 5,0 \\
\hline EF & 0,0 & 0,3 & 0,4 & 1,7 & 0,0 & 1,0 \\
\hline E & 0,0 & 0,0 & 0,1 & 0,1 & 0,0 & 1,0 \\
\hline Fclob & 0,0 & 0,0 & 0,0 & 0,0 & 0,0 & 0,0 \\
\hline ClobF & 0,0 & 0,0 & 0,0 & 0,0 & 0,0 & 0,0 \\
\hline Clob & 0,0 & 0,0 & 0,0 & 0,0 & 0,0 & 0,0 \\
\hline A & 7,0 & 6,8 & 3,2 & 44,1 & 1,0 & 18,0 \\
\hline (A) & 0,0 & 0,6 & 0,8 & 3,7 & 0,0 & 4,0 \\
\hline Ad & 1,0 & 1,7 & 1,7 & 10,9 & 0,0 & 6,0 \\
\hline Ad) & 0,0 & 0,1 & 0,3 & 0,8 & 0,0 & 1,0 \\
\hline$\sum$ A & 9,0 & 9,1 & 3,7 & 59,4 & 2,0 & 19,0 \\
\hline H & 1,0 & 1,1 & 1,0 & 6,8 & 0,0 & 4,0 \\
\hline H) & 0,0 & 0,6 & 0,7 & 3,6 & 0,0 & 3,0 \\
\hline Hd & 0,0 & 0,6 & 1,0 & 3,6 & 0,0 & 4,0 \\
\hline & 0,0 & 0,2 & 0,5 & 1,4 & 0,0 & 2,0 \\
\hline & & & & & & $c 0 n t i n u a$ \\
\hline
\end{tabular}

\footnotetext{
${ }^{9} \mathrm{O}$ tempo de latência médio (TLm) e o tempo de reação médio (TRm) estão expressos em segundos.
} 
conclusão

\begin{tabular}{ccccccc}
\hline Variáveis & Mediana & Média & $\begin{array}{c}\text { Desvio- } \\
\text { padrão }\end{array}$ & Média (\%) & Mínimo & Máximo \\
\hline$\sum \mathbf{H}$ & 2,0 & 2,4 & 1,9 & 15,4 & 0,0 & 10,0 \\
\hline Anat & 0,0 & 0,5 & 0,7 & 3,1 & 0,0 & 2,0 \\
\hline Sg & 0,0 & 0,1 & 0,4 & 0,7 & 0,0 & 2,0 \\
\hline Sex & 0,0 & 0,0 & 0,0 & 0,0 & 0,0 & 0,0 \\
\hline Obj & 1,0 & 1,3 & 1,4 & 8,7 & 0,0 & 6,0 \\
\hline Art & 0,0 & 0,2 & 0,5 & 1,3 & 0,0 & 2,0 \\
\hline Arq & 0,0 & 0,1 & 0,3 & 0,9 & 0,0 & 1,0 \\
\hline Simb & 0,0 & 0,2 & 0,4 & 1,1 & 0,0 & 2,0 \\
\hline Abs & 0,0 & 0,0 & 0,0 & 0,0 & 0,0 & 0,0 \\
\hline Bot & 0,0 & 0,7 & 1,1 & 4,7 & 0,0 & 6,0 \\
\hline Geo & 0,0 & 0,2 & 0,5 & 1,1 & 0,0 & 2,0 \\
\hline Nat & 0,0 & 0,1 & 0,2 & 0,3 & 0,0 & 1,0 \\
\hline Pais & 0,0 & 0,1 & 0,4 & 0,7 & 0,0 & 2,0 \\
\hline Elem & 0,0 & 0,2 & 0,5 & 1,1 & 0,0 & 2,0 \\
\hline Frag & 0,0 & 0,3 & 0,5 & 1,6 & 0,0 & 2,0 \\
\hline Ban & 2,0 & 2,6 & 1,3 & 16,6 & 0,0 & 6,0 \\
\hline
\end{tabular}

\subsection{Síntese das comparacões estatísticas e dos resultados descritivos no Rorschach do total}

\section{$\underline{\text { da amostra }}$}

Após explorar especificamente o possível efeito do sexo, da origem escolar e da idade nas variáveis codificadas do Rorschach, tornou-se viável a composição de uma tabela descritiva e analítica para dar visibilidade ao conjunto total dos dados, considerando-se onde foram detectadas as diferenças estatisticamente significativas. Na prática clínica da Escola Psicanalítica Francesa do Rorschach os dados são geralmente ponderados a partir do número total de respostas do protocolo e as análises interpretativas são comumente pautadas em variáveis expressas em porcentagens, compondo os dados do psicograma. Dessa forma, julgou-se necessário apresentar também a síntese quantitativa expressa em porcentagem, de modo a facilitar as análises por parte dos profissionais da área.

A Tabela 22 sumariza o perfil global da amostra avaliada, apontando as estatísticas descritivas e os resultados da síntese quantitativa das 54 variáveis da Escola Psicanalítica Francesa do Rorschach abordadas neste estudo. Esses dados objetivam funcionar como parâmetros normativos atuais (pelo menos preliminares) para as crianças de seis a oito anos de idade. 
Tabela 22 - Resultados descritivos e inferenciais das variáveis do Rorschach na amostra geral $(\mathrm{N}=180)$.

\begin{tabular}{|c|c|c|c|c|c|c|c|}
\hline Variáveis & Mediana & Média & $\begin{array}{l}\text { Desvio- } \\
\text { padrão }\end{array}$ & $\begin{array}{c}\text { Média } \\
(\%)\end{array}$ & Mínimo & Máximo & $\begin{array}{c}\text { Diferenças } \\
\text { estatisticamente } \\
\text { significativas } \\
\text { entre } \\
\text { subgrupos } \\
\end{array}$ \\
\hline $\mathbf{R}$ & 13,0 & 14,5 & 4,2 & - & 9,0 & 34,0 & $\begin{array}{c}\text { Part }>\text { Pub } \\
8>7>6\end{array}$ \\
\hline RA & 0,0 & 0,9 & 0,5 & - & 0,0 & 3,0 & \\
\hline Rec & 0,0 & 0,1 & 0,3 & - & 0,0 & 1,0 & \\
\hline Den & 0,0 & 0,0 & 0,2 & - & 0,0 & 1,0 & \\
\hline TLm $^{11}$ & 11,6 & 14,2 & 10,6 & - & 1,6 & 97,0 & Fem $>$ Masc, \\
\hline TRm & 25,6 & 28,8 & 11,6 & - & 2,9 & 80,2 & $\begin{array}{c}\text { Fem }>\text { Masc } \\
\text { Pub }>\text { Part } \\
6=7>8\end{array}$ \\
\hline $\mathbf{G}$ & 5,0 & 5,6 & 2,4 & 38,6 & 1,0 & 19,0 & $\begin{array}{c}\text { Masc }>\text { Fem, } \\
\text { Pub }>\text { Part, } \\
6>7>8\end{array}$ \\
\hline $\mathbf{D}$ & 6,0 & 6,4 & 3,3 & 44,2 & 0,0 & 21,0 & Fem $>$ Masc \\
\hline Dd & 2,0 & 2,4 & 2,7 & 16,6 & 0,0 & 20,0 & $\begin{array}{l}\text { Part }>\text { Pub, } \\
8>7>6\end{array}$ \\
\hline Dbl & 0,0 & 0,1 & 0,3 & 0,5 & 0,0 & 1,0 & \\
\hline Do & 0,0 & 0,0 & 0,0 & 0,0 & 0,0 & 0,0 & \\
\hline $\mathbf{F +}$ & 6,0 & 6,6 & 2,8 & 68,8 & 1,0 & 16,0 & \\
\hline $\mathbf{F + -}$ & 0,0 & 0,0 & 0,1 & 0,1 & 0,0 & 1,0 & \\
\hline F- & 3,0 & 3,0 & 2,0 & 20,7 & 0,0 & 11,0 & Masc $>$ Fem, \\
\hline$\sum \mathbf{F}$ & 9,0 & 9,6 & 3,6 & 66,4 & 2,0 & 26,0 & \\
\hline $\mathbf{K}$ & 0,0 & 0,5 & 0,8 & 3,1 & 0,0 & 6,0 & $8>6>7$ \\
\hline kan & 1,0 & 1,0 & 0,1 & 7,1 & 0,0 & 4,0 & \\
\hline kob & 0,0 & 0,1 & 0,2 & 0,3 & 0,0 & 1,0 & \\
\hline kp & 0,0 & 0,0 & 0,2 & 0,3 & 0,0 & 2,0 & \\
\hline$\sum \mathbf{k}$ & 1,0 & 1,1 & 1,1 & 7,7 & 0,0 & 5,0 & \\
\hline FC & 1,0 & 1,6 & 1,3 & 11,3 & 0,0 & 6,0 & \\
\hline $\mathbf{C F}$ & 0,0 & 0,7 & 1,0 & 4,6 & 0,0 & 7,0 & $6>7=8$ \\
\hline $\mathrm{C}$ & 0,0 & 0,9 & 0,5 & 1,2 & 0,0 & 3,0 & Pub $>$ Part \\
\hline FE & 0,0 & 0,6 & 0,7 & 3,8 & 0,0 & 5,0 & \\
\hline EF & 0,0 & 0,2 & 0,5 & 1,7 & 0,0 & 2,0 & \\
\hline $\mathbf{E}$ & 0,0 & 0,0 & 0,1 & 0,1 & 0,0 & 1,0 & \\
\hline
\end{tabular}

continua

${ }^{10}$ Os subgrupos serão assim identificados: relativos ao sexo $(\mathrm{Fem}=$ sexo feminino e Masc= sexo masculino), à idade $(9=9$ anos; $10=10$ anos e $11=11$ anos) e à origem escolar (Pub= escola pública e Part= escola particular).

${ }^{11} \mathrm{O}$ tempo de latência médio (TLm) e o tempo de reação médio (TRm) estão expressos em segundos. 
conclusão

Diferenças

Variáveis Mediana Média

Desvio- Média padrão

$(\%)$

estatisticamente

significativas

entre

subgrupos

\begin{tabular}{|c|c|c|c|c|c|c|c|}
\hline FClob & 0,0 & 0,0 & 0,1 & - & 0,0 & 1,0 & \\
\hline ClobF & 0,0 & 0,0 & 0,0 & - & 0,0 & 0,0 & \\
\hline Clob & 0,0 & 0,0 & 0,0 & - & 0,0 & 0,0 & \\
\hline $\mathbf{A}$ & 7,0 & 7,1 & 3,1 & 49,1 & 1,0 & 22,0 & $7>6>8$ \\
\hline (A) & 0,0 & 0,7 & 0,9 & 4,6 & 0,0 & 5,0 & Masc $>$ Fem \\
\hline Ad & 1,0 & 1,4 & 1,5 & 9,7 & 0,0 & 6,0 & \\
\hline (Ad) & 0,0 & 0,2 & 0,4 & 1,1 & 0,0 & 2,0 & \\
\hline$\sum \mathbf{A}$ & 9,0 & 9,3 & 3,4 & 64,4 & 2,0 & 23,0 & $7>6>8$ \\
\hline $\mathbf{H}$ & 0,0 & 0,7 & 1,0 & 5,0 & 0,0 & 6,0 & $\begin{array}{c}\text { Fem }>\text { Masc } \\
8>6>7\end{array}$ \\
\hline (H) & 0,0 & 0,6 & 0,9 & 4,2 & 0,0 & 4,0 & $6>8>7$ \\
\hline Hd & 0,0 & 0,5 & 0,9 & 3,1 & 0,0 & 4,0 & Part $>$ Pub \\
\hline (Hd) & 0,0 & 0,2 & 0,6 & 1,7 & 0,0 & 4,0 & \\
\hline$\sum \mathbf{H}$ & 2,0 & 2,0 & 1,8 & 14,1 & 0,0 & 10,0 & \\
\hline Anat & 0,0 & 0,4 & 0,8 & 2,9 & 0,0 & 6,0 & \\
\hline $\mathrm{Sg}$ & 0,0 & 0,1 & 0,4 & 0,5 & 0,0 & 2,0 & \\
\hline Sex & 0,0 & 0,0 & 0,0 & 0,0 & 0,0 & 0,0 & \\
\hline Obj & 1,0 & 1,1 & 1,3 & 7,9 & 0,0 & 6,0 & \\
\hline Art & 0,0 & 0,1 & 0,4 & 0,7 & 0,0 & 2,0 & $8>7=6$ \\
\hline Arq & 0,0 & 0,1 & 0,4 & 0,9 & 0,0 & 3,0 & \\
\hline Simb & 0,0 & 0,1 & 0,4 & 0,8 & 0,0 & 2,0 & \\
\hline Abs & 0,0 & 0,0 & 0,1 & 0,1 & 0,0 & 1,0 & \\
\hline Bot & 0,0 & 0,5 & 1,0 & 3,5 & 0,0 & 6,0 & $\begin{array}{c}\text { Pub }>\text { Part } \\
8>7=6\end{array}$ \\
\hline Geo & 0,0 & 0,8 & 0,4 & 1,2 & 0,0 & 2,0 & \\
\hline Nat & 0,0 & 0,0 & 0,2 & 0,2 & 0,0 & 1,0 & \\
\hline Pais & 0,0 & 0,1 & 0,3 & 0,4 & 0,0 & 2,0 & \\
\hline Elem & 0,0 & 0,1 & 0,3 & 0,7 & 0,0 & 2,0 & \\
\hline Frag & 0,0 & 0,2 & 0,5 & 1,5 & 0,0 & 2,0 & \\
\hline Ban & 3,0 & 2,7 & 1,3 & 18,5 & 0,0 & 6,0 & \\
\hline
\end{tabular}

A tabela acima revela o predomínio de D (44,2\%) sobre G $(38,6 \%)$ e Dd $(16,6 \%)$, elevado índice de respostas unicamente determinadas pela forma $(\mathrm{F}=66,4 \%)$ e bons índices de qualidade formal $(\mathrm{F}+=68,8 \%)$. Os conteúdos mais evocados foram os conteúdos animal $(64,4 \%)$ e humano $(14,1 \%)$. É importante assinalar que estes referenciais devem ser examinados com devida parcimônia e compreensão de seu alcance técnico, de modo a garantir possibilidades interpretativas válidas e consistentes. 
Ainda pode-se observar que dentre as análises estatísticas inferenciais realizadas com as 54 variáveis do Rorschach, pode-se reconhecer 18 ocorrências de diferenças significativas, anotadas nesta Tabela 22. Estas evidências empíricas atuais sugerem que, na prática clínica, essas variáveis onde foram identificadas diferenças devam ser observadas atentamente pelo avaliador para adequada interpretação dos resultados do Rorschach.

\subsection{Atlas do Rorschach}

A partir de análises estatísticas específicas das áreas interpretadas pelas crianças estudadas e também da qualidade formal de suas respostas, conforme procedimento descrito anteriormente, realizou-se a sistematização do conjunto destas variáveis de forma a compor um Atlas de referência sobre o padrão de respostas de estudantes de seis a oito anos no Psicodiagnóstico de Rorschach (segundo referenciais da Escola Psicanalítica Francesa). Este material objetiva permitir a classificação atualizada dos recortes interpretativos das respostas (área $\mathrm{G}, \mathrm{D}, \mathrm{Dd}$ ou $\mathrm{Dbl}$ ), bem como do nível de precisão formal de suas análises (qualidade formal positiva, negativa ou imprecisa) e das respostas tidas como banais, oferecendo, dessa forma, recurso técnico atual e relevante para os profissionais da área de avaliação psicológica.

Embora seja resultado central neste trabalho, o Atlas em si será apresentado nos apêndices, dada a sua dimensão. As áreas interpretadas foram assinaladas e recortadas em ordem decrescente de sua frequiência na amostra avaliada.

Além disso, foram avaliadas quais respostas atingiram o critério para corresponder a uma resposta banal (Ban), considerada como bastante freqüente no grupo de referência. Esta análise teve por base os critérios adotados por Jacquemin (1976), respeitando-se os procedimentos descritos anteriormente. Esta lista atual das banalidades está apresentada na Tabela 23.

Tabela 23 - Lista de Banalidades obtidas com esta amostra $(\mathrm{N}=180)$

\begin{tabular}{cccc}
\hline Cartão & Resposta & Área & $\begin{array}{c}\text { Freqüiência } \\
\text { simples }\end{array}$ \\
\hline I & Cara de animal $($ com ou sem Dbl) & G & 49 \\
\hline I & Morcego $($ com ou sem Dbl) & G & 62 \\
\hline III & Laço $(\Lambda$ ou V) & D1 & 31 \\
\hline V & Borboleta $(\Lambda$ ou V $)$ & G & 41 \\
\hline V & Morcego $(\Lambda$ ou $V)$ & G & 64 \\
\hline VIII & Animais quadrúpedes & D1 & 64 \\
\hline $\mathbf{X}$ & Aranha & D1 & 56 \\
\hline
\end{tabular}


Pode-se observar na tabela 23 que os resultados obtidos com a amostra avaliada no presente estudo originaram reduzido número de respostas banais. Tendo em vista o critério (descrito anteriormente) de que uma resposta seria banal se ocorresse uma vez em cada seis participantes, é possível pensar que esta amostragem de 180 crianças tenha sido insuficiente para sustentar a pesquisa de banalidades, pois, foram consideradas banais as respostas que foram verbalizadas por, pelo menos, trinta crianças, numa área circunscrita específica do cartão. No entanto, considera-se que estas banalidades obtidas, em sua grande maioria com conteúdos zoomórficos, se constituem como esperadas nas crianças da faixa etária estudada. 
5. DISCUSSÃO 

Serão abordados, inicialmente, alguns aspectos metodológicos do presente trabalho, relacionados à precisão na classificação dos protocolos. Em uma comparação com estudos internacionais, foi possível observar que a avaliação dos casos por juízes independentes consiste em procedimento freqüentemente utilizado para estimar a precisão dos resultados no Psicodiagnóstico de Rorschach, conforme também apontado por Urbina (2007) e Fensterseifer e Werlang (2008). Tanto na presente pesquisa, realizada sob o referencial da Escola Psicanalítica Francesa, quanto nos estudos encontrados fundamentados no Sistema Compreensivo, o acordo encontrado entre examinadores (independentes e às cegas) foi o método eleito para cálculo do índice de fidedignidade dos dados. No entanto, foram detectadas algumas diferenças nos tipos de procedimento adotados para se estimar estes índices de concordância.

Conforme descrito anteriormente, neste estudo, foi calculado o índice final de precisão entre examinadores seguindo-se as orientações de Weiner (1991) e Fensterseifer e Werlang (2008). Para tanto, selecionou-se aleatoriamente 36 protocolos da amostra (20\% do total de casos) codificados pelos juízes, sendo que cada resposta foi dividida em quatro categorias de classificação: localização, determinante/qualidade formal, conteúdo e banalidade, elaborandose a porcentagem de concordância verificada em cada uma delas. Os índices atingidos foram os seguintes: localizações (99\%), determinantes (93\%), conteúdos (98\%) e banalidades (94\%). Já nos estudos normativos internacionais do Rorschach identificados (Van Patten, et al., 2007; Salcuni et al., 2007; Lis, Salcuni \& Parolin, 2007; Hansen, 2007; Matsumoto et al., 2007), alguns protocolos foram selecionados aleatoriamente para cálculo dos índices de concordância, sendo eles apresentados em porcentagem e no coeficiente iota, a partir de algumas variáveis selecionadas, variando de 70 a $100 \%$ de acordo. Destaca-se que os índices de acordo entre avaliadores independentes alcançados neste estudo podem ser considerados altamente satisfatórios também quando comparados aos índices atingidos por estes trabalhos internacionais.

Para além da apresentação dos achados deste estudo, foi possível aqui também comparar os resultados encontrados com os referenciais normativos desenvolvidos por Jacquemin (1976), que avaliou crianças de três a dez anos e onze meses de idade, na cidade de Ribeirão Preto (SP). Ao se comparar estes estudos, notou-se a existência de diferenças estatisticamente significativas entre eles, sugerindo que as crianças avaliadas neste momento tenderam a apresentar resultados específicos e diferenciados no Rorschach, tendo em vista as evidências anteriormente disponíveis, com mais de três décadas. Valeria pensar, dentro do alcance dos estudos, sobre quais variáveis poderiam estar associadas estas diferenças 
encontradas, certamente considerando a evidente composição dos grupos avaliados, matriz primeira dessas especificidades de produção.

No que diz respeito à produtividade no Rorschach, no presente estudo encontrou-se um número de respostas $(\mathrm{R}=14,5)$ significativamente inferior ao encontrado por Jacquemin (1976), que observou $\mathrm{R}=17,7$. Com relação ao tempo médio de resposta (TRm), constatou-se que as crianças da amostra atual foram consideravelmente mais rápidas em seus processos associativos $(\mathrm{TRm}=28,8$ segundos), sendo o TRm de Jacquemin (1976) foi de 45,3 segundos. Certamente esses indicadores técnicos se relacionam: mais rapidez ao reagir ao Rorschach pareceu ter resultado em menor número de respostas na amostra atual. No estudo anterior o tempo médio de resposta gasto pelas crianças foi maior, porém produziram mais interpretações. A partir destas constatações, poder-se-ia pensar o quanto características do ambiente sociocultural e da realidade atual destas crianças é bem diversa do período em que o estudo anterior (Jacquemin, 1976) foi realizado. Há três décadas os meios de comunicação, os jogos eletrônicos, computadores e até desenhos animados não ocupavam o centro das atenções do mundo infantil, como nos dias atuais. A realidade virtual exige um processamento rápido e simultâneo de muitas informações novas, derrubando as fronteiras para a comunicação, tendendo a promover a aceleração das atividades cotidianas. Estes elementos, segundo Ribeiro (2010), constituem-se como fatores que parecem influenciar o modo como a criança percebe, administra e estrutura seus aspectos físicos e psicológicos, inferindo em suas emoções, interesses, percepções e preocupações que constrói sobre si, sobre os outros e sobre o mundo.

Concernente aos modos de apreensão (localizações das respostas) também foram observadas diferenças entre os atuais resultados e os dados apresentados por Jacquemin (1976), exceto com relação às respostas de localização global. No presente estudo, a média obtida para a localização $G$ foi de $38,6 \%$ e a de Jacquemin (1976), 38,9\%, mostrando-se bastante próxima ao dado obtido pelo presente estudo. Já em relação à localização $\mathrm{D}$, observase considerável variação, sendo que no presente trabalho a média foi de $44,2 \%$, em comparação a 47,5\%, no já citado estudo. A localização Dd, por sua vez, manifestou diferença ainda maior, apresentando resultado médio atual de $16,6 \%$ em relação a $11,7 \%$ do estudo anterior. Esses dados, mesmo apresentando diferenças entre si, indicam que ambas as amostras expressam, adequada apreensão global e dos detalhes relevantes da realidade. Além disso, sinalizam que as crianças atualmente avaliadas possuem tendência maior em se ater às minúcias de sua realidade. 
Ao analisar a freqüência de distribuição dos determinantes, pôde-se observar também diferenças significativas entre os dois estudos focalizados na presente discussão. A porcentagem encontrada por Jacquemin (1976) para o determinante formal (F\%) foi de $74,5 \%$ sendo a média obtida pelo presente estudo significativamente inferior 66,4\%. Esses índices sugerem que as crianças examinadas atualmente podem estar efetivando menor investimento racional na interpretação da realidade que no estudo anterior.

No que se refere ao conteúdo das respostas, no presente trabalho houve predomínio dos mesmos principais conteúdos predominantes em Jacquemin (1976). A amostra do atual estudo emitiu majoritariamente os conteúdos animal $(\mathrm{A} \%)=64,4 \%$ e Humano $(\mathrm{H} \%)$ $=14,1 \%$, assim como os resultados encontrados por Jacquemin [(1976), A $\%=55,2 \% \mathrm{e}$ $\mathrm{H} \%=14,5 \%$ ]. Porém, foi evidenciada diferença estatisticamente significativa entre o resultado médio do conteúdo animal entre esses dois estudos. Conforme pôde ser observado, as crianças recentemente avaliadas apresentaram índices de respostas zoomórficas significativamente maiores que as crianças avaliadas por Jacquemin (1976). Tais evidências podem refletir maior concretismo e estereotipia no raciocínio dos escolares desta faixa etária, na realidade atual.

Sob a perspectiva de comparação de estudos similares, ainda numa perspectiva de explanação visual, os principais dados desta atual investigação científica foram debatidos com os achados de Raspantini (2010). Este citado estudo foi desenvolvido na mesma época, em um mesmo contexto, e seguindo os mesmos moldes do presente trabalho, no entanto, focalizando crianças de nove a 11 anos de idade. Como a única diferença entre os referidos estudos é com relação à faixa etária enfocada, teve-se o objetivo de verificar especificidades concernentes às idades, nas principais variáveis do Rorschach. Em relação a produtividade e ritmo, observou-se que as crianças mais novas (atual amostra) produziram menos $(\mathrm{R}=14,5)$ e em menor tempo $(\mathrm{TRm}=28,8 \mathrm{~s})$ que as crianças de Raspantini (2010), que obtiveram média de 16,5 respostas em 32,8 segundos. Isso confirma a afirmação de Semer (2008) de que na fase de latência ocorre rebaixamento na produção de respostas no Rorschach, em virtude de maior apego à realidade externa e repressão das fantasias.

Em se tratando das localizações das respostas, o grupo de nove a 11 anos manifestou preponderância de respostas globais $(\mathrm{G}=39,1 \%)$, seguidas de respostas grande detalhe $(\mathrm{D}=$ $34,4 \%$ ) e pequeno detalhe ( $\mathrm{Dd}=25,7 \%)$. As crianças do presente estudo, em contrapartida, apresentaram predomínio de D (44,2\%) sobre G $(38,6 \%)$, seguido de Dd (16,6). Estes índices revelam que as crianças mais novas tendem a focalizar suas interpretações da realidade em elementos pregnantes da realidade, ao passo que as mais velhas (Raspantini, 2010), 
concentram-se majoritariamente nos aspectos globais dos estímulos, com forte valorização das minúcias.

No tocante aos determinantes, puderam ser observadas aproximações e disparidades entre os referidos estudos. As crianças de Raspantini (2010) apresentaram 63,1\% de respostas formais, sendo que 73,3\% destas tiveram qualidade formal positiva. Já as crianças do presente estudo expressaram índices de respostas formais mais elevados, no entanto, com inferior freqüência de distribuição no tocante à qualidade formal das respostas $(\mathrm{F}=66,4 \%$ e $\mathrm{F}+=$ $68,8 \%$ ). Isto faz pensar em maior qualidade de elaboração lógica por parte das crianças mais velhas, apontando indícios de esperado processamento maturacional dos processos analíticointerpretativos, como parece ser o caso da atividade solicitada no Rorschach.

O grupo de crianças de Raspantini (2010), com idade de nove a 11 anos, apresentou também maiores índices de respostas movimento, dentre eles, 6,4\% movimento humano e $11,3 \%$ de movimento animal, contra $3,1 \%$ de grandes cinestesias e $7,7 \%$ de pequenas cinestesias nas crianças mais novas, presentemente avaliadas. Estas, portanto, sinalizaram menor processamento imaginativo e de simbolização, acompanhando o teoricamente previsto pelos teóricos do desenvolvimento (Palacios, 2004; Rabello \& Passos, 2007).

Os índices referentes ao determinante cor, por sua vez, revelaram maior envolvimento afetivo por parte das crianças de seis a oito anos, que apresentaram 17,2\% de respostas abrangendo cores, contra 13,4\% do grupo de Raspantini (2010). Já em relação ao sombreado (estompage) enquanto determinante, os grupos obtiveram índices bastante próximos, sendo $5,8 \%$ nas crianças mais velhas e 5,6\% nas mais novas, da atual amostra.

Ao se comparar os principais conteúdos evocados pelos dois grupos de crianças, contatou-se que a amostra de Raspantini (2010) emitiu maiores índices de respostas relacionadas ao conteúdo humano $(\mathrm{H}=20,7 \%)$, contra $14,1 \%$ das crianças avaliadas no presente estudo. Porém, estas crianças apresentaram maiores índices de conteúdos zoomórficos $(\mathrm{A}=64,4 \%)$, contra $58 \%$ das crianças de nove a 11 anos, denotando maior concretismo, estereotipia e imaturidade no raciocínio dos escolares de seis a oito anos. E, por fim, em se tratando dos índices de respostas banais, os maiores índices foram obtidos pelos escolares mais velhos $(20,4 \%)$, contra $18,5 \%$ das crianças de mais tenra idade.

A partir destas constatações empíricas, obtidas por meio de explorações possíveis até o presente momento, pode-se concluir que o perfil de produção no Rorschach das crianças de nove a 11 anos difere, em número relevante de variáveis da Escola Psicanalítica Francesa do Rorschach, do perfil das crianças de seis a oito anos. Há que se pensar, portanto, que a idade seja uma variável importante de inferência no modo como as crianças percebem e interpretam 
os estímulos desta técnica projetiva de investigação da personalidade. Tais diferenças provavelmente são atribuídas às diversidades maturacionais no desenvolvimento destes escolares, o que corrobora a afirmação de Semer (2008) de que é preciso considerar que se trata de indivíduos de personalidade em desenvolvimento e de recursos internos ainda não amadurecidos, e que, portanto, possuem características de desenvolvimento específicas de cada etapa. Portanto, em explanação geral de ordem comparativa entre estes citados estudos, pode-se inferir que seus dados justificam a elaboração de normas específicas do Rorschach para o grupo de seis a oito anos e para o grupo de nove a 11 anos.

Ainda em âmbito nacional, julgou-se interessante a comparação visual dos principais dados do presente estudo com outra pesquisa desenvolvida quase na mesma época, enfocando crianças de sete a dez anos, em outra região do país. Ribeiro (2010) apresentou, recentemente, os resultados de sua investigação referente às variáveis do Rorschach no Sistema Compreensivo, com crianças da cidade de Cuiabá, no Mato Grosso. Em termos de produtividade, esta referida pesquisa encontrou médias de 15,9 respostas no grupo de crianças de sete anos e 16,6 respostas nas de oito. Pode-se observar que a produção das crianças cuiabanas foi superior à das crianças paulistas de sete e oito anos, que obtiveram médias de 14,1 e 15,4 respostas, respectivamente.

Já em relação aos tipos de localização, puderam ser observadas semelhanças entre os dois estudos, sendo que ambos manifestaram prevalência das respostas grande detalhe. As crianças cuiabanas de sete anos apresentaram média de 7,7 respostas D; 5,2 respostas W (G) e 3,0 respostas Dd, ao passo que a faixa etária dos sete anos do presente estudo apresentou $\mathrm{D}=6,3 ; \mathrm{G}=5,5$ e $\mathrm{Dd}=2,2$. O grupo cuiabano de oito anos manifestou em média $\mathrm{D}=7,8 ; \mathrm{W}(\mathrm{G})=5,2$ e $\mathrm{Dd}=3,6$, sendo que o grupo paulista de mesma idade produziu $\mathrm{D}=6,9 ; \mathrm{G}=5,4$ e $\mathrm{Dd}=3,0$. Estes dados apontaram que as crianças destas duas amostras apresentaram modos semelhantes de apreensão da realidade, dedicando maior atenção aos detalhes mais relevantes.

Outra semelhança observada entre o presente estudo e o trabalho de Ribeiro (2010) foi referente às possíveis influências do gênero e da origem escolar na produção das crianças avaliadas. Ao comparar as diferenças existentes em relação ao gênero e à procedência escolar das crianças, Ribeiro (2010) também não encontrou especificidades no perfil de meninas e meninos. No entanto, concluiu que as crianças de escolas particulares mostraram maior facilidade em lidar com situações afetivas complexas, e apresentaram sinais de mais recursos cognitivos, constatação que se aproxima dos achados da presente pesquisa. 
Com o propósito de efetuar comparações transculturais, desenvolveu-se um olhar sobre os resultados atuais frente ao classicamente apresentado como referência normativa do Rorschach para crianças: o robusto trabalho de Ames, Learned, Metraux e Walker (1961). Neste estudo clássico do Rorschach, desenvolvido com 650 crianças norte-americanas de dois a dez anos, foram consideradas as variáveis: sexo, idade, nível socioeconômico e nível evolutivo, para a classificação dos desempenhos. Esta comparação dos dados atuais às referências normativas do citado estudo internacional respeitará análises específicas em função da idade, de modo a possibilitar comentários interpretativos sobre as variáveis em foco.

Analisando os resultados referentes aos índices de produção no Rorschach, , pode-se visualizar importantes diferenças entre o estudo de Ames et al. (1961) e os aqui encontrados, com tendência a indicadores de maior produção e de expressão afetiva nas respostas de crianças de sete anos do estudo internacional. A título de comparação, com relação às crianças de seis anos de idade, as norte-americanas produziram em média, 15,8 respostas, enquanto que as crianças deste estudo apresentaram média de 13,9 respostas. As crianças norteamericanas de sete anos de idade, por sua vez, produziram em média, 18,3 respostas, enquanto que as crianças deste estudo apresentaram média de 14,1 respostas. Já as crianças com oito anos de idade norte-americanas produziram em média, 15,8 respostas, enquanto que as crianças deste estudo apresentaram média de 15,3 respostas. Nota-se que, de modo geral, as crianças deste estudo apresentaram número médio de respostas inferior àquelas avaliadas pelo referido estudo.

Em se tratando dos modos de apreensão, comparando-se os índices apresentados pelas crianças de Ames et al. (1961) com os índices das crianças presentemente examinadas, foram encontradas também diferenças no padrão de respostas das crianças destes dois trabalhos. As crianças do estudo internacional apresentaram, predomínio de $\mathrm{G}$ sobre D, seguido de Dd, ao passo que as crianças do estudo atual apresentaram predomínio de D sobre G, seguido de Dd. Essas evidências foram sugestivas de que as crianças atualmente avaliadas apreendem a realidade enfatizando os detalhes relevantes de seu contexto, enquanto as crianças examinadas no estudo anterior sinalizaram captar os estímulos da realidade de modo mais geral e global.

No que tange à classe dos determinantes, em uma comparação visual das médias percentuais das respostas determinadas pelos contornos formais, bem como os índices de precisão perceptual destes dois estudos em foco, foram evidenciadas também especificidades de produção nestes grupos. Assim, as crianças norte-americanas entre seis e oito anos 
apresentaram $\mathrm{F} \%=56,7 \%$, contra os $66,4 \%$ das crianças do presente estudo. Já com relação aos índices de F+\%, por sua vez, foram encontrados índices médios de 83,3\%, nos escolares norte-americanos, contra $68,8 \%$ nas crianças brasileiras atualmente examinadas. Estes achados foram sugestivos de que as crianças deste estudo apresentaram sinais de maior investimento racional na interpretação da realidade que no estudo anterior. Por outro lado, estas crianças do estudo internacional apresentaram tendência a maior rigor em suas análises lógicas e dos estímulos.

No tocante aos conteúdos das respostas, os de origem animal e humano, totalizaram a grande maioria das projeções diante do Rorschach, em ambos os estudos em comparação. No entanto, foram apontadas diferenças na distribuição dos índices concernentes às respostas de conteúdo animal, conforme observado a seguir: a amostra de seis a oito anos avaliada por Ames et al. (1961) emitiu em média $A=45,0 \%$, contra $A=64,4 \%$ no presente estudo. Já em relação às respostas relativas ao conteúdo humano os índices dos dois estudos praticamente coincidiram: $\mathrm{H}=14,0 \%$ nas crianças norte-americanas e $\mathrm{H}=14,1 \%$ nas crianças do presente estudo. Estes resultados pareceram sinalizar maior concretismo e estereotipia no padrão de respostas ao Rorschach nas atuais crianças, em comparação às do estudo anterior.

Acompanhando o debate com estudos internacionais desenvolvidos com crianças da mesma faixa etária aqui examinada, pôde-se também focalizar a análise de seus resultados referentes à produtividade no Rorschach. Nesta perspectiva foram identificadas as pesquisas realizadas por Silva \& Dias (2007), Matsumoto et al. (2007), Salcuni et al. (2007) e Hamel \& Shaffer (2007), todas utilizando o referencial do Sistema Compreensivo. Uma inspeção visual do número médio de respostas apresentado por estes trabalhos evidencia diferenças marcantes entre os dados obtidos por estes estudos e os dados aqui encontrados. De modo geral, as crianças avaliadas pelo presente trabalho apresentaram número de respostas bastante inferior àquelas avaliadas pelos referidos pesquisadores, produzindo, em termos médios, 14,5 respostas. A título de comparação, as crianças portuguesas de seis a dez anos apresentaram índice de produtividade entre 22,71 a 25,73 respostas, de acordo com a faixa etária considerada (Silva \& Dias, 2007). As crianças japonesas de cinco a 14 anos apresentaram produção média variando entre 17,21 a 21,79 respostas, dependendo da faixa etária focalizada (Matsumoto et al., 2007). As crianças italianas de cinco a 11 anos, avaliadas por Salcuni et al. (2007) produziram em média entre 20,7 e 21,3 respostas. Por fim, pode-se ainda apontar que o grupo de crianças americanas de seis a nove anos, avaliadas por Hamel e Shaffer (2007), produziu, em média, 24,5 respostas no Rorschach. 
No tocante aos modos de apreensão, as crianças presentemente examinadas apresentaram predomínio de D, com média de 6,4 respostas grande detalhe por protocolo. Em seguida, houve a presença de $\mathrm{G}$ com índice médio de 5,6 ocorrências e Dd com 2,4. Novamente a contraposição destes resultados àqueles obtidos por estudos realizados em outros países, faz emergir diferenças importantes no padrão de respostas das crianças avaliadas. Adaptando-se os códigos utilizados nas pesquisas internacionais para aqueles utilizados pela Escola Psicanalítica Francesa, pode-se dizer que as crianças japonesas, por exemplo, apresentaram predomínio de G sobre D e, em seguida, Dd. Já as crianças italianas apresentaram G e D bastante próximos, seguidos de Dd. As crianças portuguesas, assim como as crianças brasileiras aqui avaliadas, apresentaram predomínio de D e, em seguida, G e Dd. E, por fim, as crianças americanas, diferentemente dos outros estudos, apresentaram predomínio de $\mathrm{D}$, seguido de Dd e G como a minoria de suas respostas.

Houve evidências empíricas, portanto, de especificidades no processamento das informações advindas dos estímulos do Rorschach, favorecendo apreensões focadas em aspectos mais detalhistas ou gerais, podendo implicar em formas diferenciadas de contato e de exploração do ambiente (Rausch de Traubenberg, 1998). No entanto, há que se ponderar que os grupos de crianças possuíam não só especificidades culturais, mas também composição diferente em termos de número de participantes, critérios de seleção dos voluntários e outras variáveis, dificultando considerações de caráter conclusivo sobre o tema. Cabe apenas aqui destacar que estes aspectos merecem a devida atenção e análise por parte dos profissionais quando da utilização do Rorschach, devendo examinar criteriosamente a relatividade e as implicações clínicas de qualquer estudo normativo tanto com esta técnica projetiva, quanto com qualquer outro instrumento de avaliação psicológica.

Além disso, ainda é preciso considerar, diante dos resultados diferenciados identificados (principalmente com relação aos índices de produtividade) entre o presente trabalho e estudos internacionais, o referencial teórico do Rorschach utilizado nestas investigações científicas. A diferença de sistemas interpretativos carrega, em si, divergências com relação aos critérios para definir e abordar os indicadores da técnica projetiva, levando a procedimentos específicos de análise e de interpretação dos resultados. De acordo com Pasian e Loureiro (2010), esta diversidade tende a limitar as possibilidades de comparação entre os achados de pesquisas, que, muitas vezes, implicam em variados modos de definição operacional das variáveis relacionadas à coleta e à análise dos dados.

Estas considerações presentemente elaboradas acompanham os argumentos e as reflexões técnicas apresentadas e discutidas no estudo de Meyer et al. (2007). Estes 
pesquisadores examinaram dados de 31 amostras infantis e juvenis de estudos normativos do Rorschach, realizados em cinco países. Os autores concluíram, após exaustivas análises dos resultados destas crianças e adolescentes de diferentes contextos socioculturais (representados por seus respectivos países de origem), pela impossibilidade de integração dos referenciais normativos em um padrão geral, dadas a variabilidade de evidências empíricas encontradas nos estudos examinados. Reafirmaram, por sua vez, a necessidade de realização de estudos normativos do Rorschach com esta população, nos mais diversos contextos, de forma a produzir dados representativos dos indivíduos típicos de cada região. A presente investigação científica, dentro de suas possibilidades, caminhou nesta perspectiva, buscando contribuir para o avanço da compreensão das crianças de seis a oito anos de idade, a partir do referencial da Escola Psicanalítica Francesa do Rorschach.

Retomando as evidências específicas relativas aos resultados presentemente encontrados, vale destacar a análise realizada sobre o eventual efeito do sexo, da idade e da origem escolar no padrão geral de respostas ao Rorschach das crianças de seis a oito anos do interior paulista. As análises estatísticas inferenciais realizadas entre os subgrupos acima delineados apontaram que reduzido número de variáveis do Rorschach sofreram efeito do sexo e da origem escolar. Portanto, pode-se pressupor que o número e a natureza das diferenças observadas entre estas variáveis podem ser consideradas casuais ou pouco expressivas dentro do conjunto global da amostra.

Ainda ao serem consideradas as análises desenvolvidas, observou-se, no entanto, que a idade foi a variável que pareceu exercer maior efeito no conjunto de respostas das crianças avaliadas pelo Rorschach. De forma geral, os índices sugeriram que as crianças mais velhas da atual amostra apresentaram sinais de processos associativo-interpretativos mais rápidos, permeados por indicadores mais freqüentes de processamento imaginativo. Pode-se, pensar, portanto, que estas especificidades de interpretação dos estímulos estejam associadas ao próprio desenvolvimento processado ano a ano nestas crianças, evidenciando influências relevantes dos processos de natureza maturacional na composição dos indicadores de personalidade, no caso do Psicodiagnóstico de Rorschach. Os achados insinuaram também que as crianças mais novas desta atual amostra processaram os estímulos oferecidos com menor controle racional e sinais de vivacidade afetiva e impulsiva mais intensa, com menor controle lógico, sugerindo maior imaturidade e estereotipia do pensamento. Estes achados pareceram complementar as afirmações precedentes, confirmando aspectos teóricos postulados sobre o percurso do desenvolvimento humano geral em termos psíquicos, como argumentado anteriormente. 
Embora os dados do presente trabalho apontem para especificidades de produção das crianças no Rorschach em função dos anos de vida, as diferenças encontradas, no conjunto dos resultados, precisam ser examinadas com cautela, dado o tamanho da amostra avaliada. Os resultados atuais devem ser considerados como achados relevantes para a avaliação psicológica por meio deste instrumento projetivo em contexto sociocultural semelhante ao aqui descrito, sabendo-se da influência do amadurecimento psíquico nas variáveis do Rorschach. No entanto, estas evidências empíricas ainda não justificam, por si, a elaboração de referenciais normativos específicos para as crianças de seis, sete e oito anos, respectivamente. Seria necessário ampliar suficientemente a amostra a fim de comportar a diversidade representativa de participantes, de modo a constituir normas específicas por ano de vida, ultrapassando os objetivos inicialmente delineados para a presente investigação. É importante apenas destacar que essas evidências empíricas apontaram para a necessidade de se considerar, na avaliação clínica, as especificidades no padrão de respostas das crianças atualmente avaliadas, considerando-se seus aspectos maturacionais, para adequada interpretação dos resultados referentes ao Rorschach.

Diante destas considerações, decidiu-se pela composição dos resultados em um único atlas para as crianças de seis a oito de idade, incluindo sexo masculino e feminino e proveniência de escolas públicas ou particulares da região estudada. Vale ressaltar que as especificidades de produção no Rorschach, identificadas em função das variáveis aqui estudadas (sexo, idade e origem escolar), devem ser vistas e interpretadas qualitativamente em processos de avaliação clínica, não desconsiderando o fato de estarem inseridas em um conjunto de dados majoritariamente comuns.

Ainda neste momento, considera-se importante ponderar sobre o próprio processo de classificação das respostas ao Rorschach, processo que, em si, produz influência taxativa e geral sobre os dados. Na codificação das respostas ao Rorschach tradicionalmente utilizada pela Escola Psicanalítica Francesa, como aponta Rausch de Traubenberg (1998), classifica-se apenas um conteúdo e um determinante, ainda que a resposta contenha elementos coadjuvantes em sua determinação e em seu conteúdo. Estes elementos adicionais, desta forma, ficam classificados como aspectos secundários, compondo as tendências de cada resposta, que são avaliadas apenas qualitativamente. A não consideração quantitativa dessas tendências favorece a desconsideração de alguns conteúdos e determinantes produzidos pelas crianças, possibilitando implicações de empobrecimento nas interpretações do Rorschach. Talvez, a proposta de classificação múltipla das respostas ao Rorschach retrate melhor a produção dada pelos indivíduos, como tem feito alguns pesquisadores como Azoulay et al. 
(2007). No entanto, pelo menos até o presente momento, optou-se por esta forma clássica de codificação, seguindo orientações de Jacquemin (1976) e Pasian (1998), de modo a possibilitar, inclusive, análise comparativa dos resultados destas pesquisas normativas também desenvolvidas na atual região/fonte de estudo. Provavelmente esta alternativa metodológica deverá ser devidamente investigada em futuros projetos científicos, de modo a promover o estímulo ao aprimoramento técnico da Escola Psicanalítica Francesa do Rorschach.

É válido apontar também a necessidade de continuidade do presente trabalho, visto que os resultados presentemente apresentados foram encontrados com base na classificação das respostas pautadas pelo atlas de Jacquemin (1976). Estes achados exigem uma revisão das classificações das respostas (sobretudo relativas ao recorte interpretativo e a sua qualidade formal) a partir do novo atlas elaborado neste estudo. Somente após esta revisão, poder-se-á completar o presente trabalho, retratando o padrão normativo final das crianças de seis a oito anos do interior do estado de São Paulo.

Outra reflexão pertinente, ainda neste momento de avaliação crítica sobre o trabalho desenvolvido, refere-se ao processo de seleção das escolas e dos voluntários participantes deste estudo. A definição das escolas colaboradoras foi dirigida pelo critério de se procurar a viabilidade de execução deste projeto, selecionando-se, previamente, as instituições educacionais da cidade em foco e que concentravam maior número de alunos da faixa etária pretendida, facilitando, assim, o bom andamento da coleta de dados. Esta decisão técnica, porém, efetivamente não alcança a adequada representação da diversidade socioeconômica e cultural dos estudantes desta faixa etária na cidade em questão, tratando-se apenas de uma forma de viabilização do presente trabalho. Em contrapartida, o empenho do estudo focalizouse em alcançar um tamanho de amostra que permitisse as devidas análises estatísticas compatíveis com o tipo de estudo proposto. Assim, os 180 casos avaliados de crianças de seis a oito anos de idade oferecem o devido suporte para se abarcar, em grau suficiente, uma diversidade de estilos individuais, de modo a poder retratar o desempenho típico dos estudantes desta faixa etária no Rorschach do contexto de estudo aqui focalizado (região de Ribeirão Preto, interior do Estado de São Paulo).

Ainda concernente às possíveis limitações metodológicas do presente trabalho, vale recordar que toda a coleta e a uma das codificações dos dados foram realizadas pela própria autora deste estudo. Embora este procedimento seja passível de críticas por algumas linhas de pensamento a respeito da aplicação e codificação do Rorschach (Weiner, 1995), há que se contrapor que a aplicação da técnica por um só profissional também favorece a consistência e 
a homogeneidade dos procedimentos aplicados ao conjunto de participantes, aspecto positivo na investigação científica. Além disso, a própria pesquisadora alcançou um nível de vivência cotidiana com as crianças de seu estudo de grande proximidade, podendo agregar a sua prática enquanto profissional uma riqueza ímpar de experiências que, certamente, fortalecem sua capacitação na área, objetivo também aqui alcançado. Some a estes ganhos, os cuidados técnicos presentemente adotados no processo de codificação das respostas ao Rorschach, de modo a garantir a precisão dos resultados, fortalecendo os alcances do presente trabalho, pautado pela Escola Psicanalítica Francesa do Rorschach. 

Abordado o debate dos resultados do presente trabalho com dados de outros estudos de mesma natureza, pode-se retomar o objetivo inicialmente proposto para este estudo, relacionado ao delineamento do perfil psicológico no Psicodiagnóstico de Rorschach de crianças escolares de seis a oito anos de idade. Os resultados encontrados apontaram que esta meta foi aqui plenamente alcançada, sendo possível apresentar novos referenciais normativos do Rorschach para crianças de seis a oito anos de idade, oriundas do interior paulista. Com isso, têm-se evidências empíricas que caminham na direção do atendimento das orientações e exigências do Conselho Federal de Psicologia (CFP, 2003) para o desenvolvimento de normas adequadas a diferentes grupos de indivíduos e contextos. Desta forma, proporciona-se novos e atuais subsídios técnicos (ainda que preliminares) que podem favorecer o adequado trabalho clínico e científico dos profissionais que recorrem ao Rorschach em seu cotidiano.

Pondera-se que o presente estudo apresenta informações úteis e relevantes ao retratar os novos referenciais normativos do Rorschach para crianças de seis a oito anos de idade, oriundas do interior paulista. Apesar dos alcances técnicos inerentes ao próprio trabalho e a sua execução implicarem em avaliação crítica sobre suas possibilidades de generalização dos resultados, cabe ressaltar a clareza dos critérios e dos cuidados metodológicos aqui efetuados. Nesta perspectiva, o processo de desenvolvimento das normas deste estudo foi detalhadamente descrito, com explicações a respeito dos critérios adotados na seleção dos indivíduos e também da caracterização da região do estudo, possibilitando comparações com regiões de características similares, podendo favorecer a aplicação dos dados em outros contextos e mesmo a replicação do estudo. No entanto, cabe aos profissionais da área a devida reflexão técnica para se evitar o risco da excessiva generalização de referenciais normativos, sem a devida avaliação de sua adequação às diferentes realidades socioculturais existentes e que devem ser levadas em conta nos processos de avaliação psicológica, conforme alerta Pasian e Loureiro (2010).

Por fim, é necessário reafirmar que a dimensão territorial (de proporção continental) e a grande diversidade cultural existente no Brasil, dificultam a elaboração de padrões normativos nacionais desta técnica projetiva (Pasian \& Loureiro, 2010). Nesse ínterim, reforça-se a importância da continuidade de desenvolvimento de estudos desta natureza em diferentes regiões e contextos deste país, desde que realizados com os devidos cuidados e rigor ético e metodológico, permitindo processos de avaliação psicológica mais adequados e consistentes com as demandas da realidade. 


\section{REFERÊNCIAS ${ }^{12}$}

12 Normas adotadas de acordo com APA, seguindo as diretrizes do Sistema Integrado de Bibliotecas da Universidade de são Paulo (SIBi/USP). Disponível em: http://www.teses.usp.br/info 

Adrados, I. (1985). A técnica do Rorschach em crianças: Perfil psicológico da criança dos sete aos quatorze anos. Petrópolis: Vozes.

Alves, I. C. B. (2006). Considerações sobre a validade e precisão nas técnicas projetivas. In Noronha, A. P. P., Santos, A. A. A. \& Sisto, F. F. (Orgs.). Facetas do fazer em avaliação psicológica. São Paulo: Vetor.

Ames, L. B; Learned, J; Metraux, R. W \& Walker, R. N. (1961). El Rorschach Infantil. Buenos Aires: Paidos.

Anastasi, A. \& Urbina, S. (2000). Testagem psicológica. (M. A. V. Veronese, trad.). (7a d.). Porto Alegre: Artmed.

Andronikof, A., Chudzik, L. \& Gillaizeau, I. (2008). Caractéristiques des Rorschach d'adolescents. In International Congress of Rorschach and Projective Methods, 19 (p. 176). Leuven, Belgium: IRS.

Angelini, A. L., Alves, I. C. B., Custódio, E. M., Duarte, W. F., \& Duarte, J. L. M. (1999). Matrizes progressivas coloridas de Raven: Escala especial. Manual. São Paulo: CETEPP.

Azoulay, C., Emmanuelli, M., Rausch de Traubenberg, N., Corroyer, D., Rozencwajg, P. \& Savina, Y. (2007). Les données normatives françaises du Rorschach à l'adolescence et chez le jeune adulte. Psychologie Clinique et Projective, 13, pp. 371-409.

Anzieu, D. (1986). Os métodos projetivos. (M. L. E. Silva, trad.). (5a ed.). Rio de Janeiro: Campus.

Bagbag, F. (2008). Tunisian children Rorschach. In International Congress of Rorschach and Projective Methods, 19 (p. 53). Leuven, Belgium: IRS.

Bandeira, D. R., Trentini, C. M., Winck, G. E., \& Lieberknecht, L. (2006). Considerações sobre as técnicas projetivas no contexto atual. In Noronha, A. P. P., Santos, A. A. A. \& Sisto, F. F. (Orgs.). Facetas do fazer em avaliação psicológica. São Paulo: Vetor.

Barreto, A. P. (1955). O Psicodiagnóstico aplicado à criança. Neurobiologia, 111 (28), pp. 169-182.

Conselho Federal de Psicologia. (2003). Resolução CFP 02/2003. Brasília: CFP.

Conselho Federal de Psicologia. (2009). Recuperado em 07 de Outubro de 2007, http:// www.pol.org.br/pol/cms/pol/ 
Cruz, R. M. (2002). O processo de conhecer em avaliação psicológica. In Cruz, R. M., Alchieri, J. C. \& Sardá Junior, J. J. (Orgs.). Avaliação e medidas psicológicas: produção do conhecimento e da intervenção profissional. São Paulo: Casa do Psicólogo.

Cunha, J. A. (2005). Psicodiagnóstico-V. 5.ed. Porto Alegre: Artmed.

Erikson, E. H. (1987). Infância e Sociedade. Rio de Janeiro: Zahar editores.

Erikson, E. H. \& Erikson, J. M. (1998). O ciclo da vida completo. Porto Alegre: Artes Médicas.

Fensterseifer, L. ; Werlang, B. S. G. (2008). Apontamentos sobre o status científico das técnicas projetivas. In: Villemor-Amaral, A. E.\& Werlang, B. S. G. (Orgs.). Atualizações em métodos projetivos para avaliação psicológica, (pp. 15-33). São Paulo: Casa do Psicólogo.

Fernandez, P. \& Pardillo, J. (2008). Listado de respuestas populares em Cuba: un estudio de normalizacion transcultural con el Rorschach. In International Congress of Rorschach and Projective Methods, 19 (p. 136). Leuven, Belgium: IRS.

Fuster, P. J. (2008). Adaptar el Rorschach (SC) a las diferentes poblaciones: un estudio generalizable desde la poblacion española. In International Congress of Rorschach and Projective Methods, 19 (p. 135). Leuven, Belgium: IRS.

Güntert, A. E. V. A. (2000). Técnicas projetivas: o geral e o singular em avaliação psicológica. In F. F. Sisto, E. T. B. Sbardelini, R. Primi (Orgs.). Contextos e questões da avaliação psicológica (pp. 77-85). São Paulo: Casa do Psicólogo.

Hamel, M., \& Shaffer, T. W. (2007). Rorschach Comprehensive System Data for 100 nonpatient children from the United States in two age groups. Journal of Personality Assessment, 89(1), pp. 174-182.

Hansen, K. G. (2007). Rorschach Comprehensive System Data for a sample of 75 Danish 9 year old children: a pilot study. Journal of Personality Assessment, 89(1), pp. 52-56.

Instituto Brasileiro de Geografia e Estatística (IBGE). (2006). Recuperado em 23 de Outubro de 2007, http://www.ibge.gov.br/cidadesat/topwindow.htm?1.

International Test Comission (ITC). (2003). Recuperado em 07 de setembro de 2009, http://www.ibapnet.org.br/avalpsi_diretrizes.html 
Japur, M. (1982). O Psicodiagnóstico de Rorschach: um estudo da afetividade em préadolescentes. Dissertação de Mestrado, Instituto de Psicologia, Universidade de São Paulo, São Paulo.

Jacquemin, A. A. (1976). O teste de Rorschach em crianças brasileiras. São Paulo: Vetor.

Lelé, A. J. (2006). Resultados de 100 Psicodiagnósticos de Rorschach em mineiros. In Congresso Nacional da Associação Brasileira de Rorschach e Métodos Projetivos, 4, (pp. 87-99). Brasília: Vetor.

Lelé, A. J. (2008a). La diversite de resultats dans les modes d'apprehension: comparaison des donnees normatives au Rorschach. In International Congress of Rorschach and Projective Methods, 19 (p. 153). Leuven, Belgium: IRS.

Lelé, A. J. (2008b) Estudo preliminar de dados normativos brasileiros no Rorschach no estado de Minas Gerais. In Encontro da Associação Brasileira de Rorschach e Métodos Projetivos, 5. Ribeirão Preto, Brasil. Ribeirão Preto: ASBRo.

Lis, A., Salcuni, S., \& Parolin, L. (2007). Rorschach Comprehensive System Data for a sample of 116 preadolescent and 117 adolescent nonpatients from Italy. Journal of Personality Assessment, 89(1), pp. 91-96.

Lis, A., Salcuni, S., Parolin, L., Di Riso, D. \& Laghezza, L. (2008). Rorschach Comprehensive System Data of sample of non patient children from Italy: aged 5-7 years. In International Congress of Rorschach and Projective Methods, 19 (p. 51). Leuven, Belgium: IRS.

Matsumoto, M., Suzuki, N., Shirai, H., Nakabayashi, M., Takahashi, T. \& Yamashita, C. (2002). Japanese non-patient children and Rorschach test results: an international comparison. Japanese Journal of Child and Adolescence Psychiatry, 43, pp. 1-16.

Matsumoto, M.; Suzuki, N.; Shirai, H., \& Nakabayashi, M. (2007). Rorschach Comprehensive System Data for a sample of 190 Japanese nonpatient children at five ages. Journal of Personality Assessment, 89(1), pp. 103-112.

Matsumoto, M., Morita, M., Suzuki, N., Tsuboi, H., Hatagaki, C. \& Shirai, H. (2008). Application of Rorschach for Japonese children: what the Rorschach means for Japonese children. In International Congress of Rorschach and Projective Methods, 19 (p. 315). Leuven, Belgium: IRS.

Meyer, G. J., \& Kurtz, J. E. (2006). Advancing Personality Assessment Terminology: Time to Retire "Objective" and "Projective" as Personality Test Descriptors. Journal of Personality Assessment, 87(3), pp. 223-225. 
Meyer, G. J.; Erdberg, P. \& Shaffer, T. W. (2007). International reference samples for the Rorschach Comprehensive System. Journal of personality assessment, 89, pp. 201-216.

Nascimento, R. S. G. F. (2002). Estudo normativo do sistema compreensivo do Rorschach para a cidade de São Paulo. Psico-USF, 7(2), pp.127-141.

Nascimento, R. S. G. F., Mattos, A. P., Mori Neto, A., Hisatugo, C. C., Freitas, E. S. \& Mucarbel, F. C. (2006). Estudo normativo para o sistema compreensivo do Rorschach. In Congresso Nacional da Associação Brasileira de Rorschach e outros Métodos Projetivos, 4 (pp. 47-48). Brasília: Vetor.

Nascimento, R. S. G. F., Brunoni, G. R., Sasaki, T. N. D., Bueno R. R. \& Parsons, T. G. (2008a). Resultados preliminares de um estudo normativo com o sistema compreensivo do Rorschach em uma amostrar de adolescentes não-pacientes brasileiros. In Encontro da Associação Brasileira de Rorschach e Métodos Projetivos, 5. Ribeirão Preto, SP.

Nascimento, R. S. G. F., Brunoni, G. R., Sasaki, T. N. D., Bueno R. R. \& Parsons, T. G. (2008b). Preliminary results of normative study of the Rorschach Comprehensive System in a non patient Brazilian adolescent sample. In International Congress of Rorschach and Projective Methods, 19 (p. 52). Leuven, Belgium: IRS.

Nascimento, R. S. G. F., Batistuzzo, M. C., Sato, T. M., Brunoni, G., Bueno, R. R. \& Marques, T., (2009). Autopercepção em adolescentes por meio do Rorschach (SC): resultados de estudo normativo em São Paulo. In: Congresso Brasileiro de Avaliação Psicológica Instituto Brasileiro de Avaliação Psicológia, 4; Conferencia Internacional de Avaliação Psicológica: formas e contextos, 14 e Congresso da Associação Brasileira de Rorschach e métodos projetivos, 5. Campinas, SP. Disponível em www.ibapnet.org.br.

Noronha, A. P. P., Primi, R. \& Alchieri, J. C. (2004). Parâmetros psicométricos: uma análise de testes psicológicos comercializados no Brasil. Psicologia: Ciência e Profissão, 24(4), pp. 88-99.

Palacios, J. \& Hidalgo, V. (2004). Desenvolvimento da Personalidade dos seis anos até a adolescencia. In Coll C., Marchesi, A. Palacios, J. (Orgs.). Desenvolvimento psicológico e educação (1) - (2 ${ }^{\mathrm{a}}$. Ed.). Porto Alegre: Artmed.

Papalia, D.E., Olds, S.W. \& Feldman, R.D.(2006). Desenvolvimento Humano (10 ${ }^{\mathrm{a}}$ Ed.). Porto Alegre: Artmed.

Pasian, S. R. (1998). O Psicodiagnóstico de Rorschach: um estudo normativo em adultos da região de Ribeirão Preto. Tese de Doutorado, Faculdade de Medicina de Ribeirão Preto, Universidade de São Paulo, Ribeirão Preto, SP. 
Pasian, S. R. (2002). Atualizações sobre o psicodiagnóstico de Rorschach no Brasil: breve panorama histórico. Psico-USF, 7(1), pp. 43-52.

Pasian, S. R. \& Loureiro, S. R. (2010). Reflexões sobre princípios e padrões normativos do Rorschach. In: Pasian, S. R. (org). Avanços do Rorschach no Brasil (pp. 30 - 54). São Paulo: Casa do Psicólogo.

Prefeitura Municipal de Porto Ferreira (2009). Recuperado em 07 de outubro de 2009, http://www.portoferreira.sp.gov.br/

Instituto Brasileiro de Geografia e Estatística (IBGE). (2006). Recuperado em 23 de Outubro de 2007, http://www.ibge.gov.br/cidadesat/topwindow.htm?1.

Rabello, E.T. \& Passos, J. S. (2007). Erikson e a teoria psicossocial do desenvolvimento. Disponível em http://www.josesilveira.com. Acesso em 30 de outubro de 2009.

Raspantini, R. L. \& Pasian, S. R. (2008). Psicodiagnóstico de Rorschach em crianças de nove a 11 anos: dados preliminares. In Encontro da Associação Brasileira de Rorschach e Métodos Projetivos, 5. Ribeirão Preto, SP.

Raspantini, R. L., Bordão-Alves, D. P. \& Pasian, S. R. (2009). Psicodiagnóstico de Rorschach: a influência da procedência escolar em crianças. In: Congresso Brasileiro de Avaliação Psicológica Instituto Brasileiro de Avaliação Psicológia, 4; Conferencia Internacional de Avaliação Psicológica: formas e contextos, 14 e Congresso da Associação Brasileira de Rorschach e métodos projetivos, 5. Campinas, SP. Disponível em www.ibapnet.org.br.

Raspantini, R. L. (2010). O Psicodiagnóstico de Rorschach em crianças de 9 a 11 anos: um estudo normativo. Dissertação de Mestrado, Faculdade de Filosofia, Ciências e Letras de Ribeirão Preto, Universidade de São Paulo, Ribeirão Preto, SP.

Rausch de Traubenberg, N. (1998). A prática do Rorschach. (A. J. Lelé, trad.). São Paulo: Vetor.

Raven, J. C., Raven, J., \& Court, J. H. (1988). Matrizes progressivas coloridas de Raven. Manual. São Paulo: Casa do Psicólogo.

Resende, A. C., Rezende, T. C. \& Martins, L. D. (2006). Estudo normativo do Rorschach para crianças goianienses: dados preliminares. In Congresso Nacional da Associação Brasileira de Rorschach e Métodos Projetivos, 4, (pp. 124-135). Brasília: Vetor. 
Resende, A. C. \& Argimon, I. I. L. (2010). Perspectiva transcultural do Método de Rorschach. In: Pasian, S. R. (org). Avanços do Rorschach no Brasil (pp. 86 - 119). São Paulo: Casa do Psicólogo.

Ribeiro, R. K. S. M., Yazigi, L. \& Semer, N. L. (2008). Estudo normativo do método de Rorschach Sistema compreensivo em crianças de Cuiabá. In Encontro da Associação Brasileira de Rorschach e Métodos Projetivos, 5. Ribeirão Preto, Brasil. Ribeirão Preto: ASBRo.

Ribeiro, R. K. S. M., Yazigi, L. \& Semer, N. L., (2009). Estudo normativo do método de Rorschach em crianças de escolas públicas e privadas de Cuiabá. In: Congresso Brasileiro de Avaliação Psicológica Instituto Brasileiro de Avaliação Psicológia, 4; Conferencia Internacional de Avaliação Psicológica: formas e contextos, 14 e Congresso da Associação Brasileira de Rorschach e métodos projetivos, 5. Campinas, SP. Disponível em www.ibapnet.org.br.

Ribeiro, R. K. S. M. (2010). Estudo normativo do método de Rorschach Sistema Compreensivo para crianças de sete a dez anos, da cidade de Cuiabá - Mato Grosso. Tese de Doutorado, Escola Paulista de Medicina, Universidade Federal de São Paulo, Cuiabá, MT.

Salcuni, S.; Lis, A.; Parolin, L., \& Mazzeschi, C. (2007). Rorschach Comprehensive System Data for two samples of nonpatient children from Italy: 75 aged 57 years and 148 aged 8 11 years. Journal of Personality Assessment, 89(1), pp. 85-90.

Semer, N. L. (2008). A utilização do Rorschach em crianças e adolescentes. In: VillemorAmaral, A. E. \& Werlang, B. S. G. (Orgs.). Atualizações em métodos projetivos para avaliação psicológica, (pp. 95-106). São Paulo: Casa do Psicólogo.

Semer, N. L., Yazigi, L., Nascimento, S. G. F. \& Carvalho, L. F., (2009). Rorschach e gênero: um estudo com um grupo homogêneo de profissionais liberais. In: Congresso Brasileiro de Avaliação Psicológica Instituto Brasileiro de Avaliação Psicológia, 4; Conferencia Internacional de Avaliação Psicológica: formas e contextos, 14 e Congresso da Associação Brasileira de Rorschach e métodos projetivos, 5. Campinas, SP. Disponível em www.ibapnet.org.br.

Silva, D. R., \& Dias, A. M. (2005). Analysis of a Portuguese Rorschach form quality table from a sample of children aged 6 to 10 years old.. In International Congress of Rorschach and Projective Methods, 18, (p. 177). Barcelona, Spain: IRS.

Silva, D. R., \& Dias, A. M. (2006). Questões de desenvolvimento a propósito das normas portuguesas do Rorschach para crianças. Revista Iberoamericana de Diagnóstico e Avaliação Psicológica, 1(21), pp. 47-59. 
Silva, D. R., \& Dias, A. M. (2007). Rorschach Comprehensive System Data for a sample of 357 Portuguese children at five ages. Journal of Personality Assessment, 89(1), pp. 131141.

Souza, A. M. D. R. \& Duarte Junior, A. P. (2008). As respostas banais de sujeitos paraenses ao teste de Rorschach: Comparação com normas de populações da região sudeste e análise da estabilidade temporal dos resultados. In Encontro da Associação Brasileira de Rorschach e Métodos Projetivos, 5. Ribeirão Preto, SP.

Tavares, M. (2003). Validade Clínica. Psico-USF, 8 (2), pp. 125-136.

Urbina, S. (2007). Fundamentos da testagem psicológica. (C. Dornelles, trad.). Porto Alegre: Artmed.

Valentino, M. A.; Shaffer, T. W.; Erdberg, P., \& Figueroa, M. (2007). Rorschach Comprehensive System Data for a sample of 42 nonpatient Mexican American children from the United States. Journal of Personality Assessment, 89(1), pp. 183-187.

Van de Vijver, F. \& Hambleton, R. K. (1996). Translating Tests: Some Practical Guidelines. European Psychologist, 1(2), pp. 89-99.

Van Patten, K., Shaffer, T. W., Erdberg, P., \& Canfield, M. (2007). Rorschach Comprehensive System Data for a sample of 37 nonpatient/nondelinquent adolescents from the United States. Journal of Personality Assessment, 89(1), pp. 188192.

Viana Guerra, C. (1958). As respostas de crianças de 03 a 08 anos ao Psicodiagnóstico de Rorschach, Boletim do Instituto de Psicologia, 8 (3-4), pp.20-31.

Villemor-amaral, A. E. \& Pasqualini-Casado, L.(2006). A cientificidade das técnicas projetivas em debate. PsicoUSF, 11(2), pp.185-193.

Villemor-Amaral, A. E., Yagizi, L., Nascimento, R. S. G., Primi, R. \& Semer, N. L. (2006). Elaboração do atlas e lista de qualidade formal do Rorschach no sistema compreensivo para uma amostra brasileira: comunicação preliminar. In Congresso Nacional da Associação Brasileira de Rorschach e Métodos Projetivos, 4, (pp. 70-75). Brasília: Vetor.

Villemor-Amaral, A. E., Yazigi, L., Primi, R., Nascimento, R. S. G. F., Semer, N. L., Meyer, G. J \& Viglione, D. J. (2008). Comparing location areas and frequency of responses in the Rorschach Comprehensive System considering a Brazilian sample and American data. In International Congress of Rorschach and Projective Methods, 19 (p. 110). Leuven, Belgium: IRS. 
Weiner, I. B. (1991). Editor's note: interscorer agreement in Rorschach research. Journal of Personality Assessment, 56, p.1.

Weiner, I. B. (1993). Speaking Rorschach: a tower of babel no longer. Rorschariana, 18, pp. $1-6$.

Weiner, I. B. (1995). Methodological considerations in Rorschach research. Journal of personality assessment, 7 (3), pp. 330-337.

Weiner, I. B. (2000). Princípios da Interpretação do Rorschach (1 ${ }^{\mathrm{a}}$. Ed). São Paulo: Casa do Psicólogo.

Windholz, W. H. (1969). Rorschach em crianças: a pesquisa. São Paulo: Vetor.

Yazigi, L., Ribeiro, R. \& Semer, N. L. (2008). Normative study of the Rorschach Comprehensive System in Brazilian children. In International Congress of Rorschach and Projective Methods, 19 (p. 52). Leuven, Belgium: IRS. 

APÊNDICE A - Carta de Apresentação da Pesquisa 



\section{Tـ Universidade de São Paulo}

Faculdade de Filosofia, Ciência e Letras de Ribeirão Preto

Departamento de Psicologia e Educação

Centro de Pesquisas em Psicodiagnóstico (CPP)

\section{CARTA DE APRESENTAÇÃO}

Estamos desenvolvendo uma pesquisa em Porto Ferreira (SP) que procura informações sobre as características de personalidade de crianças de seis a oito anos de idade. Pretende-se estudar cerca de 180 crianças de diferentes escolas, públicas e particulares, desta cidade. Esta pesquisa, cujo título é: "O PSICODIAGNÓSTICO DE RORSCHACH EM CRIANÇAS: CARACTERÍSTICAS AFETIVAS DOS SEIS AOS OITO ANOS" será desenvolvida sob responsabilidade da psicóloga Suélen Fernandes, como parte das atividades do seu Mestrado em Psicologia na Faculdade de Filosofia, Ciências e Letras de Ribeirão Preto (FFCLRP) da Universidade de São Paulo (USP), sob orientação da Profa. Dra. Sonia Regina Pasian, professora do Departamento de Psicologia e Educação desta mesma faculdade.

Esta escola foi identificada como uma possível participante e, sendo assim, gostaríamos de contar com sua colaboração, autorizando nossa inserção no estabelecimento educacional sob sua responsabilidade. Nossa atuação na escola dar-se-á da seguinte forma: a pesquisadora visitará os anos escolares em questão, explicará o projeto em linhas gerais e fornecerá, para cada aluno, um Termo de Consentimento Livre e Esclarecido e um Questionário Informativo (com perguntas sobre desenvolvimento da criança). Esses documentos deverão ser entregues aos pais dos possíveis participantes e, posteriormente, devolvidos à pesquisadora. Em seguida, a pesquisadora sorteará as crianças que efetivamente participarão do estudo. Após essa seleção inicial, a pesquisadora agendará, sob anuência da coordenação da escola, um horário em que a criança possa se ausentar de suas aulas, ou um horário diferente de suas aulas regulares, para participar da avaliação psicológica Nesse contato, que durará cerca de uma hora, a pesquisadora explicará a pesquisa novamente à criança e aplicará uma prova de raciocínio e uma técnica de interpretação de figuras imprecisas, com objetivo de avaliação de características de personalidade, não apresentando riscos ou prejuízos significativos à criança. Todas as informações ministradas são confidenciais e somente serão utilizadas para investigação científica, sem nenhuma identificação das pessoas que as forneceram.

A cooperação de seu estabelecimento será muito valiosa e imprescindível para que os objetivos desse estudo sejam alcançados. Este trabalho será uma contribuição voluntária e nenhum participante receberá pagamento por auxílio. Colaborar com essa pesquisa representa contribuir para um melhor conhecimento das condições psicológicas das crianças dessa região e isso poderá auxiliar em planejamentos de eventuais serviços de Saúde Mental. Desde já, agradecemos a atenção dispensada.

Atenciosamente,

\section{SUÉLEN FERNANDES}

\section{Profa. Dra. SONIA REGINA PASIAN}

Departamento de Psicologia e Educação - FFCLRP - USP

- Suélen Fernandes - Psicóloga (CRP 06/80915) vinculada ao Centro de Pesquisas em
Psicodiagnóstico (CPP) do Departamento de Psicologia e Educação da Faculdade de Filosofia,
Ciências e Letras de Ribeirão Preto (FFCLRP-USP).
- Profa. Dra. Sonia Regina Pasian - Docente do Departamento de Psicologia e Educação da
FFCLRP/USP.
- CONTATOS: Centro de Pesquisas em Psicodiagnóstico - Departamento de Psicologia e
Educação - Faculdade de Filosofia, Ciências e Letras de Ribeirão Preto da Universidade de
São Paulo.
Endereço: Avenida Bandeirantes, 3900 - Monte Alegre. Ribeirão Preto (SP) - CEP: 14040-
901. Fones: (16) 3602.3821 / (16) 3602.3785 / (19) 9689.4113
E-mail: suelen_fernandespf@yahoo.com.br / srpasian@ @fflrp.usp.br


APÊNDICE B - Termo de Consentimento Livre e Esclarecido 



\section{Tـ Universidade de São Paulo}

\section{Faculdade de Filosofia, Ciência e Letras de Ribeirão Preto}

Departamento de Psicologia e Educação

Centro de Pesquisas em Psicodiagnóstico (CPP)

\section{TERMO DE CONSENTIMENTO LIVRE E ESCLARECIDO}

Estamos desenvolvendo uma pesquisa em Porto Ferreira (SP) que procura informações sobre as características de personalidade de crianças de seis a oito anos de idade. Esta pesquisa, cujo título é: "O Psicodiagnóstico de Rorschach em crianças: Características afetivas dos seis aos oito anos" será desenvolvida sob responsabilidade da psicóloga Suélen Fernandes, como parte das atividades do seu Mestrado em Psicologia na Faculdade de Filosofia, Ciências e Letras de Ribeirão Preto (FFCLRP) da Universidade de São Paulo (USP), sob orientação da Profa. Dra. Sonia Regina Pasian, professora do Departamento de Psicologia e Educação desta mesma Faculdade.

Neste trabalho, pretende-se estudar cerca de 180 crianças de diferentes escolas, públicas e particulares, desta cidade. Esta escola em que seu(sua) filho(a) estuda irá colaborar conosco nesta pesquisa. Desta forma, gostaríamos de contar com sua colaboração, autorizando a participação dele(a) na mesma. Será realizado um sorteio entre as crianças autorizadas a participar da pesquisa, que selecionará aquelas que efetivamente participarão da mesma. Cada criança selecionada passará por uma breve avaliação psicológica, sendo que este processo implica em que ela responda a perguntas de raciocínio e de interpretação de figuras, não apresentando riscos ou prejuízos para a criança. Aos pais será solicitado que preencham um questionário sobre o histórico de vida de seu(sua) filho(a), caso autorizem sua participação nesta pesquisa.

Todas as informações são confidenciais e somente serão utilizadas para investigação científica, sem nenhuma identificação das pessoas que as forneceram. Não será fornecido oferecido aos participantes nenhum pagamento por sua colaboração voluntária ou informação detalhada sobre os resultados, dado o objetivo do trabalho. A sua cooperação será muito valiosa e imprescindível para que os objetivos desse estudo sejam alcançados. Colaborar com essa pesquisa representa contribuir para um melhor conhecimento das condições psicológicas das crianças dessa região e isso poderá auxiliar em planejamentos de eventuais serviços de Saúde Mental. No entanto, a recusa em participar da mesma, não implicará em qualquer prejuízo para a criança, nem tão pouco para sua família. necessário.

Desde já, agradecemos sua colaboração e estaremos disponíveis para outras informações, caso

Atenciosamente,

$$
\begin{aligned}
& \text { SUÉLEN FERNANDES } \\
& \text { CRP: 06/80915 }
\end{aligned}
$$

SONIA REGINA PASIAN

Orientadora

$\mathrm{Eu}$,

declaro que estou de acordo com a participação de meu (minha)

(a) como voluntário no

projeto de pesquisa intitulado "O Psicodiagnóstico de Rorschach: um estudo normativo em crianças de seis a oito anos", sob responsabilidade de Suélen Fernandes e da Profa. Dra. Sonia Regina Pasian, assim como estou ciente de que os registros relativos a esse trabalho serão utilizados como material de trabalho científico e poderão ser divulgados em congressos e publicados em revistas ou livros especializados, resguardando-se o devido sigilo quanto à minha identificação.

Porto Ferreira, de de 200

Telefone para contato:

(Assinatura do responsável pela criança)

Observação: Se tiver qualquer dúvida, entre em contato com a pesquisadora pelo telefone: (19) 9689.4113, ou pelo e-mail: suelen_fernandespf@yahoo.com.br. Ou ainda entre em contato com o Departamento de Psicologia e Educação da FFCLRP-USP e esclareça-se conosco pelo telefone: (16) 3602.3785 ou (16) 3602.3821 . 
APÊNDICE C - Questionário informativo sobre história pessoal 



\section{Tك Universidade de São Paulo}

Faculdade de Filosofia, Ciência e Letras de Ribeirão Preto

Departamento de Psicologia e Educação - Centro de Pesquisas em Psicodiagnóstico (CPP)

\section{FORMULÁRIO PARA PARTICIPAÇÃO NA PESQUISA}

Por favor, Senhores Pais:

- Respondam às questões abaixo da forma mais completa que lhes for possível no momento.

- Reafirmamos nosso objetivo de, como esse levantamento, conhecer melhor as características dos estudantes participantes dessa pesquisa, para poder relacionar seu desenvolvimento pessoal com seu padrão de respostas às atividades propostas.

- Também reafirmamos nosso compromisso de completo sigilo das informações e dos participantes.

- Favor devolver esse questionário juntamente com uma cópia assinada do Termo de Consentimento Livre e Esclarecido para a pesquisa.

- Novamente, agradecemos sua valiosa colaboração!

1. Nome do estudante:

2. Idade:

3. Data de Nascimento:

4. Sexo: ( ) Fem. ( ) Masc.

5. Ano Escolar:

6. Com quantos anos entrou na escola?

7. Já repetiu de ano? ( ) Não. ( ) Sim. Quantas vezes?

Qual(is) ano(s)

8. Número de irmãos:

9. Posição do estudante entre os irmãos (único ou primeiro, etc.)

10. Já apresentou graves problemas de saúde? ( ) Não.( ) Sim. Qual(is)?

Com que idade?

11. Mais especificamente: já apresentou problemas psicológicos ou neurológicos? ( ) Não. ( ) Sim. Qual(is)?

Com que idade?

12. Fez ou faz uso de medicamento por causa desse problema? ( ) Não. ( ) Sim.

Qual (is)

Quando? Por quanto tempo?

13. Já fez ou faz algum tratamento com psicólogo ou psiquiatra? ( ) Não. ( ) Sim. Qual(is)? Com que idade?

14. Estado civil dos pais: ( ) solteiro ( ) casado ( ) viúvo(a) ( ) separado ou divorciado ( ) amasiado

15. Pessoas que moram na casa do estudante:

\begin{tabular}{|l|l|l|l|l|l|}
\hline Nome & Parentesco & Idade & Escolaridade & Profissão & Renda \\
\hline & & & & & \\
\hline & & & & & \\
\hline & & & & & \\
\hline & & & & & \\
\hline
\end{tabular}

16. Observações que julga importantes sobre seu(sua) filho(a): 
APENDICE D - Glossário referente ao processo de classificação das variáveis do Rorschach (adaptado de Rausch de Traubenberg, 1998; Azoulay et al., 2007) 



\section{GLOSSÁRIO}

\section{Posição da prancha (rotações):}

$\wedge$ - posição normal.

$\vee$ - posição invertida.

< - posição lateral esquerda.

> - posição lateral direita.

\section{Produtividade:}

$\mathbf{R}$ - Número total de respostas efetivas em todos os cartões.

RA - respostas adicionais dadas espontaneamente no momento da investigação.

Rec - Recusas: não-respostas ao cartão.

Den - Denegação: número de respostas dadas espontaneamente no momento da aplicação e negadas no inquérito.

T.L. - Tempo de latência (em segundos): o tempo decorrido entre a apresentação da prancha e a primeira resposta efetiva do respondente.

T.L.m - Tempo de latência médio (em segundos): soma dos tempos de latência onde houve resposta, dividido pelo número de cartões onde houve interpretação.

T.T. - Tempo total (em minutos e segundos): tempo total da aplicação da prova (inquérito não é incluído).

T.R.m - Tempo de reação médio (em segundos): tempo médio por resposta; tempo total dividido pelo número total de respostas.

\section{Tipos de Apreensão / Localizações das respostas - Modo como o indivíduo apreende os} estímulos da realidade:

G - Resposta global: resposta que implica o todo da mancha, o mais aparente e superficial. $\mathrm{G} \%-100 \times \sum \mathrm{G} / \mathrm{R}$.

GDbl - respostas G integradas com detalhe branco (Dbl); são contadas como G.

D - Resposta de grande detalhe: Área significativa e relevante da prancha.

$\mathrm{D} \%-100 \times \sum \mathrm{D} / \mathrm{R}$.

DDbl - são contadas como D. 
Dd - Resposta pequeno detalhe: Percepção e interpretação de pequenas partes do cartão, referente às minúcias.

$\mathrm{Dd} \%-100 \times \sum \mathrm{Dd} / \mathrm{R}$.

DdDbl - são contadas como Dd.

Dbl - Grande detalhe branco: Seguindo os mesmos critérios de Azoulay et al. (2007), foi considerada área Dbl quando somente a forma ou a percepção é de vácuo naquela área, com justificativa de resposta o branco (ausência de cor). Quando a cor é destacada na resposta, considera-se, então, a área D e não Dbl.

$\mathrm{Dbl} \%-100 \times \sum \mathrm{Dbl} / \mathrm{R}$.

Do - Detalhe oligofrênico ou inibitório: Recorte dado a uma área onde normalmente é produzida uma interpretação de caráter mais geral, que inclui o detalhe atualmente nomeado.

Do\% - $100 \times \sum \mathrm{Do} / \mathrm{R}$.

\section{Determinantes das respostas - Fatores principais de determinação das respostas e sua precisão formal:}

$\mathbf{F}=$ Resposta determinada unicamente pela forma da mancha. Ou seja, pelos aspectos de contorno da área interpretada.

$\mathbf{F}+=$ Respostas com forma bem vista (boa precisão formal): respostas que respeitam o parecer formal de um grupo de referência, ou seja, com o que é mais frequente em um determinado ambiente.

F+- = Forma imprecisa da resposta, em área pouco específica do cartão; forma indeterminada. F- = Respostas com forma mal vista; resposta que não corresponde à área interpretada do cartão (má precisão formal).

F\% - Percentagem das respostas = forma em relação ao total de respostas: $\mathrm{F} \%=100 \times \sum \mathrm{F} / \mathrm{R}$.

F+\% - Percentagem das boas formas em relação ao total das respostas-forma: indicação do quanto dentro das respostas forma houve precisão.

$\mathrm{F}+\%=100(\mathrm{~F}+0,5 \mathrm{~F}+-) / \sum \mathrm{F}$

$\mathbf{F}+\mathbf{e x t} \%$ - Percentagem das boas formas dos demais determinantes: indicação de precisão formal entre os determinantes afetivos.

$$
\mathrm{F}+\mathrm{ext} \%=\sum \mathrm{K}+; \mathrm{k}+; \mathrm{FC} ; \mathrm{FE} / \mathrm{R}
$$

$\mathbf{K}$ - Cinestesia humana: respostas que contenham movimentos de pessoas inteiras.

Kat- humano prestes a se movimentar.

kp - fragmento de forma humana vista em movimento: ação feita por uma parte de humano.

kan - Cinestesia animal: respostas contendo movimento animal, que precisa estar inteiro e de fato em ação.

kob - Cinestesia objeto: respostas contendo movimento forte, que é próprio do objeto interpretado.

$\sum \mathbf{k}$-Cinestesia menores: $\sum \mathrm{kan}+\sum \mathrm{kob}+\sum \mathrm{kp}$.

FC- Resposta forma-cor: resposta prioritariamente determinada pela forma e secundariamente pela cor; há predomínio da forma sobre a cor. 
CF - Resposta cor-forma: resposta prioritariamente determinada pela cor e secundariamente pela forma; há predomínio da cor sobre a forma.

C - Resposta cor pura: determinação exclusiva da cor na resposta.

O sinal 'atribuído a $\mathrm{C}$ indica a utilização do preto, cinza e branco como cor de superfície. Segundo a importância relativa de $\mathrm{C}^{\prime}$ e da $\mathrm{F}$, temos três tipos de respostas: $\mathrm{FC}^{\prime}$; $\mathrm{C}^{\prime} \mathrm{F}$ e $\mathrm{C}^{\prime}$, que também são incluídas na $\sum$ C. Seus valores são análogos aos de FC; CF e C.

$\sum$ Cponderada - Total ponderado das respostas que envolvem determinante cor (cromático e acromático $)=0,5 \mathrm{FC}+1 \mathrm{CF}+1,5 \mathrm{C}$.

Cn - Cor nomeada: apenas nomeações das áreas coloridas do cartão.

FE - Resposta forma-estompage: determinadas pela tonalidade, textura ou perspectiva da mancha, onde a forma predomina.

EF - Resposta estompage-forma: há predomínio da estompage sobre a forma.

E - Resposta estompage pura: determinação da resposta foi exclusivamente o sombreado do cartão.

$\sum$ Eponderada - Total ponderado das respostas cor: $0,5 \mathrm{FE}+1 \mathrm{EF}+1,5 \mathrm{E}$.

FClob - Resposta forma claro-escuro relacionada à angústia, a conteúdo disfórico, ligado necessariamente ao preto do cartão.

ClobF - Resposta claro-escuro forma: há predomínio de resposta clob sobre a forma.

Clob - Resposta claro-escuro pura: há manifestação exclusiva de respostas disfóricas.

\section{Conteúdos das respostas:}

A / (A) - Resposta de conteúdo animal.

Ad / (Ad) - Resposta de detalhe (parte) animal.

A\% - Percentagem das respostas animais em relação ao número total de respostas totais:

$\mathrm{A} \%=100 \mathrm{x}[\mathrm{A}+(\mathrm{A})+\mathrm{Ad}+(\mathrm{Ad})] / \mathrm{R}$

H / (H) - Resposta de conteúdo humano.

Hd / (Hd) - Resposta de detalhe (parte) humano.

$\mathbf{H} \%=$ Percentagem das respostas humanas em relação ao número de respostas totais: $\mathrm{H} \%=100 \mathrm{x}[\mathrm{H}+(\mathrm{H})+\mathrm{Hd}+(\mathrm{Hd})] / \mathrm{R}$

Anat - Resposta de conteúdo anatômico

Sg - Resposta de conteúdo sangue

Sex - Resposta de conteúdo sexual

Obj - Resposta de conteúdo objeto

Art - Resposta de conteúdo artístico

Arq - Resposta de conteúdo arquitetônico

Simb - Resposta de conteúdo simbólico 
Abs - Resposta de conteúdo abstrato

Bot - Resposta de conteúdo botânico

Geo - Resposta de conteúdo geográfico

Nat - Resposta de conteúdo natureza

Pais - Resposta de conteúdo paisagem

Elem - Resposta de conteúdo elemento

Frag - Resposta de conteúdo fragmento

\section{Funcionamento afetivo:}

T.R.I. - Tipo de Ressonância Intima (forma habitual do individuo vivenciar sua afetividade) Fórmula que exprime a relação entre as cinestesias humanas e as respostas-cor ponderadas: T.R.I. $=x \mathrm{~K} / y \sum \mathrm{C}-$ Porporção do número de movimento humanos sobre a somatória de respostas-cor.

-Extratensivo Puro: $0 \mathrm{~K}$ para $<y \sum \mathrm{C}$

-Extratensivo Dilatado: $x \mathrm{~K}<y \sum \mathrm{C}$

-Introversivo Puro: $x \mathrm{~K}>0 \sum \mathrm{C}$

-Introversivo Dilatado: $x \mathrm{~K}>y \sum \mathrm{C}$

-Ambigual: $x \mathrm{~K}=y \sum \mathrm{C}$

-Coartativo: $x \mathrm{~K}=y \sum \mathrm{C}=1$

-Coartado: $x \mathrm{~K}=y \sum \mathrm{C}=0$

F.T.L. - Fórmula das tendências latentes (recursos afetivos em potencial, não manifestos, mas, possíveis de serem desenvolvidos futuramente) - Exprime a relação entre as cinestesias não-humanas e as respostas estompage:

T.L. $=(\mathrm{kan}+\mathrm{kob}+\mathrm{kp}): \sum \mathrm{E}-$ Somatória das respostas de pequeno movimento comparativamente às respostas estompage.

$3^{\text {a }}$. Fórmula (I.R.A.) - Índice de Reatividade Afetiva (índice de sensibilidade do indivíduo a situações afetivas) - Relação do número das respostas dadas nas pranchas VIII, IX e X dividido pelo número total de respostas:

I.R.A. $=100 \times$ Número de respostas VIII+IX+X / R.

F.A. - Fórmula da angústia - índice de elementos de ansiedade e/ou angústia que o indivíduo demonstra no teste:

$$
\text { F.A. }=\mathrm{Hd}+(\mathrm{Hd})+\text { Anat }+\mathrm{Sg}+\text { Elem fog }+ \text { Sex X } 100 / \mathrm{R} .
$$


7. Respostas Banais: Índice de compartilhamento do pensamento coletivo:

Ban - Resposta banal - respostas de mesma localização e conteúdo que aparecem com determinada freqüência em certo grupo populacional.

Ban\% - Percentagem das respostas banais em relação ao número total de respostas:

Ban $\%=100 x$ Ban / R.

Orig. - Resposta original - Respostas dadas uma vez em cem por sujeitos considerados "normais" (com funcionamento típico). 
9. ANEXOS 

ANEXO A - Aprovação do Comitê de Ética em Pesquisa 

Of.CEtP/FFCLRP-USP.032/2008-9/5/2008

Senhor(a) Pesquisador(a):

Comunicamos a V. Sa. que o trabalho intitulado "O PSICODIAGNÓSTICO DE RORSCHACH EM CRIANÇAS: CARACTERISTICAS AFETIVAS DOS SEIS AOS OITO ANOS" foi re-analisado pelo Comitê de Ética em Pesquisa da FFCLRP-USP, em sua $70^{\text {a }}$ Reunião Ordinária realizada em 07/05/2008, e enquadrado na categoria: APROVADO, de acordo com o Processo CEP-FFCLRP n³71/2007 - 2007.1.2474.59.8.

Atenciosamente,

Profa. Dra. ADELAIDE DE ALMEIDA Cooretenadora do Comitê de Étiea em Pesquisa - FFCLRP-USP

Ilustríssimo(a) Senhor(a)

Profa. Dra. SONIA REGINA PASIAN

Docente do Departamento de Psicologia e Educação

Desta FFCLRP-USP

CEP-FFCLRP-USP - Fone: (016) 602-3653 - Fax: (016) 633-5015

Avenida Bandeirantes, 3900 - Bloco A - 14040-901 - Ribeirão Preto - SP - Brasil 
ANEXO B - Documento emitido pelo Departamento Municipal de Educação de Porto Ferreira 

PREFEITURA MUNICIPAL DE PORTO FERREIRA

Oficio: $650 / 07$

Assunto: Resposta ao Oficio $n^{\circ} 01 / 2007$

Segue abaixo os dados solicitados no oficio de $n^{\circ} 01 / 2007$, sobre o total de alunos matriculados em Porto Ferreira, nas redes municipal e privada de ensino no ano de 2007, com idades compreendidas entre 6 e 8 anos (nascidos respectivamente nos anos de 1999, 2000 e 2001)

\begin{tabular}{|c|c|c|c|}
\hline REDE & 1999 & 2000 & 2001 \\
\hline Municipal & 649 & 645 & 642 \\
\hline Particular & 94 & 84 & 55 \\
\hline Total & 741 & 729 & 697 \\
\hline
\end{tabular}

Alenciosamente,

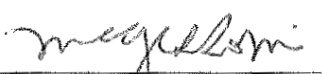

Maria Cecilia Gallo da Cunha Leme Rossi Diretora do Departamento Muinicipal de Educaçăo

IIma Sra

Suélen Fernandes

Porto Ferreira - SP

Avenida 24 de Outubro, 721/729 - Centro - CEP 13.660-000 - Porto Ferreira - SP

Fone (019) 3589.5300 - Fax: 3589.5319

E-mail: educacao@portoferreira.sp.gov.br 